\title{
Invited review: An evaluation of the likely effects of individualized feeding of concentrate supplements to pasture-based dairy cows
}

\author{
J. L. Hills, ${ }^{*}$ W. J. Wales,† F. R. Dunshea,ł S. C. Garcia,§ and J. R. Roche\# ${ }^{1}$ \\ *Tasmanian Institute of Agriculture, Dairy Center, The University of Tasmania, Burnie, Tasmania 7320, Australia \\ †Agriculture Research Division, Department of Environment and Primary Industries, Ellinbank, Victoria 3821, Australia \\ †Melbourne School of Land and Environment, The University of Melbourne, Parkville, Victoria 3010, Australia \\ $\S M C$ Franklin Laboratory, Faculty of Veterinary Science, University of Sydney, Camden, New South Wales 2570, Australia \\ \#DairyNZ, Private Bag 3221, Hamilton 3240, New Zealand
}

\section{ABSTRACT}

In pasture-based dairy systems, supplementary feeds are used to increase dry matter intake and milk production. Historically, supplementation involved the provision of the same amount of feed (usually a grain-based concentrate feed) to each cow in the herd during milking (i.e., flat-rate feeding). The increasing availability of computerized feeding and milk monitoring technology in milking parlors, however, has led to increased interest in the potential benefits of feeding individual cows (i.e., individualized or differential feeding) different amounts and types of supplements according to one or more parameters (e.g., breeding value for milk yield, current milk yield, days in milk, body condition score, reproduction status, parity). In this review, we consider the likely benefits of individualized supplementary feeding strategies for pasture-based dairy cows fed supplements in the bail during milking. A unique feature of our review compared with earlier publications is the focus on individualized feeding strategies under practical grazing management. Previous reviews focused primarily on research undertaken in situations where cows were offered ad libitum forage, whereas we consider the likely benefits of individualized supplementary feeding strategies under rotational grazing management, wherein pasture is often restricted to all or part of a herd. The review provides compelling evidence that between-cow differences in response to concentrate supplements support the concept of individualized supplementary feeding.

Key words: grazing, substitution, milk response, feed conversion efficiency

\section{INTRODUCTION}

Significant variability in commodity prices and perceived animal welfare concerns around permanent

Received June 11, 2014

Accepted November 13, 2014

${ }^{1}$ Corresponding author: John.Roche@dairynz.co.nz housing of livestock have led to increased global interest in grazing systems for dairy cows. Pastures, including temperate and tropical grasses and legumes, are, under most circumstances, the most cost-effective sources of nutrients (Peyraud and Delaby, 2001), with the cost of milk production declining quadratically with increased utilization of grazed pasture (Dillon et al., 2008). However, one of the challenges of a pasture-based system is the seasonal variation in pasture availability and nutritive value (Chapman et al., 2008, 2009; Roche et al., $2009 \mathrm{~b}, \mathrm{c})$, resulting in the need to provide supplementary feed during periods of pasture or nutrient deficit. Even when there are no restrictions in the quantity and nutritive characteristics of pasture available, pasture DMI is considered the primary factor limiting milk yield (Leaver, 1985; Kolver and Muller, 1998; Bargo et al., 2002; Kolver and de Veth, 2002; Dillon, 2006). This is of particular concern for cows with high genetic merit for milk production (Buckley et al., 2000a,b; Horan et al., 2006; Peyraud and Delagarde, 2013). Concentrate supplements are used in pasture-based systems as a management tool either to manage deficits in pasture supply (Holmes and Roche, 2007) or to increase overall DMI and milk production (Stockdale, 2000b; Bargo et al., 2003).

An issue with the successful use of concentrate supplements in pasture-based systems is the variability in the milk response to these supplements (Leaver, 1985; Peyraud and Delaby, 2001; Bargo et al., 2003; Kellaway and Harrington, 2004; Holmes and Roche, 2007; Baudracco et al., 2010a), with substitution of supplementary feed for pasture having the greatest influence on the milk production response (Stockdale, 2000b; Bargo et al., 2003). In general, the higher the rate of substitution of supplementary feed for pasture, the lower the average milk response to the supplement (Stockdale, 2000b). Major factors contributing to substitution of supplements for pasture have been defined at the herd level, including pasture availability and nutritive characteristics, cow genotype, stage of lactation, and type and nutritive characteristics of the supplement (Stock- 
dale, 2000b; Linnane et al., 2004; Holmes and Roche, 2007; Roche et al., 2007c; Baudracco et al., 2010a; Sheahan et al., 2011). However, the degree to which pasture DMI varies in response to supplements at an individual animal level and the extent to which this can be exploited to improve the efficiency of production is not well understood.

Concentrate supplementation in pasture-based systems is usually determined by the average nutritional requirements of the herd, rather than by those of individual cows. Many of the early experiments comparing individualized and flat-rate feeding strategies (Bines, 1985; Leaver, 1988; Gill and Kaushal, 2000) were conducted with all cows having ad libitum access to forage and concluded that individualized feeding of concentrate supplements gave no production advantage over flat-rate feeding. However, the conditions under which these studies were conducted do not reflect on-farm recommended pasture allocation practices. Results of a more recent study in Australia, where cows were offered a restricted pasture allowance (Garcia et al., 2007), indicated that cows fed a concentrate supplement based upon an individual requirement produced $7 \%$ more fat and protein compared with cows fed at a fixed rate based on an overall herd requirement. This study also indicated significant between-cow variation in DMI (CV $=32 \%$ ), highlighting the potential for exploiting this variability through individualized feeding strategies.

The integration of computerized milk recording systems with in-parlor feeding systems has provided the ability to offer cows different amounts (and types) of concentrate supplements according to predefined parameter(s) (e.g., milk yield, DIM, BCS, parity) and to feed multiple supplements (e.g., a cereal grain, nonforage fiber concentrate feeds, a protein meal, micro-ingredients) in differing amounts to each cow at milking. However, the value proposition from individualized feeding of cows in grazing systems remains unclear, with few, if any, studies reporting the effects on feed conversion efficiency, marginal milk production response, BCS, health, and fertility.

Any advantage to be gained from the individualized feeding of cows compared with flat-rate feeding depends on the existence of both sufficient betweenanimal variability in response to supplementation and a profitable economic response associated with exploiting this variability. André et al. (2010a,b) reported considerable between-cow variation in milk yield in response to concentrate DMI in an observational study of 4 farms in the Netherlands. They concluded that this variation could be exploited to improve economic profitability of dairy farming through optimization of individual concentrate feeding. By applying individual economic settings for concentrate supply based on daily milk yield, potential economic gains were reported to range from $€ 0.20$ to $€ 2.30 /$ cow per day (André et al., 2010a). There was no consideration of the effect of substitution of forage (either summer grazed pasture and or silage) in the study by André et al. (2010a), and the majority of cows were housed indoors for part or all of the year. In pasture-based systems, the amount of pasture consumed and its nutritive value may influence the between-cow variability in response to supplement and will need to be considered as part of a dynamic model for calculating optimum supplementation rates. Understanding this variability and identifying a means for measuring pasture DMI at an individual animal level are key challenges for determining the potential for individualized feeding in pasture based-dairy systems.

The objective of this paper was to review key factors affecting cow responses to supplements in pasturebased systems. The effect of supplementary feeding on DMI and grazing behavior, rumen function, energy balance (EBAL), milk production, reproduction, and health will be discussed, with a focus on the implications of feeding cows to individual requirements rather than as a herd. Where knowledge gaps exist concerning the potential effect of individualized feeding in a pasture-based system, recommendations will be made for further research.

\section{FACTORS LIMITING PRODUCTION OF COWS AT PASTURE}

In pasture-based systems, DMI is recognized as the factor limiting milk production to the greatest degree (Leaver, 1985; Kolver and Muller, 1998; Bargo et al., 2002; Kolver et al., 2002; Dillon, 2006), because the nutritional profile of temperate pasture species (i.e., grasses and legumes) is usually not limiting in its provision of AA, carbohydrates, minerals, and vitamins. To this end, the provision of nonpasture feeds (i.e., supplements) is practiced to increase total DMI and, thereby, milk production (Bargo et al., 2003).

According to Liebig's principle of the minimum (Liebig, 1840), the increase in production through increased consumption will be determined by the most limiting resource. In pasture-based systems with low to medium levels of supplementation (up to $2 \mathrm{t}$ of DM/ cow per lactation), total ME consumed is the factor most limiting production (Baudracco et al., 2010b; Higgs et al., 2013). Where higher levels of supplementation are used and particularly where the supplement is low in $\mathrm{CP}$ or particular AA, other factors can become first limiting and reduce the predicted marginal milk production response to additional ME.

The dietary components from which ME is provided (i.e., NSC, NDF, CP, fat) can influence the composition 
of the additional production, with NSC-based supplements generally resulting in greater milk, lactose, and protein yields and a lower milk fat yield compared with a similar ME intake from NDF-based supplements (Carruthers et al., 1997; Bargo et al., 2003; Roche et al., 2010; Higgs et al., 2013). Energy-corrected milk, however, is generally not affected by the ingredient origin of the additional ME consumed because the reported increase in lactose and protein yields associated with NSC-based concentrate supplements is equivalent, in energy terms, to the lower fat yield (Roche et al., 2010). The following section establishes the importance of $\mathrm{ME}$ as a primary constraint on milk production from cows grazing high-quality pasture (i.e., with high ME and $\mathrm{CP}$ content and balanced AA profile).

\section{Nutritional Limitations of Dairy Cows Grazing Temperate Pasture}

Although intensively grazed forages can be of high quality, the large difference in daily and lactational milk yields between grazing cows and those fed a TMR is often considered proof of a nutritional deficiency in pasture that is limiting milk production. To determine the reasons for the differences in production, Kolver and Muller (1998) compared cows grazing high-quality pastures (Dactylus glomerata) with cows being fed TMR. They then simulated the diets in the Cornell Net Carbohydrate and Protein System (CNCPS; Fox et al., 1995). Grazing cows produced $15.4 \mathrm{~kg}$ less milk than cows on TMR; the results of the model simulation indicated that $61 \%$ of this effect was due to lower DMI, $24 \%$ of the difference was due to energy expenditure in grazing and walking, $12 \%$ was estimated to be due to the excretion of surplus N, $7 \%$ reflected the greater energy content of the milk from grazing cows, and 5\% was due to differences in the partitioning of energy between milk production and BCS. They concluded that intake of nutrients, rather than a limitation in any one nutrient in pasture, was the primary factor constraining milk production from high-quality pasture, with the remaining factors reflecting differences in energy partitioning to activity, milk composition, or urea synthesis. These data confirmed the high nutritional value of temperate pastures as feeds for ruminants and emphasized that the majority of the difference in milk production between TMR-fed cows and cows grazing high-quality pasture related to the system of farming and not the nutritional profile of the feed, per se.

Because DMI explained more than $60 \%$ of the difference in milk production between TMR-fed and grazing dairy cows, providing cows with a nutritionally balanced supplement should increase production through increased intake of nutrients. Liebig's principle of the minimum predicts that growth rate or, in this case, milk production is determined by the most limiting resource (i.e., the primary limiting factor; Liebig, 1840). Increasing DMI through supplementation, therefore, would only increase production if the nutritional factor most limiting production were supplied. Such a limitation could reflect either (1) the provision of a resource that is limiting production through its absence (i.e., deficiency); or (2) the provision of a resource that facilitates the removal of a particular dietary component that is limiting production because it has been provided to the point of oversupply (i.e., toxicity).

In line with Liebig's principle and using the CNCPS, Kolver (2003) simulated changes to the nutrient profile and digestion rates of protein and fiber in pasture to determine which nutritional factor was most limiting production. When cows were fed solely on temperate pastures, altering the availability of RDP or microbial protein or the supply of individual amino acids did not increase production, even though an increase in DMI did. These data indicate that milk production was limited by total ME intake. Kolver (2003) did not simulate low-CP $(<15 \%$ DM) summer pasture, but the slow rate of degradation of both $\mathrm{CP}$ and NDF in this scenario and the well-balanced AA profile of temperate pastures for milk production, combined with the exceptional ability of the ruminant to recycle $\mathrm{N}$ across the ruminal epithelium and through saliva (Reynolds and Kristensen, 2008), means that ME is still likely to be the nutritional factor most limiting milk production in cows consuming temperate pasture as their sole diet.

Although ME is the primary nutritional factor limiting milk production in a grazing dairy cow, with the increased provision of nutritionally incomplete supplements [e.g., low CP, grain-based concentrate (GBC) supplements], there comes a point at which other factors limit milk production. For example, total supply of AA to the small intestine or the supply of individual $\mathrm{AA}$, can become most limiting when a low-protein cereal grain is the primary supplement (e.g., corn and lysine limitation). Furthermore, GBC supplements can be provided in excess, disrupting rumen function and, thereby, reducing DMI and digestive efficiency (Bramley et al., 2008). For example, Auldist et al. (2013b) offered increasing levels of GBC supplements as a TMR to grazing dairy cows in early lactation. The high levels of grain supplementation resulted in substantially less milk than their predicted ME and MP supply would indicate (CNCPS simulation; Fox et al., 1995). In an assessment of the diets, NFC and NDF were calculated to be 45 and $29 \% \mathrm{DM}$ at the highest level of supplementation, respectively, indicating the potential for a significant digestive upset. The rumen $\mathrm{pH}$ and VFA data presented by the authors confirm the likelihood 
of this digestive upset. By replacing some of the source of NFC (i.e., wheat) with canola meal, a feed source providing $\mathrm{ME}$ from fermentable $\mathrm{NDF}$ and $\mathrm{CP}$ primarily, NFC and NDF returned to 38 and $32 \%$ DM, respectively, reported rumen parameters returned to normal patterns, and DMI and milk production increased significantly. This is an example of Liebig's principle of the minimum, wherein the provision of the limiting resource (i.e., in this case, NDF and $\mathrm{CP}$ ) allowed the reduced use of a resource that had been oversupplied to the detriment of the animal's function (i.e., NFC).

Liebig's principle would support the role for individualized feeding of pasture-based dairy cows, with the ability to individualize cows' diets and provide for these limitations through individualized feeding of different feed ingredients. To best use Liebig's principle in the supplementation of dairy cows, we must be able to define the "cascade of nutritional limitations" that arises with the increased use of nutritionally imbalanced feed ingredients. In an effort to do this, Kolver (2003) simulated the nutritional factors limiting milk production in grazing cows supplemented with low-protein GBC. He concluded that ME intake (i.e., the product of total DMI and ME content) remained the primary factor limiting milk production until the proportion of concentrate supplement in the diet exceeded $20 \%$ DMI, with other nutrients potentially limiting production at supplementation rates greater than $20 \%$ DMI. In his simulation, individual AA became the factors identified as limiting production when grain exceeded $20 \%$ of DMI. As a result, the provision of more of the chosen supplement would have resulted in lower milk production responses. He suggested that this limitation might be a contributory factor to the reported decline in marginal milk production responses with increasing levels of supplementation (Kellaway and Porta, 1993; Kolver, 2003).

The hypothesis that providing more than $20 \%$ of DMI as low-CP feed leads to a change in the cascade of nutritionally limiting factors was recently tested by Higgs et al. (2013). Their results indicate that the $20 \%$ threshold postulated by Kolver (2003) was, in fact, too low. They reported that ME intake was still the nutritional factor limiting milk production in early lactation cows consuming $25 \%$ of their diet as a low-CP/ high-starch concentrate supplement. These results are consistent with those reported by Roche et al. (2013a), wherein response to a low-CP GBC supplement (i.e., high starch) was linear up to $6 \mathrm{~kg}$ of $\mathrm{DM} / \mathrm{d}(\sim 30 \%$ DMI). In a more extreme example, Auldist et al. (2013b) offered early lactation cows a diet of $36 \%$ fresh pasture, $18 \%$ pasture silage, and $46 \%$ cracked wheat grain. Based on inputting feed and animal production data into CNCPS (Fox et al., 1995), the primary limit- ing nutritional factor remained ME. Therefore, a fixed point of supplementation at which total ME intake is no longer the factor most limiting production cannot be defined. In each situation, diet composition and cow production parameters must be modeled to determine the nutrient limitation cascade, taking account of both deficiency limitations and likely limitations caused by the oversupply of particular feed components (e.g., NFC).

\section{Source of ME}

In acknowledging that $\mathrm{ME}$ is the nutritional factor most limiting production in grazing dairy cows, consideration must be given to the type of ME or, more accurately, the origin of the ME (i.e., NSC, NDF, fat, or protein). Carruthers et al. (1997), Garcia et al. (2000b), Roche et al. (2010), and Higgs et al. (2013) tested the hypothesis that the milk production response to supplements is determined by ME intake and not the source of ME. Carruthers et al. (1997), Garcia et al. (2000b), and Roche et al. (2010) all fed cows isoenergetic diets but replaced some of the energy obtained from pasture with dextrose (Carruthers et al., 1997) or starch from a corn- and barley-based concentrate feed (Garcia et al., 2000b; Roche et al., 2010). Milk energy secreted and EBAL were not affected by carbohydrate type, although milk, lactose, and protein yields and the protein-to-fat ratio in milk were generally greater in the cows consuming a portion of their ME from starch. Higgs et al. (2013) compared offering cows the same amount of ME as either starch (i.e., crushed corn grain) or a fermentable NDF-based concentrate (i.e., based on wheat middlings), without controlling pasture DMI. Both groups produced the same yields of fat and protein, although protein-to-fat ratio was greater in the cows consuming starch (i.e., greater protein yield and lower fat yield in NSC-based cows compared with NDF-based cows). Model simulations of both diets indicated that, even at this level of supplementation, ME intake remained the nutritional factor limiting production. The effects of nutrition on milk composition will be covered in detail in a later section of this review.

In fluid milk payment systems, these results place a premium on NSC-based supplements, as milk yield increases by approximately $0.36 \mathrm{~kg}$ more per $\mathrm{kg}$ of NSC intake compared with a similar ME intake from nonforage fiber-based supplements (Roche et al., 2010). In component milk payment systems, however, where lactose is generally not valued but protein is worth approximately twice the value of fat, milk revenue is not greatly affected by source of ME (Roche et al., 2010), as the differences in fat and protein yields between the ME sources have approximately the same monetary 
value. Source of ME has been reported to affect pasture DMI (i.e., substitution rate) and this will be covered in detail in later sections.

In summary, temperate pastures can be of high quality, with ME intake being the factor that limits milk production at low to medium levels of supplementation. When low-CP GBC is the predominant supplement, other factors may limit production when supplementation exceeds 30 to $50 \%$ of DMI. The requirement to "balance" the concentrate for limiting nutritional factors could be a justification for the individualized feeding of cows. Nutritional scenarios need to be modeled to determine the cascade of nutritional limitations and, thereby, identify the primary limiting nutritional factor. In this, consideration needs to be given to both nutrient deficiency and the oversupply of particular nutritional factors, because both scenarios may limit production.

\section{SUPPLEMENTATION STRATEGIES}

Supplements can be presented to grazing cows in a range of ways, with the type of supplement and facilities present often dictating the method of feeding. Choosing the most efficient and appropriate way of providing supplements continues to be a challenge for dairy producers. In this section, different approaches to feeding concentrate supplements to pasture-based dairy cows will be summarized.

Methods of feeding supplements range from flat-rate feeding, where the same amount of supplement is offered to each cow in a herd for every day of the supplementary feeding period, to more complex feeding systems based on a chosen cow-level parameter, in which cows are offered different amounts of supplements on the basis of this parameter (e.g., individual milk yield). Research investigating the merits of different systems for presenting mixed concentrates to dairy cows has continued since the 1940s. Within the flat-rate system, concentrates can either be allocated at a constant rate throughout the lactation (the uniform flat-rate system) or be stepped up or down (stepped flat-rate) in response to stage of lactation (Leaver, 1988). A further level of complexity is introduced when a combination of nutrient sources are incorporated into pellets or are offered as a loose mix, with the objective of complementing nutrients obtained from pasture or conserved forage to optimize nutrient intake and increase milk production.

\section{Flat-Rate Feeding of Concentrates Versus Stepped Feeding with Stage of Lactation}

Numerous experiments were undertaken in 1970s and 1980s to determine whether cows would benefit from the provision of a greater amount of supplements in early lactation than in mid and late lactation compared with providing the same amount each day of lactation. For example, Rakes and Davenport (1971) compared cows fed equal amounts daily throughout lactation with cows fed larger amounts in early lactation and smaller amounts in mid and late lactation. They reported no significant differences in annual milk production over 3 lactations $(6,400 \mathrm{~kg}$ of milk/cow per lactation) when approximately $3,250 \mathrm{~kg}$ of concentrate/cow was consumed annually. Similarly, in a comprehensive research program in Denmark exploring a range of concentrate allocation methods (Østergaard, 1979), means of 298 lactations and 8 different concentrate feeding strategies were compared with a standard treatment based on the Danish feeding standard, in which cows were offered concentrate relative to individual milk yield (4.8 MJ of ME/kg of FCM yield). Grass silage was offered ad libitum in combination with 3 levels of concentrate feeding $(1,200,1,530$, or $1,850 \mathrm{~kg}$ of concentrate mix/cow per lactation; Table 1) to determine if any response depended on amount of concentrate fed. Average milk yield increased with concentrate feeding level $(5,700,5,900$, and $6,400 \mathrm{~kg}$ of FCM/cow per lactation, respectively) but was not affected by method of feeding.

In the UK, Gordon (1982) reported no benefits from stepped feeding over a 2-yr period, with concentrate DMI of 1,200 and $1,150 \mathrm{~kg} /$ cow per lactation and cows producing 4,900 and $4,850 \mathrm{~kg} / \mathrm{cow}$ per lactation, with no differences in milk fat or protein yields. In that study, the grass silage offered had a relatively high $\mathrm{ME}(680 \mathrm{~g} / \mathrm{kg}$ of digestible $\mathrm{OM}$ in DM). Taylor and Leaver (1984) hypothesized that there may be an interaction between silage quality and feeding strategy. They compared both flat-rate and stepped feeding allocation strategies when cows were consuming high or low ME silage (10.5 and 8.9 MJ of $\mathrm{ME} / \mathrm{kg}$ of $\mathrm{DM}$, respectively); again, there was no evident effect of feeding allocation method, but clear differences were observed in milk production in favor of the higher-ME grass silage.

In 7 comparisons of flat-rate and stepped-feeding strategies (Gordon, 1982; Taylor and Leaver, 1984; Poole, 1987; Rijpkema et al., 1990; Aston et al., 1995), milk yield averaged 22.8 and $23.0 \mathrm{~kg} / \mathrm{d}$, respectively, when average concentrate DMI was $7.9 \mathrm{~kg} /$ cow per day. In summary, there is little compelling historical evidence to suggest a benefit from feeding higher amounts of mixed concentrate supplements in early lactation and stepping down the amount offered with advancing stage of lactation, when fed under the conditions of forage being provided ad libitum. 
Table 1. Total feed intake (grain and grass) and milk production/cow per year for different strategies of feeding a concentrate grain mix to dairy cows (data from Østergaard, 1979)

\begin{tabular}{lcccccccccc}
\hline & \multicolumn{9}{c}{ Strategy of feeding grain mix } \\
\cline { 2 - 8 } Item & $\mathrm{L}_{0}$ & $\mathrm{~L}_{-0.5}$ & $\mathrm{M}_{0}$ & $\mathrm{M}_{-0.5}$ & $\mathrm{M}_{+2,-1}$ & $\mathrm{M}_{-1}$ & $\mathrm{H}_{0}$ & $\mathrm{H}_{+1,-0.5}$ & $\mathrm{Standard}$ \\
\hline Grain mix (kg of DM) & 1,161 & 1,234 & 1,585 & 1,537 & 1,491 & 1,517 & 1,841 & 1,860 & 1,441 \\
Grass silage (kg of DM) & 2,246 & 2,312 & 2,110 & 2,072 & 2,219 & 2,117 & 2,045 & 2,022 & 1,870 & 6,38 \\
Milk yield (kg of FCM/cow per year) & 5,657 & 5,734 & 6,062 & 5,906 & 5,899 & 5,830 & 6,388 & 6,406 & 5,772 \\
\hline
\end{tabular}

${ }^{1} \mathrm{~L}=4.5 \mathrm{~kg}$ of grain mix $/$ cow per day; $\mathrm{M}=6.0 \mathrm{~kg}$ of grain mix $/$ cow per day; $\mathrm{H}=7.5 \mathrm{~kg}$ of grain mix/cow per day; $0=$ flat-rate feeding over entire lactation at either $\mathrm{L}, \mathrm{M}$ or $\mathrm{H} ;-0.5=$ grain mix is reduced by $0.5 \mathrm{~kg}$ every $14 \mathrm{~d}$ throughout lactation; $+2,-1=$ grain mix is increased by $2 \mathrm{~kg} /$ cow every $14 \mathrm{~d}$ until wk 12 and reduced by $1.0 \mathrm{~kg}$ every $14 \mathrm{~d} ;-1=$ grain mix is reduced by $1.0 \mathrm{~kg} /$ cow every $14 \mathrm{~d}$ throughout lactation; $+1,-0.5=$ grain mix is increased by $1 \mathrm{~kg} /$ cow every $14 \mathrm{~d}$ until wk 12 and reduced by $0.5 \mathrm{~kg}$ every $14 \mathrm{~d}$; Standard = feeding amount of grain mix based on milk yield (4.8 MJ of ME/kg of FCM).

\section{Flat-Rate Feeding of Concentrates Versus Feeding to Individual Milk Yield}

Moisey and Leaver (1985) compared flat-rate feeding of mixed concentrates during the first $20 \mathrm{wk}$ of lactation with a feeding strategy based on individual cow milk yield at 2 wk postcalving. They reported no differences in milk yield and concluded that there was no advantage in feeding to yield. In further research from the UK (Taylor and Leaver, 1984), cows were offered 2 amounts of mixed concentrates ( 7 and $11 \mathrm{~kg}$ of concentrates/cow per day) at either a flat or variable rate (based on individual milk yield at 2 wk postcalving) and that was reduced 3 times during the 25-wk experiment. The difference in milk yield between the systems of allocation was not significant (23.9 and $22.9 \mathrm{~kg} /$ cow per day for flat-rate and feeding to yield, respectively). However, on the flat-rate system, cows produced more milk fat because of a combination of numerically higher milk yield and milk fat concentration. Cows consuming the higher amount of supplement produced more milk (25.4 vs. $22.9 \mathrm{~kg}$ of milk/cow per day).

With the increased milk production potential of cows through genetic selection, further research was undertaken by Rijpkema et al. (1990) to compare flatrate feeding with feeding individual cows according to actual milk production. Over 4 experiments, they detected no effect of feeding system on annual milk yield $(6,719,7,141,7,084$, and 6,943 vs. $6,733,6,971$, 7,062 , and $7,049 \mathrm{~kg} \mathrm{milk} / \mathrm{cow}$ for the conventional method of feeding to milk yield compared with flat-rate feeding, respectively). They concluded that when cows were group fed roughage ad libitum, there was no milk production benefit to feeding high-yielding cows with concentrates to the cows' estimated individual energy requirements or their capacity to produce milk.

In 12 comparisons of flat-rate and individualized feeding strategies (Gordon, 1982; Taylor and Leaver, 1984; Moisey and Leaver, 1985; Taylor and Leaver, 1986; Rijpkema et al., 1990), milk yield averaged 25.1 and $24.8 \mathrm{~kg}$, respectively, when average concentrate DMI was $8.9 \mathrm{~kg} /$ cow per day. In summary, there is no evidence that the system of concentrate allocation throughout lactation has any effect on milk production when the same total amount of concentrate is consumed and when forage is not limiting.

\section{Limitations of Previous Research}

The cows in the aforementioned experiments were producing reasonable yields of milk (i.e., up to $7,100 \mathrm{~kg}$ of milk/yr) relative to annual yields often reported for grazing cows in farm systems experiments (Horan et al., 2006; Roche et al., 2006a; Macdonald et al., 2008); therefore, the current milk yield of grazing cows being superior to historical counterparts (Macdonald et al., 2008) is probably not a valid reason to revisit the topic. It may be necessary to confirm these conclusions, however, in higher-producing cows being fed TMR.

Although the validity of the consistent research results reported is beyond reproach, one important factor must be considered in interpreting the appropriateness of the results for grazing systems. In virtually all of the studies reviewed, the effect of feeding strategy was undertaken in cows fed silage indoors or in situations of unlimited forage availability. This is important, because there are very few comparisons of the feeding methods reviewed in grazing cows, particularly in situations where the grazing cow has only restricted access to forage (i.e., a well-managed rotational grazing system).

Pasture allowance ( $\mathrm{kg}$ of pasture $\mathrm{DM} /$ cow per day) is considered the system-level factor that has greatest effect on pasture DMI and substitution rate (Stockdale, 2000b), although the type and quality of pasture available may contribute to differences. Pasture DMI increases as pasture allowance is increased but at a declining rate. In reviewing DMI data from 31 grazing experiments, Baudracco et al. (2010a) reported that maximum DMI occurred at a pasture allowance of 31 $\mathrm{kg}$ of $\mathrm{DM} / \mathrm{cow}$ per day above a 3 -cm residual pasture height. Below this allowance, cows cannot achieve their 
potential DMI. However, such an allowance would lead to significant wastage of pasture, as the marginal increase in pasture utilization with increasing pasture allowance is low (15-25\%; Peyraud and Delagarde, 2013). Peyraud and Delagarde (2013) suggested that limiting pasture allowance to $90 \%$ of a cow's voluntary DMI at pasture provides a good compromise between per-cow and per-hectare milk production. To this end, in pasture-based systems, cows are usually offered a restricted allowance of pasture, with supplements used to fill a gap in nutrient requirements where there are seasonal deficits of pasture DM (Holmes and Roche, 2007). When pasture allowance is restricted, substitution of supplements for pasture is reduced and the marginal milk production response increased (Grainger and Mathews, 1989; Wales et al., 1999; Stockdale, 2000b).

Providing restricted pasture allowance creates competition between cows for scarce resources and inevitably leads to variations in the relative deficit between nutrient supply and demand for individual cows within a herd. It is plausible that cows of higher genetic merit for milk production will experience greater nutrient deficits compared with cows of lower genetic merit (Penno et al., 2001), although this will be affected by the social hierarchy of the herd (discussed subsequently in more detail). If true, where supplements are provided at a flat rate to the herd, restricted pasture in combination with restricted supplementation will lead to high-genetic-merit cows becoming the most restricted animals in the herd (Garcia et al., 2007). Garcia and Holmes (2005) reported that high-genetic-merit cows will try to compensate for their higher requirements by increasing DMI of the feed that is least restricted. In a situation of restricted pasture allowance and supplementation, identifying those cows having the greater relative nutrient deficit and supplying them with more supplement than cows with smaller nutrient deficits may improve the efficiency of milk production, through low substitution of supplements for pasture in low-genetic-merit cows and more efficient partitioning of nutrients to milk in high-genetic-merit cows (Garcia et al., 2007). This implies that there could be a benefit from individualized bail feeding practices when pasture allowance is restricted.

Another related factor to be considered when pasture allowance is restricted is the effect of social hierarchy on an individual cow's ability to achieve adequate pasture DMI. If pasture is already restricted, cows of lower social order will be limited in their ability to select the highest quality pasture, which will likely reduce their milk production. There may be a reason, therefore, to supplement cows in a restricted pasture allowance based on their place in the herd's social hierarchy, with cows lower in the dominance spectrum likely to benefit more from additional supplementary feed. Unlike the previous argument for individualized feeding on an individual milk production basis, this is not a feature of a cow's genetic ability to produce milk, but instead is a result of social status and (or) foraging ability. Garcia et al. (2000a) reported that when cows were fed corn silage on a restricted basis for $2 \mathrm{~h}$ after milking, the variation in individual DMI was not associated with their milk yield but with their social hierarchy. An issue related to this social effect is the effect of the time that individual cows arrive at the pasture after milking, with those arriving last faced with increased pasture restriction and reduced pasture quality compared with cows arriving first (Kaur et al., 2013). More research needs to be conducted to examine the social factors affecting grazing behavior and the subsequent DMI of individual cows at pasture to determine how important these factors are in optimizing the efficiency of milk production when supplementing cows in pasture-based systems.

Because of the effect of pasture allowance on substitution rate and milk response to supplement, it is plausible that the effect of individualized feeding under a slight pasture restriction, as practiced in efficient rotational grazing systems (Peyraud and Delagarde, 2013), would be different from what has been previously reported. The only recent data exploring this question (Garcia et al., 2007) compared the feeding of concentrates based on individual cow milk yield (average of 5 $\mathrm{kg}$ of DM/cow per day, but ranging from 3 to $7 \mathrm{~kg}$ of $\mathrm{DM} /$ cow per day) with feeding $5 \mathrm{~kg}$ of $\mathrm{DM} /$ cow per day (i.e., flat-rate fed), when grazing a limited allowance of lucerne. They reported a significant $7 \%$ increase in the yield of milk fat and protein in the cows fed individual allowances of concentrates relative to their milk yield. However, corn silage was offered as an additional supplement in this study, and it is possible that this filled the forage gap deficit in the most restricted cows. If so, because corn silage is nutritionally inferior to lucerne, this may explain, in part, the difference in milk production between the herds. Further research needs to provide a better understanding of the importance of feeding to individual cow milk yield when cows are managed in a typical, marginally restrictive rotational grazing system.

\section{COW-LEVEL FACTORS AFFECTING RESPONSE TO SUPPLEMENTS AND THEIR POTENTIAL VALUE IN INDIVIDUALIZED FEEDING STRATEGIES}

The maximum theoretical milk production response to $1 \mathrm{~kg} \mathrm{DM}$ of a supplement containing $12 \mathrm{MJ}$ of ME/ $\mathrm{kg}$ of DM is between 2.0 and $2.5 \mathrm{~L}$ of milk, depending on supplement type and milk composition. This assumes that pasture DMI is not affected, the entire supplement is consumed, and all of the supplement's 
energy is converted into milk (Holmes and Roche, 2007). In reality, some of the supplement is invariably lost in the feeding process, supplemented cows reduce their DMI of pasture compared with unsupplemented cows (Stockdale, 2000b), and some of the extra energy might be partitioned to body reserves (Roche et al., 2006a). In addition, the digestibility of pasture is usually negatively affected by the consumption of starchbased feeds (Williams et al., 2005; Leddin et al., 2010). These factors explain why typical responses to supplements are much lower than the maximum theoretical response to supplements (Holmes and Roche, 2007).

Until the 1990 s, typical reported marginal milk production responses to supplements were in the order of 0.4 to $0.6 \mathrm{~kg}$ of milk $/ \mathrm{kg}$ of concentrate. However, since then, marginal responses have increased to approximately $1 \mathrm{~kg}$ of milk $/ \mathrm{kg}$ of concentrate, with supplementation levels of up to $6 \mathrm{~kg} / \mathrm{d}$ (see reviews by Stockdale, 1999; Bargo et al., 2003; Dillon, 2006; Baudracco et al., 2010a; Peyraud and Delagarde, 2013). Although some of this effect may be due to changes to grazing management (i.e., lower allowances, greater pasture utilization), the majority of the effect is probably due to a cow-level effect rather than farm system-level effects. If individualized feeding offers any advantage over flatrate feeding in rotationally grazed dairy systems, it is imperative to understand the cow characteristics by which cows should be individually fed. These cow-level factors will be discussed in the following sections.

\section{Grazing Behavior, Pasture DMI, and Substitution Rate}

Stockdale (2000b) comprehensively reviewed factors known to be associated with substitution rate but could only explain $51 \%$ of the variation observed, through the components included in his review. Stockdale (2000b) concluded the factors most influential in substitution rate were pasture DMI in unsupplemented cows and the cow herself, the latter being quantified only by her BW. Substitution rate increased with increasing pasture DMI and declined with increasing cow BW. Other publications reporting the effect of concentrate supplementation on substitution rate also defined a cow effect using BW (Dulphy, 1978; Grainger and Mathews, 1989; Larcombe, 1989; Penno, 2002), implying a linear decline in substitution rate with increasing cow BW; substitution rate decreased by between 10 and 25 percentage points with every $100-\mathrm{kg}$ increase in BW, depending on unsupplemented pasture DMI (Grainger and Mathews, 1989).

Although the positive effect of pasture DMI on substitution rate is consistent with the physiological regulation of hunger and satiety (Roche et al., 2008a), recent research results indicate there are effects of cow genetics on substitution rate that are not accounted for by BW (Fulkerson et al., 2008). Both Linnane et al. (2004) and Sheahan et al. (2011) investigated the effect of differing genetic strains of Holstein-Friesian on grazing behavior, DMI, and substitution rate under different supplementary feeding strategies. Their findings are consistent with production results from other studies designed to examine production responses to supplements in cows of differing genetic ancestry (Kennedy et al., 2003; Horan et al., 2005; Fulkerson et al., 2008). Linnane et al. (2004) compared 3 genetic strains of Holstein-Friesian dairy cow: one strain was exclusively selected for milk yield (high production; HP), a second strain shared a similar genetic ancestry to the HP strain, but was selected for production and functional traits in a multi-variable genetic index (high durability; HD), and the third strain originated in New Zealand and also was the result of a multi-variable genetic index that included functional traits (New Zealand; NZ). Sheahan et al. (2011) compared 2 genetic strains: one strain was between the HP and HD strains reported by Linnane et al. (2004), with a heavy historical emphasis on selection for milk yield but a recent inclusion of functional traits, and the other was a New Zealand Holstein-Friesian (i.e., the product of a multi-variable genetic index). In both studies, substitution rate was greater in the NZ cow (substitution rate $=52$ and $55 \%$ ) than in either the HD cow (substitution rate $=30$ and $24 \%$ ) or the HP cow (substitution rate $=7 \%$ ), confirming an effect of genetics on substitution rate and providing further support for the concept of individualized feeding according to genetic merit. Although differences were also detected in cow BW between treatments (e.g., HP cow was on average $22 \mathrm{~kg}$ heavier than NZ cow in Linnane et al. (2004)), this difference in BW would only account for a $6 \%$ difference in substitution rate. The genotype $\times$ nutrition interaction reported by Kennedy et al. (2003) and Fulkerson et al. (2008) supports this effect of cow genetics on DMI and substitution rate. These results indicate an opportunity to identify cows within a herd that have low substitution rate and, by extrapolation, high marginal responses to supplementary feeds (Fulkerson et al., 2008), and could be individually fed for greater efficiency of feed use.

The effect of supplementation on pasture DMI is evident in grazing behavior measurements. Bargo et al. (2003) and Sheahan et al. (2011) concluded that cows reduced their time spent grazing by $12 \mathrm{~min}$ for every 1 $\mathrm{kg}$ DM of concentrate supplement consumed. However, this effect of supplement on grazing time was not uniform throughout the day. Sheahan et al. (2011) reported a linear decline in grazing time with concentrate supplementation during the primary a.m. grazing bout, but no 
effect of supplement on grazing time in the main presunset grazing bout. Sheahan et al. (2013a) subsequently tested the effect of timing of supplementation on grazing behavior and reported that either a.m. or p.m. supplementation reduced grazing time during the primary a.m. grazing bout compared with an unsupplemented control, but did not affect grazing time during the main pre-sunset grazing bout. These results indicate complex physiological mechanisms regulating feeding in grazing dairy cows that extend, at least, over several hours.

Although the data presented by Linnane et al. (2004) and Sheahan et al. (2011) on the effect of supplementation on grazing time agree with the review of Bargo et al. (2003), the genetic differences in substitution rate were not explained by differences in grazing time. In fact, the NZ strain grazed for longer but consumed less pasture DM than the HD cow (Sheahan et al., 2011), and the HP cow had a greater reduction in time spent grazing when supplemented $(30 \mathrm{~min} / \mathrm{kg}$ of DM concentrate) than either the $\mathrm{NZ}$ or $\mathrm{HD}$ strain $(7 \mathrm{~min} / \mathrm{kg}$ of DM concentrate; Linnane et al., 2004), despite having the lowest substitution rate. The effect of supplement on pasture DMI is, therefore, more complicated than merely the effect on grazing time. The other behavior factors that contribute to pasture DMI are bite mass and bite rate. These factors, along with grazing time, are behavioral proxies for the balance between the physiological factors regulating hunger and satiety and reflect a reduction in the "drive to eat" in cows provided with supplementary feed.

Intake regulation is complex and has been extensively reviewed for ruminant farm animal species by Roche et al. (2008a). Physical distension of the rumen and gastrointestinal tract; metabolism of products of digestion in the liver; and endocrine products of the gastrointestinal tract, pancreas, adipose tissue, and, possibly, muscle, all contribute signals that are processed centrally in the brain to control hunger, satiety, and energy expenditure. Intake regulation needs to be considered on different time scales (Roche et al., 2008a) from meal initiation and the regulation of meal size (short-term/acute regulation) to the longer-term regulation of DMI required to maintain a physiological steady state (chronic regulation). Acute regulators are required to have short half-lives, exhibit significant variation throughout the day, respond to the ingestion of energy-dense feedstuffs, and may even exhibit circadian rhythms. Chronic controllers of DMI, in comparison, are less likely to exhibit diurnal change, need not necessarily have short half-lives, but must provide information on the status of the body's long-term energy status (adipose tissue depots).

Physical distension does not appear to be a DMIlimiting factor in cows grazing highly digestible tem- perate pastures (Van Soest, 1994), with grazing during the a.m. ceasing before ruminal distension could be a primary regulating factor and the onset of sunset resulting in a cessation of DMI during the p.m. feeding event (Sheahan et al., 2011). Physical distension may be a significant regulatory factor with tropical pastures, although Stockdale (2000b) reported no evident difference in substitution rate between temperate and tropical pastures in Australia. These results imply that something other than physical fill regulates substitution rate when concentrate feeds are offered.

Similarly, although hepatic oxidation of energy fuels and the induction of satiety through the lower discharge rate of hepatic vagal afferents (Forbes, 1992; Allen et al., 2009) are known to be involved in satiety in monogastric species, much of the presented metabolic and behavioral data do not support the hepatic oxidation of metabolites as a plausible physiological mechanism controlling substitution rate in grazing dairy cows. For example, elevated blood glucose concentrations prefeeding in the afternoon and the provision of additional fermentable energy (either starch or a nonforage fiber source) should result in a relatively quick decline in feeding activity following the p.m. milking if the hepatic oxidation theory is correct. On the contrary, however, cows continue to feed until darkness and have the least substitution of supplement for pasture (Sheahan et al., 2013b) at this time, despite the more positive cow energy status compared with the a.m. feeding event. The reported decrease in substitution rate from early to late lactation (Stockdale, 2000b) further questions the appropriateness of the hepatic oxidation theory, as a greater substitution would be expected with advancing lactation and the consequential lower requirements for glucose for milk lactose synthesis (Allen and Bradford, 2009) Collectively, these data do not support the hepatic oxidation theory as the primary cow factor regulating DMI and substitution rate in grazing dairy cows.

There is increasing evidence in grazing systems (Sheahan et al., 2011, 2013a,b) that circulating factors produced in the gastrointestinal tract and splanchnic organs in response to the ingestion and digestion of feeds are primary signals informing the brain of the short-term energy status of the animal. These factors can act directly on the brain, stimulating hormonal and neuronal changes within the hypothalamus, or indirectly, via effects on the vagus nerve and the nucleus of the solitary tract. These stimuli reflect the immediate energy status of the animal relative to metabolic demand (Roche et al., 2008a): when ME intake is less than immediate demand, peripheral orexigenic factors stimulate control centers within the hypothalamus to "instruct" the animal to eat; when ME intake is more than immediate demand, anorexigenic factors released 
peripherally have the opposite effect centrally. A simplified model of DMI regulation is presented in Figure 1 (adapted from Seeley and Schwartz, 1997).

Many circulating factors have been implicated in DMI regulation and there is increasing evidence that the primary neuroendocrine factors regulating DMI in monogastric species (Arora and Anubhuti, 2006) are also regulatory factors in ruminant DMI (Roche et al., 2008a). For example, Sheahan et al. (2013a,b) reported a correlation between the diurnal profile of plasma ghrelin, a potent orexigen in monogastric species, and feeding behavior; plasma ghrelin declined during the a.m. primary grazing bout, consistent with declining hunger with feed consumption, and increased before sunset, despite a positive energy state from previous feed ingestion, but consistent with the evolutionary drive to eat before dark in diurnal species and measured cow feeding behavior. In comparison, insulin appeared to be a hormone associated with satiety, increasing with feeding in the a.m., but failing to increase until just before sunset in the p.m., despite the greater voracity of feeding. Further confirmation of a role for these hormones in DMI regulation comes from infusion studies. Wertz-Lutz et al. (2006) reported an increase in feeding activity and DMI immediately following ghrelin infusion in steers, and Roche et al. (2008c) reported a decline in plasma ghrelin concentration with the glucose-induced increase in insulin concentrations during an in vivo glucose tolerance test.
These, and other, neuroendocrine factors may be the components of the animal that regulate DMI and substitution rate and, if so, could be used to identify cows that would produce more milk in response to concentrate supplementation. Roche et al. (2008b) reported a negative correlation between $\mathrm{BW}$ and the change in preprandial to postprandial ghrelin concentrations ( $\Delta$-ghrelin), with $\Delta$-ghrelin being used as a proxy for satiety (i.e., a smaller $\Delta$-ghrelin was purported to indicate a lower satiety from supplementation and, by extension, a lower substitution rate). Therefore, the smaller $\Delta$-ghrelin with increasing BW (Roche et al., 2008b) would partly explain the lower substitution rate in heavier animals (Stockdale, 2000a). However, BW explained less than $3 \%$ of the difference in $\Delta$-ghrelin. In addition to the relationship between $\Delta$-ghrelin and BW, there are limited data highlighting an effect of cow genetics on plasma ghrelin concentrations, with baseline average plasma ghrelin concentrations increasing with genetic selection for milk production (Roche et al., 2006a,b). These trends are consistent with the decline in substitution rate with genetic selection for milk production (Linnane et al., 2004; Fulkerson et al., 2008; Sheahan et al., 2011).

Further evidence of a role for these neuroendocrine factors in controlling substitution rate is in the effect of concentrate supplementation on plasma ghrelin concentration. Roche et al. (2007c) measured a linear decline in plasma ghrelin concentration following

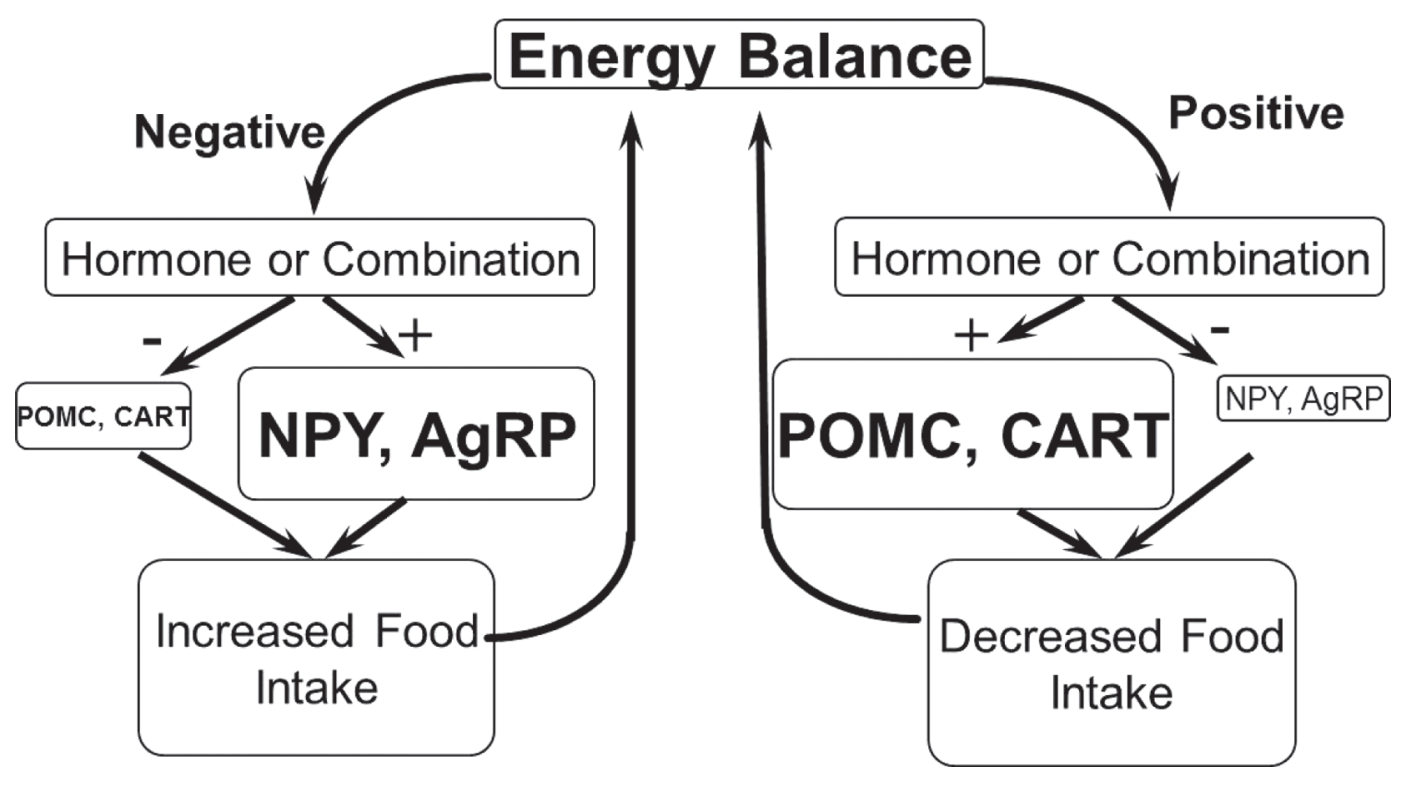

Figure 1. Simplified model depicting the neuroendocrine basis of intake regulation. NPY = neuropeptide Y, AgRP $=$ Agouti-related peptide, $\mathrm{POMC}=$ proopiomelanocortin; CART $=$ cocaine- and amphetamine-regulated transcript. Adapted from R. J. Seeley and M. W. Schwartz, Current Directions in Psychological Science (Vol. 6; pages 39-44), copyright ( ${ }^{1} 1997$ by SAGE Publications. Reprinted by Permission of SAGE Publications. 
supplementation with concentrates at the a.m. milking, the time when supplementation has the greatest effect on grazing time (Sheahan et al., 2011, 2013b). These data provided evidence of a neuroendocrine basis for substitution rate. Confirming this relationship between neuroendocrine factors and substitution rate in grazing cows, Sheahan et al. (2013b) reported an effect of supplement type on substitution rate and the postprandial decline in plasma ghrelin. In their study, starch-based concentrate feeds resulted in a greater decline in plasma ghrelin concentrations and a greater substitution rate compared with fermentable fiber-based concentrates.

In summary, the reported data collectively indicate that neuroendocrine factors play a significant role in regulating the pasture DMI response to supplementary feeds and may, in fact, be the animal factors that contribute to the unexplained variation in substitution rate in grazing dairy cows. Further research is required on the role of these neuroendocrine factors on DMI regulation and in the control of substitution rate. If they are suitable biomarkers for the animal effect on substitution rate, they could be used to individually feed supplements to minimize substitution rate and maximize the milk production response to supplements and, ultimately, could be used to select cows that produce more milk from every kilogram of supplement consumed, thereby enhancing feed conversion efficiency in grazing systems.

\section{Milk Production}

The regulation of dairy cow metabolism, particularly in early lactation, ensures a large supply of glucose, AA, and both long- and short-chain FA for the mammary gland (i.e., homeorhesis; Bauman and Currie, 1980), while ensuring constant levels of glucose in blood. Homeorhesis notwithstanding, a significant opportunity exists to manipulate milk yield and milk composition via genetics or nutritional means and possibly a combination of both (Fulkerson et al., 2008). Because of the greater sensitivity of milk fat to dietary manipulation than either protein or lactose, nutritional control of milk fat has, historically, received more attention than the other components (Jenkins and McGuire, 2006). However, because of the greater value of milk protein in compositional payment systems, the need to increase nitrogen-use efficiency at a cow level, and the recognition that the ability of the mammary gland to synthesize milk protein does not function at maximum capacity (Griinari et al., 1997), considerable effort has been focused on understanding the factors regulating milk protein synthesis over the last 2 decades. Although very few payment systems globally acknowledge the true value of lactose in milk powder production, lactose yield is directly related to milk yield and, so, manipulation of this milk component is important in systems where producers receive payment primarily for fluid yield.

The supplementation of grazing dairy cows with GBC supplements has been extensively researched. In a comprehensive review of the literature investigating the supplementation of grazing dairy cows, Bargo et al. (2003) concluded that, on average, supplementation increases milk yield $(1 \mathrm{~kg} / \mathrm{kg}$ of DM concentrate DMI), milk protein percentage $(+0.01 \% / \mathrm{kg}$ of $\mathrm{DM}$ concentrate DMI $)$ and yield $(+0.01 \mathrm{~kg} / \mathrm{kg}$ of DM concentrate DMI $)$, and milk fat yield $(+0.02 \mathrm{~kg} / \mathrm{kg}$ of DM concentrate DMI), but reduces milk fat percentage $(-0.13 \% /$ $\mathrm{kg}$ of DM concentrate DMI; Bargo et al., 2003). Supplementation would also be expected to increase lactose yield (Roche et al., 2010; Higgs et al., 2013), with the effect on milk lactose percentage being small and dependent on the type of supplement consumed (Higgs et al., 2013). There was considerable variation around the response to supplement reported by Bargo et al. (2003), much of which was probably related to grazing management, cow genetics, and the type of concentrate supplement offered.

Grazing Management. Marginal milk production responses to supplementation are affected by pasture DMI. As previously discussed, the greater the pasture DMI, the greater the substitution rate when cows are offered a supplement and the smaller the increase in total DMI, and the lower the marginal milk production response to supplements. Wales et al. (1999) reported that pasture DMI increased linearly with increasing pasture allowance, but that cows ate only $0.18 \mathrm{~kg}$ of DM extra for each $1.0 \mathrm{~kg}$ of DM offered $\left(\mathrm{R}^{2}=0.99\right)$; although the actual pasture DMI was also dependent on the pasture mass offered, this did not affect the slope of the response. These data imply that postgrazing pasture residual mass increases with increasing pasture DMI relative to the cow's potential DMI, and Roche and White (2012) hypothesized that the postgrazing residual mass could, therefore, be used to predict substitution rate and the milk production response to supplement.

In summary, utilization of pasture declines with increasing pasture allowance, irrespective of pasture mass. As a result, postgrazing residual mass increases with allowance and probably reflects the balance between hunger and satiety. It is reasonable to assume, therefore, that substitution rate increases and marginal milk production response to concentrate supplements will decline with increasing postgrazing residual mass. Further research is required to better understand the proportion of the variation in marginal milk production responses to supplements that can be explained by 
postgrazing residual mass and the interaction, if any, with cow genetics.

Cow Genetics. Kolver et al. (2002) and Kennedy et al. (2003) reported genotype $\times$ diet interactions for milk production. North American Holstein-Friesian cows produced more milk when fed high-concentrate diets, either in addition to fresh pasture (Kennedy et al., 2003) or in a TMR (Kolver et al., 2002). Fulkerson et al. (2008) expanded on this, noting that Australian Holstein-Friesian cows did not achieve the difference in milk production predicted by their EBV when fed fresh pasture and low levels of concentrate supplements ( $0.3 \mathrm{t}$ of $\mathrm{DM} /$ cow per lactation), but did produce the difference predicted by the EBV when fed $\geq 0.8 \mathrm{t}$ of DM supplement/cow per lactation. This effect of genetics on response to supplement probably reflects the environment in which bull daughters are evaluated (i.e., progeny tested) and relates to the genetic differences in substitution rate discussed earlier. These data indicate a need to consider the genetic merit of the cow when deciding on the most effective use of supplement and mean that targeting supplement based on EBV for milk fat and protein yields could allow for greater marginal milk production responses to supplementary feed.

Systems of allocating concentrate based on the current milk production of the cow may not have the same effect as that reported for EBV for milk component yield. Although Bargo et al. (2003) reported differences in the response to concentrate supplement between different milk yield categories, this only occurred when concentrate supplementation was greater than approximately $6 \mathrm{~kg}$ of $\mathrm{DM} / \mathrm{d}$, at which point the marginal response declined in low-yielding cows. Below this point, the slopes of the response lines were similar in high- and low-yielding cows. This may explain why results from previous studies indicated no benefit to individualized feeding of cows based on milk yield compared with feeding all cows the same amount of concentrate (see earlier discussion).

In summary, the collective literature indicates a significant cow effect in the marginal milk production response to supplements. The interactions of this cow effect with grazing management, supplement type, and supplement amount have not been adequately explored. Nonetheless, there appears to be a potential benefit to individually feeding cows concentrate feeds based on some measure of genetic merit, but the benefit probably depends on factors associated with grazing management and type of concentrate supplement.

Supplement Type. Supplement type can also affect the milk production response to supplements. Although the additional fat and protein produced when cows are supplemented can be predicted by the increase in ME intake resulting from supplementation, irrespective of supplement type (Higgs et al., 2013), substitution rate and therefore the marginal milk production response are affected by supplement type (as previously discussed). In addition, the ratio of fat to protein and volume of fluid milk produced are affected greatly by the type of supplement offered. For example, Roche et al. (2010) reported a 0.26-kg increase in milk volume per kg of DM starch-based supplement consumed when ME intake was held constant, despite no difference in ECM or $4 \%$ FCM (equivalent to $0.36 \mathrm{~kg}$ of milk $/ \mathrm{kg}$ of starch). Higgs et al. (2013) confirmed this effect of NFC, with a $50 \%$ greater milk volume response from a corn GBC than one based on fermentable fiber, despite similar yields of fat and protein combined. This effect of carbohydrate type is probably a result of differences in the output of rumen fermentation and associated differences in gluconeogenesis and glucose production. Starch-containing concentrates are primarily fermented to propionate in the rumen, which is efficiently used as a glucose precursor by the liver (Steinhour and Bauman, 1988) through direct action on the transcript abundance of phosphoenolpyruvate carboxylase (Koser et al., 2008). As glucose uptake by the mammary gland is not insulin dependent, greater gluconeogenesis should almost certainly increase the production of lactose by the mammary gland and, because of the need to keep milk and blood isotonic, an increase in water movement into the secretory cells and greater milk volume. Although White et al. (2012) reported no effect of concentrate supplementation on the expression of cytosolic phosphoenolpyruvate carboxylase in grazing dairy cows, Roche et al. (2010) reported greater circulating glucose concentrations in grazing cows consuming $5 \mathrm{~kg}$ DM of a corn-grain based concentrate, even when ME intake was not improved. This effect of carbohydrate type on milk volume has implications for milk revenue in systems paid for fluid milk, and, probably, EBAL, with increased lactose a drain on energy consumed.

Concentrate supplements high in NFC almost always increase milk protein concentration as well as milk protein yield (Sporndly, 1991; Bargo et al., 2003), provided the availability of MP is not limiting production (Mackle et al., 2000). This is not an effect of ME intake, with Roche et al. (2010) reporting a greater proteinto-fat ratio with increased NFC, although ME intake and ECM yield did not differ. This effect of starch is almost invariably linked to the ruminal production of propionate and the associated increase in circulating insulin. Griinari et al. (1997) and Mackle et al. (1999), using a hyperinsulinemic-euglycemic clamp, reported a 25 to $30 \%$ increase in milk protein yield when insulin concentrations were increased 4-fold. This increase in milk protein yield was due to increases in both milk yield and milk protein concentration. The insulin led 
to a greater uptake of AA by the mammary gland, with circulating concentrations of EAA reduced by $33 \%$ and branched-chain AA by $>40 \%$ (Mackle et al., 2000). The mammary gland was able to support the increased milk protein yields by increasing extraction efficiency of EAA, mammary blood flow, and glucose uptake.

Although the results of Griinari et al. (1997) and Mackle et al. $(1999,2000)$ established the physiological principle that insulin stimulates the uptake of AA by the mammary gland, the insulin concentrations used were supraphysiological, especially when considered in a euglycemic setting, and their relevance in normal physiological ranges for insulin and glucose should be questioned. However, it should be noted that Dunshea et al. (2005) were able to increase milk protein secretion with both supplemental branched-chain AA and an euglycemic clamp in lactating sows with insulin concentrations within the physiological range (i.e., $50 \%$ increase in insulin). Furthermore, the results reported by Rius et al. (2010) confirm the mechanisms elucidated by the aforementioned authors; abomasal infusions of starch and associated increases in plasma insulin increased milk and milk protein yields, increased mammary plasma flow, reduced arterial concentrations of AA, and increased mammary clearance rates and the net uptake of some AA. Starch infusions increased phosphorylation of ribosomal protein S6 and endothelial nitric oxide synthase, consistent with changes in milk protein yields and plasma flow, respectively.

Fermentable fiber-based concentrates and concentrates with high fat contents do not increase milk protein percentage and, in many instances, may reduce it. This effect, although much more difficult to predict, reflects a failure to change the insulin-glucose axis toward increased AA uptake. For example, when fermentable fiber-based concentrate feeds are offered, the ruminal production of acetate and butyrate increases and there is little change, if any, in ruminal propionate production (Van Soest, 1994). Therefore, the endocrine changes necessary to increase AA uptake by the mammary gland are not enacted and milk protein percentage does not change. In comparison, Palmquist and Moser (1981) reduced blood glucose and insulin concentrations and induced insulin resistance when feeding bypass fat. This could be the mechanism by which dietary fat negatively affects milk protein percentage.

The effect of concentrate supplementation on milk fat content is varied and heavily dependent on concentrate composition. Fermentable fiber-based concentrates tend to increase milk fat content and yield compared with NSC-based concentrates (Higgs et al., 2013), probably because of the increased availability of acetate and butyrate from ruminal fermentation relative to propionate. In most circumstances, NSC-based concentrates do not affect milk fat yield but decrease milk fat percentage because of the increase in milk volume (Jenkins and McGuire, 2006). However, in unusual circumstances, NSC-based concentrates can lead to a depression in milk fat yield. In TMR-based systems, this depression in milk fat has been attributed to the production of particular isomers of CLA during the ruminal biohydrogenation of linoleic acid, most notably trans-10,cis-12 CLA. The particular conditions that result in this isomer are not fully understood, but small quantities abomasally infused decreased milk fat by up to $50 \%$ in a dose-dependent manner (Baumgard et al., 2000; de Veth et al., 2006; Jenkins and McGuire, 2006). In pasture-based systems, this particular CLA isomer has not been identified in milk, either because it is not an intermediary in the biohydrogenation of linolenic acid (C18:3), the predominant FA in pasture, or it is present in such small quantities that its peak coalesces with the leading edge of the peak for cis-9,trans-11 CLA during chromatography (Dunshea et al., 2008). However, with the inclusion of enough GBC, the amount of linoleic acid (C18:2) and the rumen conditions could be right for the production of trans-10,cis-12 CLA and the suppression of milk fat.

In summary, supplementation of concentrate to grazing dairy cows increases milk yield and the yields of fat, protein, and lactose. However, the size of this response is dependent on substitution rate, and the relative proportions of fat, protein, and lactose in the increase in milk component yield is primarily dependent on supplement composition. Offering an NSC-based concentrate increases milk protein percentage (and yield) through an insulin-induced increase in mammary blood flow and in the uptake of AA by the mammary gland. Fermentable fiber-based concentrates, on the other hand, can lower the protein content of milk but tend to increase milk protein yield through increases in milk volume. Supplementation with bypass fat can lower milk protein yield through negative effects on blood insulin and glucose concentrations. Compared with milk protein percentage, milk fat percentage is often reduced by NSC-based concentrates and enhanced by the inclusion of fermentable fiber-based concentrates. Fermentable fiber-based concentrates also increase the yield of milk fat; however, the effect of NSC-based concentrates on milk fat yield is variable.

\section{Energy Balance and BCS}

A cow's BCS is a subjective assessment of her adipose and muscle tissue stores (Roche et al., 2004, 2009a). In most mammals, these reserves are stringently maintained by peripherally and centrally produced hormones (Roche et al., 2008a), in accordance with the "lipostat- 
ic" theory (Kennedy, 1953; Anukulkitch et al., 2009). The provision of nutrients for the neonate mammal, however, is facilitated by lipolysis and muscle catabolism for a period postpartum. Dairy cows also exhibit this mammalian tendency to nurture the neonate from tissue stores (Bauman and Currie, 1980), losing condition for approximately 40 to $100 \mathrm{~d}$ after calving before replenishing lost tissue reserves (Friggens et al., 2004; Pryce and Harris, 2006; Sumner and McNamara, 2007; Roche et al., 2009a). What makes dairy cows distinct from all other mammalian species, however, has been the intense trans-generational genetic selection for total milk production and early lactation milk production, in particular during the last $50 \mathrm{yr}$ (Dillon et al., 2006). Such selection pressures have resulted in many physiological changes that facilitate greater mobilization of BCS in dairy cows than other mammals (McNamara and Hillers, 1986b; Roche et al., 2007a; Lucy et al., 2009; Grala et al., 2011).

The importance of BCS (i.e., energy state) and EBAL at key times in the lactation cycle was extensively reviewed by Roche et al. (2009a). However, because of the likely effect of genetics and nutrition on BCS and BCS change (Roche et al., 2006a; McCarthy et al., 2007) and the effect of cow BCS on response to concentrate supplements (Stockdale, 2000a), a summary of the role of BCS in animal productivity, health, and reproduction as well as the nutritional factors regulating lipolysis and lipogenesis is required.

Importance of BCS for Milk Production, Reproduction, Health, and Welfare. A cow's BCS at calving and during the reproductive period, as well as the change in BCS between calving and breeding, are important parameters for milk production, health and welfare, and reproductive function (Roche et al., 2009a). Any strategy that ensures a calving BCS of 3.0 to 3.25 and ensures BCS loss postcalving $\leq 0.5$ BCS units will improve cow productivity and health, while also ensuring a favorable public perception of cow welfare (Roche et al., 2009a).

Lipogenesis and Lipolysis. Within adipocytes, 2 metabolic processes - lipolysis and lipogenesis - are continuously occurring, resulting in intracellular triglycerides constantly being degraded and resynthesized. Simply, when the requirement for energy is greater than the supply of energy, the rate of lipolysis exceeds that of lipogenesis and re-esterification, the cow loses BCS (i.e., is in negative EBAL), and blood NEFA concentrations increase. In comparison, when ME intake exceeds requirements, the rates of lipogenesis and reesterification exceed that of lipolysis, and the cow, who is in positive EBAL, stores the excess fuels and BCS increases (Brockman and Laarveld, 1986; Roche et al., 2009a). This relationship is complicated in a lactating mammal, however, because at least a portion of the additional energy consumed can be used for milk production if other nutrients are not limiting. Similarly, milk production can be reduced to compensate for a reduction in nutrient consumption, thereby sparing maternal tissues. In such situations, EBAL does not change by an amount commensurate with the change in DMI.

Role of Nutrition in Regulating Energy Balance and BCS Change. The balance between lipolysis and lipogenesis is under endocrine regulation. Growth hormone directly regulates ruminant adipose stores by enhancing the response to lipolytic stimuli (Liesman et al., 1995), attenuating the lipogenic response to insulin (del Rincon et al., 2007), and inhibiting the insulinmediated uptake of glucose by adipocytes. Catecholamines, such as epinephrine and norepinephrine, act as potent lipolytic stimulators (Bauman and Currie, 1980; Sechen et al., 1990), activating the regulatory subunits of both hormone-sensitive lipase and perilipin proteins, thereby increasing lipolysis (Stipanuk, 2000). In comparison, insulin suppresses gluconeogenesis, stimulates lipogenesis from acetate in bovine adipocytes, and increases the uptake of glucose by adipose tissue (Bauman and Currie, 1980; Vernon and Finley, 1985; Brockman and Laarveld, 1986). In addition, it results in a greater abundance of growth hormone receptors in liver tissue (Rhoads et al., 2004), in effect reducing the circulating concentration of growth hormone and its indirect lipolytic action.

This endocrine regulation of adipose tissue metabolism is abundantly evident in the high-producing dairy cow in early lactation. During the transition between gestation and lactation, there is a reduced abundance of the primary hepatic growth hormone receptor (GHR-1A), reducing the production of IGF-1 by $\sim 70 \%$ and, in effect, taking the brakes off growth hormone production. This phenomenon is commonly referred to as the uncoupling of the somatotropic axis (Block et al., 2001; Lucy et al., 2001; Radcliff et al., 2003; Rhoads et al., 2004) and is peculiar to the high-producing dairy cow (Lucy et al., 2009). At the same time, circulating insulin concentrations are low (Bines and Hart, 1982), peripheral tissues are resistant to insulin action (Bauman and Currie, 1980), and bovine adipose tissue is increasingly responsive to catecholamines (McNamara, 1988). Collectively, these endocrine patterns facilitate a net release of NEFA from adipose tissue.

This endocrine regulation of adipose tissue metabolism can be manipulated by nutrition, although there appears to be an interaction with stage of lactation and cow genetics (Roche et al., 2009a). During periods of feed restriction, transcript abundance of GHR-1A in liver is reduced (Breier et al., 1988; McGuire et al., 1992), growth hormone concentrations increase (Kay 
et al., 2013), and IGF-1 and insulin concentrations decline (Brockman and Laarveld, 1986; Kay et al., 2013). These changes result in increased lipolysis, reduced lipogenesis, and a net export of NEFA out of adipose tissue. In comparison, supplementing grazing dairy cows with concentrates results in an earlier recoupling of the somatotropic axis and a consequential decline in growth hormone concentration and an increase in circulating concentrations of insulin and IGF-1 (Grala et al., 2011). In addition, concentrate supplementation of grazing dairy cows reduces insulin resistance and increases the rate of glucose clearance following an in vivo glucose tolerance test (Chagas et al., 2009). These changes result in either an earlier return to positive EBAL or a more positive EBAL and an increase in adipose stores.

These effects of nutrition are, however, affected by both stage of lactation and cow genetics and, possibly, an interaction between the 2. Early lactation lipolysis is genetically controlled, whereas lipogenesis is under both genetic and environmental regulation (McNamara and Hillers, 1986a,b; Roche et al., 2009a). McNamara and Hillers (1986a) reported that high-genetic-merit cows had lipogenesis rates approximately $40 \%$ those of low-genetic-merit cows throughout lactation, and noted no effect of underfeeding on lipogenesis at 15 DIM, whereas lipogenesis was reduced by $40 \%$ by underfeeding at 30 DIM. In comparison, lipolysis was $\sim 20$ to $40 \%$ greater and the response to lipolytic signals was between 12 and $50 \%$ greater in high-genetic-merit cows throughout lactation (McNamara and Hillers, 1986b); energy restriction had no effect on lipolysis in early lactation. The lack of effect of nutrition on lipogenesis or lipolysis in very early lactation indicates the prioritization of nutrients for milk production and that rates of lipolysis are near the physiological maximum and cannot be increased further by undernutrition. A decline in circulating insulin concentrations (Bines and Hart, 1982) and a greater uncoupling of the somatotropic axis (Lucy et al., 2009) with genetic selection for milk production further supports a homeorhetic adaptation to facilitate milk production at the expense of body tissue.

Several recent experiments have explored the effect of nutrition on the inter-lactation profile of BCS change. Roche et al. (2006a) reported that concentrate feeding in early lactation did not affect the rate of BCS loss in early lactation, but reduced the duration of BCS loss (i.e., fewer DIM to nadir BCS), thereby slightly increasing nadir BCS. Similar conclusions were reported in an independent study in Ireland (McCarthy et al., 2007). This lack of effect of nutrition on rate of BCS loss in early lactation is consistent with the subsequent findings of others (Friggens et al., 2007; Roche, 2007;
Pedernera et al., 2008; Delaby et al., 2009) and are in agreement with the general conclusion of $\mathrm{McNa}-$ mara and Hillers (1986a,b), that lipolysis is primarily regulated genetically, whereas lipogenesis is environmentally controlled. The greater post-nadir BCS gain with increasing concentrate supplementation (Roche et al., 2006a; McCarthy et al., 2007) concurs with this hypothesis. Further evidence of this effect of NSC supplementation on BCS was reported by Washburn et al. (2002) and Roche et al. (2007a), who reported consistently lower BCS across the intercalving interval in cows fed grazed pasture compared with a genetically similar cohort fed TMR.

The reason for the inconsistent effects of diet in early versus mid to late lactation is not clear. However, it is probably associated with the physiological effects of GH and insulin discussed previously. Lucy et al. (2009) reported a recoupling of the somatotropic axis between 28 and 56 DIM in New Zealand HolsteinFriesian cows, although they did not detect a return to the prepartum expression of hepatic GHR-1A in North American Holstein-Friesian cows by 84 DIM. This is consistent with the different timing of nadir BCS in these genetic strains in an independent data set (Roche et al., 2006a). Although data presented by Grala et al. (2011) and Chagas et al. (2009) are in agreement with the genetic strain effects on these physiological factors affecting lipid metabolism, they, respectively, reported an earlier recoupling of the somatotropic axis and a reduction in insulin resistance in grazing cows offered more than $3 \mathrm{~kg}$ of $\mathrm{DM} / \mathrm{d}$ concentrates in early lactation. These data imply that the genetic target for nadir BCS can be modified by nutrition, consistent with the lipogenic findings of McNamara and Hillers (1986a) and Smith and McNamara (1990), but the effect on BCS is not biologically large (0.06 BCS units/100 kg of NSC equivalent: 5-point scale; $R^{2}=0.78$; Roche et al., 2006a). Furthermore, this effect of nutrition on adipose tissue metabolism is affected by the genetic merit of the cow (Roche et al., 2006a), with HP cows gaining only $50 \%$ of the BCS with concentrate supplementation compared with NZ cows. The post-nadir increase in BCS in cows offered diets containing greater concentrations of NSC is likely associated with the lipogenic and antilipolytic effects of insulin (Vernon, 1992), the circulating concentration of which would be expected to be greater due to the increased ruminal production of propionate. The lower insulin concentration in high-genetic-merit cows (Bines and Hart, 1982) is consistent with the lower level of BCS gain in the HP cows.

In summary, adipose tissue metabolism consists of a balance between lipolysis, lipogenesis, and FA re-esterification. Although BCS loss is a natural mammalian 
adaptation, intensive selection for milk production has resulted in cows that are prepared to mobilize BCS to the detriment of health and reproduction. After approximately 30 DIM, the balance between lipolysis and lipogenesis can, on average, be turned in favor of BCS gain in grazing dairy cows by increasing the consumption of concentrate supplements. However, HP cows require a greater level of concentrate supplement to effect change in these metabolic pathways. The ability to individually offer cows concentrate supplements based on BCS or BW criteria offers a potential opportunity to improve production, reproduction, and, perhaps, health, and to enhance public perception of dairying through effective management of otherwise thin cows. In addition, the net efficiency of producing milk from BCS in grazing cows is low because of the low efficiency of BCS gain from autumn pasture (Mandok et al., 2013). The efficiency of gaining condition is also $10 \%$ greater in lactating cows than in nonlactating cows (Moe and Tyrrell, 1972; Yan et al., 1997). These factors mean that the opportunity to manage BCS through individualized feeding at key periods during lactation and gestation should improve feed conversion efficiency on grazing dairy farms

\section{Potential for Using Cow-Level Factors to Define Individualized Feeding Strategies that Improve Production and Energy Balance}

Compelling evidence indicates that cow-level factors could be used to define appropriate individualized feeding strategies for grazing dairy cows. The dairy cow herself affects the marginal milk production and BCS response to concentrate supplementation, and this effect relates, in some way, to the balance between the supply of and demand for nutritional factors (e.g., ME, protein, AA). There are published cow genetic differences in the concentration of humoral hunger and satiety agents, substitution rate and total DMI, and in the partitioning of nutrients between milk and BCS. With higher levels of supplementation, there is an increasing chance of different nutrient deficiencies limiting responses to supplement, such that provision of multiple feeds will be required to maximize productivity from supplementary feeding. In addition, the marginally deficient rotational grazing management protocol and aspects of behavioral hierarchy that result in greater access to pasture for some cows (e.g., whether cows are milked early or late in the milking schedule) result in a competitive environment of feed acquisition. It is plausible that some combination of these cow factors, complex nutritional deficiencies, and cow $\times$ grazing management interacting factors could be used to define appropriate supplementation of cows such that the final milk production response to supplementary feeds (i.e., immediate and deferred responses) will be greater than if all cows in the herd were fed similarly (i.e., flat-rate feeding).

\section{IMPLICATIONS OF INDIVIDUALIZED FEEDING ON RUMEN FUNCTION AND HEALTH}

Grazing dairy cows are diurnal animals verging on crepuscular, with almost all of the pasture DMI achieved in 2 large grazing bouts immediately after sunrise and immediately before sunset (Hafez, 1969; Sheahan et al., 2011). This is very different from the feeding behavior of housed cows, wherein cows eat small meals more frequently and spend less time eating and more time ruminating (Thorne et al., 2003). These differences have potentially important consequences for rumen function, with a rapid postfeeding decline in rumen $\mathrm{pH}$ due to the large volume of fermentable material and less saliva production because of less rumination activity. These conditions have been suggested by some researchers to represent (subacute) ruminal acidosis (Bramley et al., 2008; Enemark, 2008; O'Grady et al., 2008), with negative consequences for cow health and productivity. Such conditions are exacerbated when cows are offered concentrate supplements in addition to grazed pasture, because the timing of the supplementation (i.e., at milking) and the resultant fermentation coincides with the consumption and associated fermentation of pasture and because of the rapidity and nature of the fermentation when the supplement is NSC. Rumen function in grazing dairy cows will be examined in this section and the possible effect of supplementary feeding on rumen function and associated health issues considered, with a particular focus on individualized feeding strategies that could be used to improve cow health and productivity.

\section{Rumen Function in Grazing Dairy Cows}

Because of the diurnal nature of feeding activity (Sheahan et al., 2011), rumen $\mathrm{pH}$ follows a sinusoidal pattern, with peaks prefeeding in the morning and afternoon and relatively deep troughs after the major feeding bouts (Wales and Doyle, 2003; Wales et al., 2004). de Veth and Kolver (2001a,b) reported that although rumen fermentation appeared to continue unimpeded when the mean rumen $\mathrm{pH}$ was 5.8 or greater in dualflow continuous culture systems, a mean rumen $\mathrm{pH}$ of 5.4 or excessive periods of the day at $\mathrm{pH} 5.4$ resulted in reduced fiber digestion and less microbial protein flowing to the small intestine. Wales et al. (2004) advanced this thinking when they compared mean rumen fluid $\mathrm{pH}$ of 5.6 and 6.1 in vitro, with the $\mathrm{pH}$ either main- 
tained constant throughout the day or allowed to vary in the sinusoidal pattern exhibited under grazing. They reported a decrease in DM and NDF digestibility at the lower mean $\mathrm{pH}$, consistent with the earlier reports of de Veth and Kolver (2001a,b), but also noted that the extent of the reduction in digestibility was exacerbated by the sinusoidal pattern of $\mathrm{pH}$ change. These results indicate that the sinusoidal pattern of rumen fermentation and the period that cows spend at suboptimal $\mathrm{pH}$ (i.e., $\mathrm{pH}<5.8$ ) is as important, if not more so, as the mean rumen $\mathrm{pH}$. These data are important because the mean rumen $\mathrm{pH}$ of cows grazing temperate pastures is frequently $\leq 6.0$ and has been reported to decline below pH 5.8 (Kolver and de Veth, 2002) in supplemented dairy cows; with a mean rumen $\mathrm{pH}$ of 5.8 , the nadir $\mathrm{pH}$ could be as low as pH 5.4 (Wales and Doyle, 2003). In fact, Gibbs and Laporte (2008) reported that in unsupplemented cows grazing highly digestible pasture in New Zealand, cows spent, on average, 80, 20, and $10 \%$ of their time at $\mathrm{pH}$ below $6.0,5.5$, and 5.0, respectively.

The reduced DM and NDF digestibility associated with the sinusoidal pattern of rumen $\mathrm{pH}$ in vitro (de Veth and Kolver, 2001a,b; Wales et al., 2004), however, are not consistent with in vivo data. Kolver and de Veth (2002) collated 121 treatment means from 23 studies in which cows consumed 50 to $100 \%$ of their diet as fresh grass or legume pastures. They reported an increase in microbial protein flow and milk and milk component yield with decreasing mean rumen $\mathrm{pH}$, down to a mean rumen $\mathrm{pH}$ of 5.6. Microbial protein $\mathrm{N}$ flow increased by between 16.5 (between study) and 18.1 (within study) g/d for every 0.1-unit decline in mean rumen pH. Similarly, milk, fat, and protein yields increased by $1.1 \mathrm{~kg} / \mathrm{d}, 25 \mathrm{~g} / \mathrm{d}$, and between 27 and $44 \mathrm{~g} / \mathrm{d}$, respectively, with every 0.1 -unit decline in rumen $\mathrm{pH}$. The data indicated no relationship between DM or NDF digestibility and mean rumen $\mathrm{pH}$. These results are consistent with the detailed profiling of rumen $\mathrm{pH}$ on commercial farms in New Zealand (Gibbs and Laporte, 2008) and, to a lesser extent, Australia (Bramley et al., 2008), and Ireland (O'Grady et al., 2008).

The reasons for the apparent inconsistency between in vivo and in vitro studies are not clear. The lower $\mathrm{pH}$ in vivo is almost always associated with greater DMI, a factor not accounted for in the aforementioned in vitro studies. In addition, in in vitro dual culture systems, hydrochloric acid is used to reduce the $\mathrm{pH}$ beyond the normal accumulation of acids during fermentation. In comparison, when cows are fed fresh pasture, the decrease in $\mathrm{pH}$ is predominantly through the production of acetic acid. These acids may have very different effects on the activity of the rumen microorganisms, which could explain, at least in part, the lower DM and NDF digestibility in vitro. It may also reflect other effects of diet that cannot be modeled in these simplistic in vitro systems, such as additional saliva production, faster rumen liquid passage rates, or adaptation of the microbial population to low $\mathrm{pH}$.

\section{Individualized Supplementation of Grazing Dairy Cows and the Risk of Acidosis}

As outlined in the previous section, the collective literature from studies involving cows consuming primarily fresh pasture do not support the presence of low rumen $\mathrm{pH}$ as an indicator of rumen dysfunction. Milk production data, VFA patterns, grazing and rumination behavior, and even DNA profiling of the microbial populations (Kolver and de Veth, 2002; Wales and Doyle, 2003; Gibbs and Laporte, 2008) indicate that the rumen is functioning normally at what would be regarded as suboptimal rumen conditions in housed cows being fed a TMR (Enemark, 2008). However, it is widely recognized that the consumption of NSC by grazing dairy cows causes rumen $\mathrm{pH}$ to decline further (Dalley et al., 2001; Bramley et al., 2008) and the rumen VFA profile shifts to more propionate, valerate, and lactate, and less acetate. With the moderate to high use of GBC supplements on many farms and the less controlled access of cows to "high sugar" forage crops (e.g., turnips, swedes, fodder beet), the potential for cows to become acidotic is greater and the potential of individualized feeding strategies to avert that risk must be considered.

Different cereal grains contain different amounts of starch, and the site of digestion and the rate of degradation of the starch also differ. Starch is encased in the endosperm of the cereal, enmeshed in a protein matrix (Rooney and Pflugfelder, 1986). The ease with which the protein matrix is degraded by rumen microorganisms determines the speed of starch fermentation and, consequently, the rate of acid production. With the exception of corn and sorghum, almost all starch from cereal grains is fermented in the rumen (Orskov, 1986). The extent of prefeeding processing of the grain also influences the speed of fermentation, either by assisting in the breakdown of the protein matrix or the gelatinization of the starch (e.g., steam flaking) or by increasing the surface area immediately available to microbial enzymes (e.g., milling the grain).

Increasing the proportion of NSC in the diet through increased consumption of GBC supplements generally reduces rumen $\mathrm{pH}$ and fiber digestibility (Leddin et al., 2009,2010 ), and increases the production of propionate, lactate, and valerate (Dalley et al., 2001; Wales 
and Doyle, 2003; Bramley et al., 2008; Auldist et al., 2013b). Although the effect of NSC intake on mean rumen $\mathrm{pH}$ appears to be linear (Figure 2), the effect on the profile of VFA concentration is not. The data presented in Figure 2 highlight this. Rumen $\mathrm{pH}$ declined linearly with increasing consumption of wheat, whereas the effect of diet on the profile of propionate and valerate concentration only became apparent when the cows consumed more than $11 \mathrm{~kg}$ DM of crushed wheat. Incidentally, the effect of diet on measured rumen parameters occurred whether cows were fed their wheat in 2 equal feeds at milking or as part of a mixed ration (Auldist et al., 2013b).

In addition to the increased risk of acidosis associated with high levels of starch consumption, challenging cows with $0.4 \%$ of $\mathrm{BW}$ as fructose in the diet can cause fluctuations in DMI and lactic acidosis (Golder et al., 2012). The effect of fructose, however, must be considered in the practicality of the treatment. Cows were fed their fructose allocation during milking combined with their grain allotment. For a $500-\mathrm{kg}$ cow, this treatment was equivalent to eating $1 \mathrm{~kg}$ DM of fructose in approximately $10 \mathrm{~min}$ and in conjunction with $2 \mathrm{~kg}$ DM of triticale. Such a rate of consumption of fructose is not likely, even when cows are grazing high-sugar forage crops (e.g., brassicas or fodder beet). Nonetheless, the results do highlight the importance of appropriate adaptation strategies and precise allocation of crop.

\section{Potential for Individualized Feeding to Mitigate the Risk of Rumen Dysfunction and Acidosis}

The provision of large amounts of GBC ( $>11 \mathrm{~kg}$ of $\mathrm{DM} / \mathrm{d}$ ) to cows in conjunction with high-quality pasture reduces rumen $\mathrm{pH}$ and shifts VFA patterns to those indicative of acidosis risk (Auldist et al., 2013b). Therefore, one needs a biomarker of rumen state that is correlated with the point at which the consumption of NSC indicates a deviation from a normal rumen state. The changes in rumen parameters are often reflected in changes to milk composition (i.e., fat and protein percentage, fat-to-protein ratio), but the effect is not consistent.

To be able to optimally feed cows requires an accurate estimate of what is being consumed to enable accurate ration balancing or, ideally, a biomarker of rumen function and cow metabolic status. The former will allow optimal management of a herd, ensuring that the diet is constructed to achieve the best out of the herd. However, it does not account for the individual animal. In addition, it is currently impractical to measure the amount of pasture that is being consumed during grazing. The lack of this information makes ration balanc- ing more difficult and either more conservative, so as to avoid the higher end of the NSC supplementation, or more precarious, by potentially pushing NSC consumption too high for many cows. This was reflected in the recent publication of Auldist et al. (2013b), wherein milk production and rumen parameters improved when 2 to $2.5 \mathrm{~kg} \mathrm{DM}$ of wheat was replaced by canola meal. Individualized management of cows will require the identification of an as-yet-unknown factor in milk (i.e., a milk signature or "fingerprint") that reflects when rumen parameters are indicative of poor rumen function and an associated decline in productivity. Until such a factor is identified and its measurement simplified, individualized feeding of cows to ensure optimal rumen function will likely involve ration balancing on the basis of diet composition, in particular NSC and NDF concentrations.

Rumen modifiers such as monensin, virginiamycin, tylosin, and lasalocid have been evaluated for their ability to control the risk of acidosis (RAGFAR, 2007). Although evidence suggests that various rumen modifiers may provide some control of acidosis risk (Golder et al., 2014) when cows are fed high levels of concentrates (14 and $16 \mathrm{~kg}$ of DM; Auldist et al., 2013a) or when substantial ruminal concentrations of lactic acid $(>20$ $\mathrm{mmol} / \mathrm{L}$ ) were present (Golder et al., 2014), the risk of acidosis was not controlled by the rumen modifiers used. The large variability between animals in response to rumen modifiers (Golder et al., 2014) supports the need for a biomarker indicative of poor rumen function to ensure all animals are managed optimally.

In summary, production, behavior, and measured rumen parameters indicate that although rumen $\mathrm{pH}$ is low in cows grazing high-quality temperate pastures, rumen function is not compromised and, in fact, milk production is often negatively associated with rumen $\mathrm{pH}$. Supplementing cows with NSC increases the risk of acidosis in a nonlinear fashion. Recent studies indicate that a threshold level of NSC consumption exists, below which the cow functions normally but above which she produces suboptimally (Auldist et al., 2013b) and is, likely, at an increased risk of acidosis. If this threshold can be identified for individual cows, the diet can be altered to replace NSC with fermentable fiber sources or rumen modifiers, thereby increasing DMI, feed conversion efficiency, and milk production (Auldist et al., 2013b), and reducing the risk of acidosis. Many biological parameters change during the shift from a nonacidotic state to subclinical and clinical acidotic states, and future research should focus on identifying a signature in milk that could be easily measured in real time. Such information could be used to allocate ration ingredients individually to cows to maximize profitability and optimize health. 


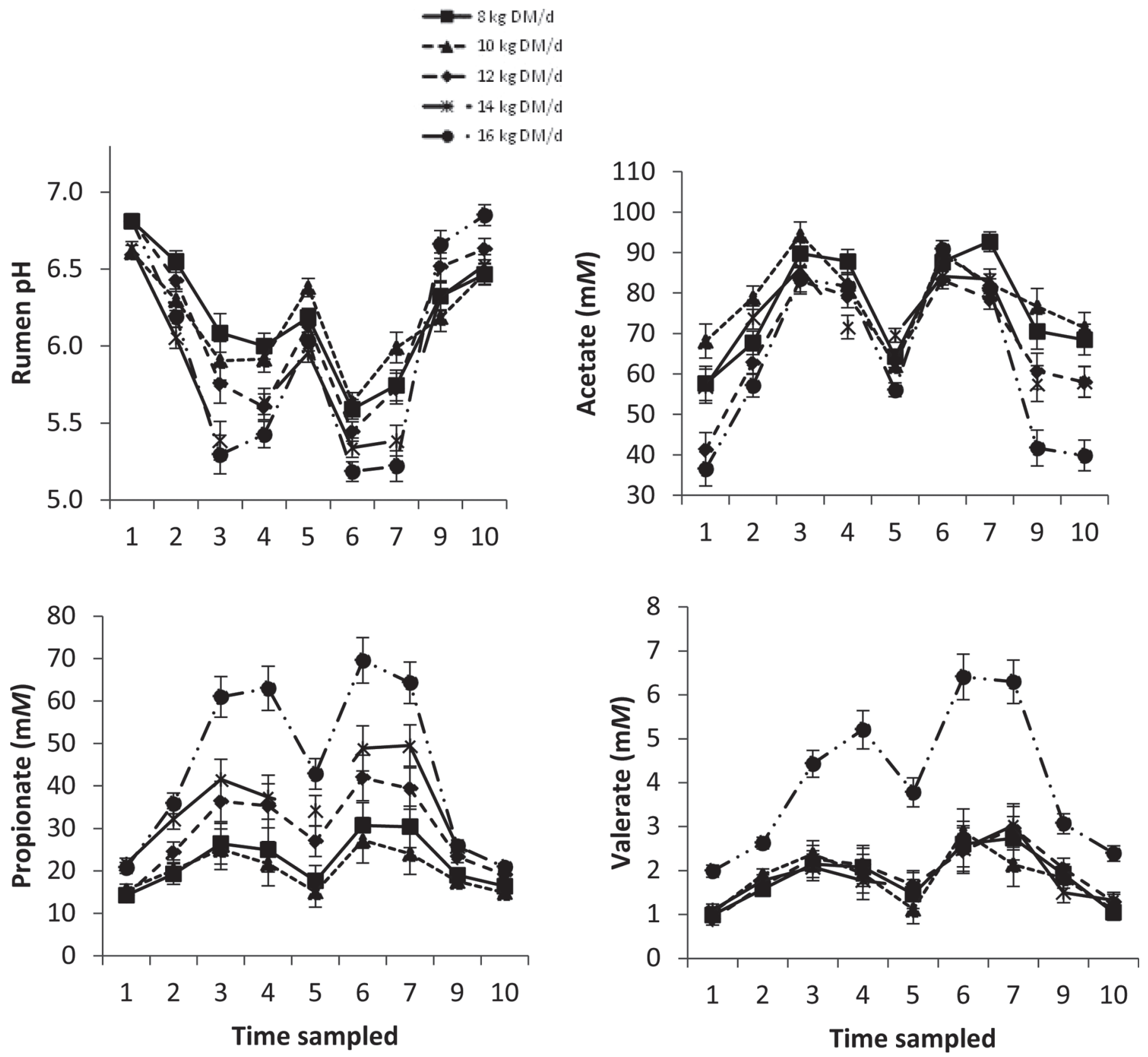

Figure 2. Effects of feeding rate of wheat supplement on rumen $\mathrm{pH}$ and VFA for grazing cows fed wheat in the bail at milking and pasture silage in the paddock. The ratio of grain:forage fed as supplement was 75:25 (DM basis). Values are means $\pm \mathrm{SEM} ; \mathrm{n}=2$ cows/feeding rate (W. J. Wales, L. C. Marett, J. S. Greenwood, M. M. Wright, M. Hannah, and M. J. Auldist, Agriculture Research Division, Department of Environment and Primary Industries, Ellinbank Centre, Victoria, Australia; unpublished data).

\section{Individualized Supplementation of Grazing Dairy Cows and the Risk of Laminitis}

Laminitis (a noninfectious inflammation of the corion that leads to lameness in dairy cattle) is often associated with acidosis (RAGFAR, 2007; Enemark, 2008), with increased DMI of a GBC linked to an increase in the incidence of lameness (Manson and Leaver, 1988a,b). Although the pathogenesis of laminitis remains uncer- tain and laminitis can exist independently of acidosis, the main precipitating factor is a change in diet (for a recent review, refer to Lean et al., 2013).

Manson and Leaver (1988a,b), evaluated the effects of feeding a GBC at 7 or $11 \mathrm{~kg} / \mathrm{d}$ on lameness of dairy cows on a grass silage-based diet. Cows on the higher concentrate diet had 3.7 times more observations of lameness/cow per week, and the severity and duration of lameness incidents were significantly greater than in 
cows on the lower concentrate diet. The major cause of lameness was sole problems in the hind feet. Similar effects of high-concentrate diets on sole hemorrhages were reported by Livesey et al. (1998), although Pryce et al. (1999) reported no significant difference in lameness risk in more than 1,000 cows that were fed diets differing in the level of concentrate offered.

In addition to an increased risk of lameness with increasing feeding of GBC, challenging cows with doses of oligofructose of between 0.75 and $2.1 \%$ of BW have also been associated with an increase in the incidence of lameness (Thoefner et al., 2004, 2005; Danscher et al., 2009, 2010). However, the size of these doses must be considered (i.e., equivalent to 4 to $10 \mathrm{~kg}$ of oligofructose for a 500-kg cow) in any assessment of the risk of lameness from consumption of fructose. In addition, the speed at which the fructose allotment is consumed is also likely to contribute to the ruminal conditions predisposing cows to lameness.

Negative associations have also been reported between feeding highly degradable protein and severity of lameness in cattle (Bazeley and Pinsent, 1984; Ossent and Lischer, 1997), with evidence for increased lameness with cows on a high-protein diet (19.3\%) compared with a low-protein diet (16.1\%; Manson and Leaver, 1988b). This effect could be related to concentration of blood ammonia and its potential negative effect on the sensitive germinal cells of the lamellae and corium. Nevertheless, with low levels of lameness detected in unsupplemented grazing dairy cows, when dietary protein is often in excess of $25 \%$ DM, some other factor must be contributing to the lameness reported in these circumstances.

In summary, there is probably limited scope for individualized feeding of cows to avoid lameness, other than through the aforementioned strategies to avoid rumen dysfunction. The role of dietary components is important to the risk of lameness, with increased incidence associated with increased supplementation of GBC. Although high levels of oligofructans and highly degradable protein may increase the risk of lameness, the levels tested were in excess of biologically plausible scenarios under grazing. Nonetheless, these risk factors would be detected by an effective biomarker of rumen state and could be considered in the provision of individualized diets, especially for cows receiving high levels of concentrate supplements.

\section{Individualized Supplementation of Grazing Dairy Cows and Heat Stress}

The thermal environment can have a major effect on both the productivity and health of high-producing dairy cows. Lactating dairy cattle are particularly susceptible to heat stress due to the high metabolic loads of milk synthesis and visceral metabolism that are associated with high DMI. According to Kadzere et al. (2002), at ambient temperatures above 25 to $26^{\circ} \mathrm{C}$, a cow reaches a stage where she can no longer cool herself adequately and heat stress begins. Other factors, such as humidity, solar radiation, and wind speed can influence an animal's response to heat stress. A temperature-humidity index (THI) that takes into account both temperature and humidity levels $[\mathrm{THI}=0.72(\mathrm{~W}+\mathrm{D})+40.6$, where $\mathrm{W}$ is wet bulb and $\mathrm{D}$ is dry bulb temperature in $\left.{ }^{\circ} \mathrm{C}\right]$ has been suggested to be a good measure of thermal stress (McDowell et al., 1976). At a THI >78, cows experience moderate heat stress and show markedly reduced DMI and milk production, and other physiological effects are generally evident (Silanikove, 2000). However, the THI does not take into account the duration and intensity of a thermal stress event, or the effect of air movement and solar radiation. More recently, a heat load index (HLI) that incorporates air temperature, air movement, and solar radiation effects has been developed (Gaughan et al., 2008). Based upon the HLI and associated with an accumulated heat load combining the intensity and duration of a cow's exposure to heat, a specific dairy heat load index (DHLI) has been developed (Dunshea et al., 2013). Above a DHLI threshold of 75, the core body heat of a cow increases, leading to heat stress and associated physiological effects. The DHLI has recently been included as part of a dairy risk assessment program that assists producers with predicting heat events and implementing appropriate management and nutritional interventions (Dunshea et al., 2013).

Response to Heat Stress. During periods of high thermal stress, animals reduce heat storage by reducing metabolic heat production and dissipating heat to the environment via latent and sensible pathways (Renaudeau et al., 2012). Heat stress negatively affects milk production, with reported reductions ranging from $14 \%$ in early lactation up to $35 \%$ in mid lactation (Bernabucci et al., 2010). Reduced DMI accounts for about $35 \%$ of the decrease in milk production due to heat stress (Rhoads et al., 2009). The reduction in DMI is considered an adaptation by cows to reduce metabolic heat production. It follows, therefore, that diets that have a higher level of heat increment, such as fibrous summer pastures (Silanikove, 2000), would increase a cow's heat load more than energy-dense diets containing GBC or fat supplements (Wang et al., 2010).

Heat stress also causes altered blood acid-base chemistry because of an increase in evaporative cooling and body fluid loss. Respiratory alkalosis caused by increased panting leads to decreased blood bicarbonate concentrations, compromising bicarbonate buffering capacity and increasing susceptibility to metabolic acidosis (Renaudeau et al., 2012). Insulin resistance might 
contribute to increasing heat load in lactating dairy cows, because insulin resistance is closely associated with an impaired ability to regulate body temperature (DiGiacomo et al., 2014). Genetic selection for increased insulin sensitivity, or dietary agents that increase insulin sensitivity, may help alleviate heat stress (Dunshea et al., 2013).

Variability in Response to Heat Stress. Considerable variation exists for heat tolerance between individual cow breeds and even between individuals within a breed (Hansen, 2004; Gaughan et al., 2009). It is clear that the sensitivity of cattle to thermal stress is increased when milk production is increased (Berman, 2005). For example, Dunshea et al. (2013) identified high- (28 to $38 \mathrm{~kg}$ of milk/d) and low-yielding ( $<23 \mathrm{~kg}$ of milk/d) cows and measured their susceptibility to heat stress using a system based on panting scores, and reported that higher milk yields were associated with increased heat stress risk.

Alleviating Heat Stress Through the Diet. One means of decreasing the susceptibility of a ruminant animal to heat stress is to reduce the heat of fermentation. The simplest way to achieve this is to reduce DMI during high temperatures (Russell, 2007). However, reducing DMI is not desirable in production animals. Increasing the energy density of the diet through increased use of GBC or fat supplements is a viable method for decreasing the volume of feed consumed and subsequently reducing the heat of ruminal fermentation. Another possible way to decrease the heat of fermentation is to reduce the amount of ruminal starch fermentation by increasing the amount of starch in the diet that escapes ruminal fermentation (Russell, 2007). A recent study using infrared thermography indicated that dairy cows fed wheat-based diets have higher average flank temperatures, as well as greater differences between left and right flank temperature, than do dairy cows fed corn-based diets (Bland et al., 2013). Therefore, feeding corn rather than wheat-based diets may improve the ability of dairy cows to handle heat stress. Alternatively, treating wheat with starch-binding agents that reduce the rate of rumen fermentation may provide a means of reducing the heat increment of the wheat's fermentation (Dunshea et al., 2012).

The use of dietary agents for increasing sensitivity to insulin, such as chromium, may also assist with alleviating heat stress (DiGiacomo et al., 2014). Chromium added to the diet of Holstein-Friesian cows has been reported to increase both milk yield and DMI during periods of high ambient temperature (Al-Saiady et al., 2004). Hung (2012) also reported that dietary chromium can improve the ability of sheep to overcome heat stress and that some of the effect may be via improved insulin sensitivity. Insulin resistance is also known to cause oxidative damage and there is evidence in sheep that supplementing with antioxidants may help mitigate the effects of heat stress (Chauhan et al., 2012). The feeding of dietary betaine has been reported to increase DMI in heat-stressed cattle (Cronje, 2005; Loxton et al., 2007; DiGiacomo, 2011) and sheep (DiGiacomo 2011). Conversely, in a more recent study in lactating dairy cows, dietary betaine increased milk yield during a thermoneutral period but was associated with reduced feed and water intake during a period of heat stress (Hall et al., 2012). The use of dietary buffers to assist with alleviating symptoms of heat stress has been extensively reviewed by Sanchez et al. (1994). There have been increases in milk production interpreted as a response to the addition of sodium bicarbonate to cow diets (Schneider et al., 1986), although the effect is curvilinear (Sanchez et al., 1994).

Individualized Feeding and Heat Stress. The opportunity to individually bail feed supplements that may reduce the risk of heat stress, such as betaine, chromium, or antioxidants, or to offer grains with a different rate of ruminal fermentation or heat increment is a potential way in which individualized feeding of cows could reduce the risk and level of heat stress (Dunshea et al., 2013). Being able to identify those animals that are at a higher risk of heat stress and individually feed them multiple supplements is integral to the success of individualized feeding strategies to reduce the negative effects of heat stress on production and welfare of lactating dairy cows. Further research is required to identify biomarkers of heat stress or other ways to identify at-risk cows and to confirm the potential benefits of feed additives, such as chromium and betaine, in reducing the effect of heat stress on lactating dairy cows.

\section{A ROLE FOR INDIVIDUALIZED FEEDING IN IMPROVING THE REPRODUCTIVE OUTCOMES OF GRAZING DAIRY COWS}

\section{Background}

Dairy cow fertility has declined in recent decades (Royal et al., 2000; Lucy, 2001; Berry et al., 2008; Friggens et al., 2010; Roche et al., 2011), with cows taking longer to return to estrus (Lucy, 2001), displaying weaker signs of estrus, having poorer conception rates, and having greater embryo loss (Lucy, 2001; Diskin, 2008b; Friggens et al., 2010). As a result, calving rate to first insemination has declined (Royal et al., 2000), intercalving interval has increased (Lucy, 2001), cows require more services/conception (Lucy, 2001; Mee et al., 2004), and, of particular importance in seasonal systems, the 6 -wk recalving rate has declined (Burke et 
al., 2008). Multifactorial reasons underlie this decline in fertility, but an associated increase in milk production has been a consistent feature. The decline is primarily manifested as a lower pregnancy rate and more days from calving to conception (days open; Diskin, 2008a), although negative effects on duration of postpartum anestrus have also been reported (Lucy, 2001; Friggens et al., 2010), particularly in pasture-based dairy cows (Rhodes et al., 2003).

Reproductive failure is often postulated to be a result of the greater negative EBAL associated with cows intensively selected for milk production (Roche et al., 2006a). This hypothesis has merit, with association analyses implying relationships between measures of EBAL in early lactation and reproduction outcomes (Beam and Butler, 1999; Roche et al., 2007b, 2009a). Care must be taken, however, not to confuse inductive reasoning from observed associations (hypothesis generation) with experimental evidence of cause and effect; just because something is associated with a particular reproductive outcome does not necessarily mean the outcome will be different if steps are taken to alter the associated factor. Despite this, there is a growing belief among farmers and industry professionals that manipulating nutrition (e.g., increased DMI, altered structure to NSC content, altered protein composition, dietary fat content and FA composition) will be the answer to reproductive woes. In this section, the perceived problems associated with nutritional limitations in pasture-based systems will be outlined and the possibility of improving reproductive outcomes through individualized feeding examined.

\section{Timing of Nutritional Intervention Is Important}

The chain of reproduction events between when a cow calves and recalves is long and complex, but can, essentially, be split in 2 when considering the interaction with nutrition (Roche et al., 2011): preovulatory reproductive failure and postovulatory reproductive failure. The effects and appropriate timing of a nutritional intervention could be different for both components and should be considered separately.

Preovulatory reproductive failure is primarily a function of the timing of return to estrus postpartum. An early resumption of estrous cycles following calving is important, because delays result in reduced conception rates and pregnancy rates (Thatcher and Wilcox, 1973; Beukes et al., 2010). Extended anovulatory-anestrus remains a major cause of sub-fertility in pasture-based dairy herds (Rhodes et al., 2003) and has been recognized as an important contributory component of sub-fertility associated with increased milk production (Lucy, 2001; Friggens et al., 2010). The physiological processes underpinning the postpartum return to estrus and the effect of nutrition on these processes must, therefore, be understood.

Postovulatory reproductive failure is a major component of poor reproductive performance. When high-fertility bulls are used and cows are correctly inseminated, fertilization rates of $90 \%$ and over should be expected, irrespective of cow milk yield (Diskin, 2008b). Based on an average calving rate of $55 \%$, Sreenan and Diskin (1986) calculated an embryonic and fetal mortality rate (excluding fertilization failure) of about $40 \%$ for moderate-producing cows and they estimated that 70 to $80 \%$ of the loss occurred between d 8 and 16 after insemination (early embryo mortality). The comparative figure for embryonic and fetal mortality rate in highproducing cows (i.e., those undergoing greater negative EBAL or those with a higher metabolic rate) is $55 \%$, based on a calving rate of $40 \%$. Some of this embryonic and fetal mortality may be alleviated by a nutritional intervention.

\section{Potential Limitations of Pasture as a Feed for Reproductive Success}

Roche et al. (2011) extensively reviewed the interaction between nutrition and reproduction for pasturebased systems and summarized the perceived limitations of pasture as a feed. Briefly, although perennial pastures can be of high feed quality (i.e., high ME and $\mathrm{CP}$ content), differences in feed supply and quality at different times of the year, cow potential DMI relative to actual, a greater negative EBAL in unsupplemented grazing cows relative to supplemented grazing cows or those fed TMR, and the composition and nutrient balance of the most commonly grazed pastures have been suggested as contributors to poor fertility in pasturebased systems.

Pasture Supply Relative to Demand. Temperate pasture production is characterized by a spring peak that typically exceeds DMI requirements of the herd; insufficient moisture and excessive temperatures in summer often resulting in reduced growth and less than desired pasture quality; and cool temperatures in winter and early spring, resulting in less than required pasture growth. These climatic factors and their association with the seasonality of pasture growth and quality were presented in detail by Roche et al. (2009b). Start of breeding to maintain a 365-d intercalving period in seasonal spring-calving systems coincides with a flush in pasture growth and adequate pasture provision in moderately stocked dairy farms. However, climatic conditions are variable, even in relatively stable climatic zones (e.g., New Zealand). Roche et al. (2009c) reported that minimum grass temperature (tempera- 
ture at the plant's growing point) was only 36 to $44 \%$ repeatable. In addition, rainfall and, therefore, moisture availability in nonirrigated farming systems was only $3 \%$ repeatable within fortnight, across years, and solar radiation was $57 \%$ repeatable within fortnight, across years. These 3 factors (i.e., temperature at the plant's growing point, soil moisture availability, and solar radiation) are the dominant forces in determining pasture growth rate, assuming nutrients are not limiting (Holmes, 1989). Their lack of repeatability within fortnight, across years, suggests that, in seasonal systems, average pasture supply may not always equal dairy cow feed demand during breeding. This may provide the rationale for the individualized feeding of cows relative to their DIM and proximity to breeding, depending on the effect of periods of underfeeding and negative EBAL on reproduction outcomes.

Pasture Quality. Pasture quality is also highly variable, with estimated repeatabilities within fortnight, across years, ranging from 22 to $54 \%$ for temperate forages (Roche et al., 2009b), depending on the quality parameter of interest. Compared with diets formulated to maximize milk production, optimally managed temperate pastures have high concentrations of RDP and NDF and low NSC. If these suggested "deficiencies" in pasture supply and quality relative to an "ideal diet" limit reproductive success, it could be beneficial to provide cows with individualized diets relative to the stage of their reproductive cycle through in-parlor feeding to increase the likelihood of a successful pregnancy.

In summary, although temperate pastures are primarily of high nutritional value for ruminant animals, variability in feed supply and an inability of high-producing dairy cows to consume sufficient pasture to meet their requirements, or a deficiency or oversupply of key nutrients at particular times relative to breeding, could contribute to reproductive failure in grazing systems. Being able to individually feed cows relative to their DIM or day relative to breeding could perhaps improve pregnancy rates either by alleviating negative EBAL or by altering diet composition to support reproductive processes. The likely advantages of individualized feeding from a reproduction perspective will be explored in subsequent sections.

\section{Pasture Supply, EBAL, and Reproduction: Implications for Individualized Feeding Strategies}

All mammals utilize stored reserves postpartum (i.e., have some degree of negative EBAL in early lactation; Roche et al., 2009a), but intensive selection for milk production has resulted in an even greater loss of body reserves than would be required for the sustenance of a calf (Pryce et al., 2002; Berry et al., 2003).
This increased prioritization of nutrients and energy for milk production has been associated with a decline in reproduction (Lucy, 2001), with the inference being that reproduction will be improved through the provision of nutrients that reduce negative EBAL. This hypothesis is predicated on the beliefs that (1) all of the effect of cow genetics on reproductive failure is a result of increased levels of negative EBAL associated with selection for increased milk production; and (2) the provision of certain feeds or ration ingredients will reduce the extent of negative EBAL in grazing cows.

There is logic in this line of postulation, as both in vivo and in vitro evidence in grazing systems indicates negative effects of BCS loss and positive effects of BW gain on the likelihood of attaining a successful pregnancy outcome (Buckley et al., 2003; Roche et al., 2007b). Nutritionists often refer to a "rising plane of nutrition" when recommending diets to improve reproductive outcomes. Early lactation EBAL is negatively associated with the duration of the postpartum anestrous interval, with shorter durations to first ovulation associated with a more positive EBAL (Patton et al., 2007; Roche et al., 2007b, 2009a; Garnsworthy et al., 2008). In addition, postpartum EBAL is positively associated with pregnancy rate to first and subsequent inseminations (Buckley et al., 2003; Roche et al., 2007b, 2009a). Roche et al. (2007b) reported that 6 - and $12-w k$ pregnancy rates declined 3 to $4 \%$ for each additional BCS unit lost postpartum (10-point scale; Roche et al., 2004). The hypothesis is further strengthened by the results of multiple studies in which genetic strains, differing in their origin or propensity for milk production, were compared. Results indicated that strains differed in both the extent of their postpartum negative EBAL and their reproductive success (Jonsson et al., 1999; Buckley et al., 2000b; Fulkerson et al., 2001; Horan et al., 2004; Macdonald et al., 2008).

The proposed hypothesis also has merit physiologically. Negative EBAL delays postpartum ovarian activity by impinging on the pulsatile secretion of $\mathrm{LH}$, reducing follicular responsiveness to $\mathrm{LH}$ and FSH, and ultimately by suppressing follicular estradiol production (Diskin et al., 2003). Beam and Butler (1997) reported that follicles emerging after the negative EBAL nadir, rather than before, exhibited greater growth and diameter and enhanced estradiol production, and were more likely to ovulate. Consistent with the effect of negative EBAL on follicle development and oocyte quality, embryo competency is compromised shortly after fertilization in cows in negative EBAL (Sartori et al., 2002; Santos et al., 2004; Leroy et al., 2005). There is, therefore, a plausible basis for the hypothesis that the greater negative EBAL resulting from genetic selection for milk production has resulted (i.e., causation) 
in the lower pregnancy rates recorded in these cows and for a role to individually feed cows relative to their DIM, milk yield, and BW (or BCS) change.

Several factors are, however, inconsistent with this hypothesis. First, de Vries and Veerkamp (2000) reported that only 3 to $4 \%$ of the variation in interval to first ovulation could be explained by total energy deficit or EBAL in early lactation. Second, the recent genetic strain comparison studies (Horan et al., 2004; Macdonald et al., 2008) indicated a 15-percentage-unit difference in 6-wk in-calf rate between North American Holstein-Friesian cows and Holstein Friesian cows originating in NZ. However, the difference in BCS loss postcalving (i.e., the extent of the negative EBAL) between these strains only accounted for a 5-percentageunit difference in this metric (Roche et al., 2007b). This would imply that two-thirds of the difference in 6 -wk pregnancy rate is not accounted for by the difference in early lactation EBAL.

Some of the physiological phenotypes underpinned by the genetic selection of these strains have recently been elucidated for grazing dairy cows and support the hypothesis that factors other than EBAL are responsible for the differences in reproductive success. Walker et al. (2012) reported differences in the expression of genes in the uterus that are involved in uterine immune suppression, embryonic nourishment, maternal pregnancy recognition, luteolysis, and implantation preparation, when they compared North American and NZ Holstein-Friesian dairy cows grazing temperate ryegrass pastures. The measured differences would increase the risk of embryo loss in the North American cow. These results are consistent with those recently published by Cummins et al. (2012a,b,c) in grazing dairy cows in Ireland, wherein cows divergent in their EBV for fertility but similar in milk production were compared. There was no difference in early lactation EBAL, but there were significant differences in reproductive success and in many of the associated physiological processes. In particular, the sub-fertile cows had a lower conception to first service (33 vs. 55\%) and 6-wk pregnancy rate (41 vs. $72 \%$ ), and a greater number of services/ pregnancy (2.2 vs. 1.4) and days open (calving to conception interval was 114 and $86 \mathrm{~d}$ for sub-fertile and fertile cows, respectively). Physiological and molecular measures support these differences; sub-fertile cows had more follicular waves (2.7 vs. 2.2$)$ and a longer estrous cycle ( 25 vs. $21 \mathrm{~d}$ ). They also had smaller preovulatory follicles and corpora lutea and lower circulating concentrations of progesterone. Furthermore, a greater proportion of sub-fertile cows ovulated to a silent heat ( 22 vs. $2 \%$ ) and, of those that did exhibit heat, their activity was less expressed than the fertile comparison. There were also differences in the somatotropic axis, with lower circulating concentrations of IGF-1 in the sub-fertile cows (Cummins et al., 2012a,b,c). This feature has been associated with extended postpartum anestrus (Patton et al., 2007). None of these effects can be attributed to an effect of EBAL either in early lactation or during the breeding period.

Although the effect of genetics on reproduction may not be primarily a result of EBAL differences, an argument could be made that improving EBAL within a herd (i.e., within a genotype) will improve reproduction. Consistent with this premise, both Buckley et al. (2003) and Roche et al. (2007b) reported positive associations between change in BW during the breeding period and 3- and 6-wk pregnancy rates. In a unique experiment, Burke et al. (2010b) investigated the importance of the energy status of grazing dairy cows during breeding (i.e., the rising plane of nutrition). In an experiment involving more than 750 multiparous cows, $>300$ cows were subjected to a $45 \%$ feed restriction during the first $2 \mathrm{wk}$ of the seasonal breeding period. The 3 -wk submission rate and the 3- and 6-wk pregnancy rates were 6,8 , and $7 \%$ less, respectively, for the restricted cows than for the cows that were adequately fed (i.e., 94,53 , and $78 \%$, respectively). Although these are sizeable effects on reproduction, the scale of the reproductive failure must be viewed in the context of the size of the nutritional imposition: cows at peak lactation and at the onset of breeding in a seasonal reproductive program were subjected to a $45 \%$ reduction in DMI. Energy balance was not measured in that experiment, but one would assume that such a restriction in DMI would have resulted in a significant negative EBAL at a crucial time, despite a significant decrease in milk production. The size of this effect is consistent with Roche et al. (2007b), who predicted a $1 \%$ increase in 6 -wk pregnancy rate for every $0.2 \mathrm{~kg} / \mathrm{d}$ increase in BW gain. Contextualizing this, the small changes in $\mathrm{BW}$ gain or EBAL elicited through the supplementation of grazing dairy cows (Roche et al., 2006a; McCarthy et al., 2007) are unlikely to greatly affect reproduction.

An additional factor that must be considered in any role for individualized feeding in alleviating the negative EBAL to improve reproduction is the increasing body of evidence indicating that nutrition during the period of greatest negative EBAL (i.e., DIM 1-30) has only small effects on the homeorhetically directed lipolysis during this time, as cows have been genetically selected to partition nutrients consumed toward milk production. Consistent with this failure of nutritional strategies to greatly influence early lactation EBAL, experimental treatments in which grazing cows have been restricted (Burke and Roche, 2007; Burke et al., 2010b) or provided with additional supplementary feeds (Fulkerson et al., 2001; Kennedy et al., 2003; 
Horan et al., 2004; Kolver et al., 2005; Pedernera et al., 2008) have failed to positively affect pregnancy rates, although in some instances submission rates have been improved by the provision of additional feed (Fulkerson et al., 2001; Macdonald et al., 2008).

In summary, although the extent of the negative EBAL is acknowledged to influence pregnancy rate, the published results that relate to grazing dairy systems indicate that the majority of the genetic effects associated with reproductive success or failure are not due to the early lactation EBAL. In addition, supplementation has only small, if any, effects on EBAL. By extension, reproduction will not be improved greatly by nutrition strategies aimed at alleviating negative EBAL, making it unlikely that individualized feeding of cows to alter EBAL will result in significant improvements in reproduction.

\section{Diet Composition and Reproduction}

Different dietary ingredients result in different rumen fermentation patterns and, therefore, differences in postruminal products of digestion. On entering the blood, these products can have marked effects on blood ammonia, urea, and glucose concentrations, which, in turn, can affect hormone concentrations and the balance of hormone axes and, possibly, the composition of follicular and uterine fluids. If these nutrition-derived physiological subtleties affect reproduction, they could provide a valid reason for the individualized feeding of dairy cows relative to their DIM or stage of pregnancy.

The effects of altering diet composition for grazing dairy cows were extensively reviewed by Roche et al. (2011). The focus of this section, therefore, will be on the possibility of improving reproduction by manipulating the diet of individual cows at key times relative to breeding. The primary components of the diet that are considered most relevant for reproduction are carbohydrate composition (i.e., structural carbohydrates vs. NSC), CP, and the associated products of digestion or metabolism (i.e., ammonia and urea), and fat (i.e., FA).

Carbohydrate Composition. The type of carbohydrate consumed (i.e., structural or nonstructural) has been reported to influence both preovulatory and postovulatory reproduction variables, with both structural carbohydrates and NSC benefitting different events in the reproductive process. Increasing the ratio of NSC to structural carbohydrate in an otherwise isoenergetic and isonitrogenous diet has been reported to reduce the period of postpartum anestrus in TMR-based rations (Gong et al., 2002; Garnsworthy et al., 2008). The effect is probably a result of an insulin-induced sensitivity of ovarian follicles to gonadotropins (Roberts et al., 1997; Butler et al., 2004). Insulin and IGF-I upregulate the expression of gonadotropin receptors in follicles (Diskin, 2008a), thereby enhancing estradiol production from granulosa cells (Spicer et al., 1993; Gong et al., 2002).

These results are partly consistent with experimental results in grazing cows. For example, it has been demonstrated experimentally that the low BCS-induced suppression of LH pulsatility in grazing cows can be restored with oral administration of a glucogenic/insulinogenic precursor, such as monopropylene glycol (Chagas et al., 2007). In comparison, however, a generous pasture allowance after calving had no such effect in either primiparous (Burke et al., 1995) or multiparous dairy cows (Burke and Roche, 2007). In support of altering the NSC to structural carbohydrate ratio in early lactation, Burke et al. (2010a) reported that the duration of postpartum anestrus was $8 \mathrm{~d}$ less in multiparous grazing dairy cows when NSC to structural carbohydrate ratio was increased in an otherwise isoenergetic diet, and Fulkerson et al. (2001) reported an earlier resumption of ovulation and earlier estrous detection with increasing level of GBC (NSC) supplementation. These data indicate a reproductive benefit to providing dairy cows with NSC during early lactation.

However, the effect of glucogenic/insulinogenic precursors on postpartum anestrus is not consistent. Kolver et al. (2005, 2006) reported increased insulin and IGF-1 concentrations in cows consuming either 3 or $6 \mathrm{~kg} \mathrm{DM}$ of a high-starch concentrate but no effect of concentrate feeding on time to estrus or pregnancy rates. Horan et al. (2004) and Kennedy et al. (2003) investigated responses to supplements in cows differing in their genetic merit for milk production and survival traits and reported no effect of diet on either the duration of postpartum anestrus or pregnancy rates. Similarly, Pedernera et al. (2008) offered diets designed to achieve 6,000 or $9,000 \mathrm{~L}$ of milk/lactation and detected no difference in reproduction outcomes, despite a significant increase in IGF-1 concentration in cows fed to achieve higher production. On-farm studies investigating the use of a glucogenic supplement, proven in research experiments to advance the timing of first postpartum ovulation, have also been disappointing. Chagas et al. (2010) tested the effect of drenching monopropylene glycol in 4 herds generally characterized as having low cow BCS. Milk protein percentage was significantly increased, confirming the insulinogenic effect of the diet (Rius et al., 2010), but there was no reproductive benefit.

The reason for the difference in the ovulatory response to NSC in these grazing experiments is not clear; however, it may rest in the effect of supplement on cow metabolism. In the experiments that indicated a positive response to NSC provision in both grazing and 
TMR-based systems (Gong et al., 2002; Chagas et al., 2007; Garnsworthy et al., 2008; Burke et al., 2010a), ME intake was controlled and milk energy output was not changed. For the most part, when NSC was provided as a supplement to pasture, thereby increasing ME intake and milk energy output (Kennedy et al., 2003; Horan et al., 2004; Kolver et al., 2005, 2006), the time to ovulation was not decreased. The effect of NSC and the NSC to structural carbohydrate ratio requires further investigation in grazing dairy cows.

The effect of NSC on reproduction is even more intriguing, however, because the effect on postovulatory fertility appears to be negative, with reduced pregnancy rates in cows receiving NSC supplements compared with fermentable fiber supplements (O'Callaghan and Boland, 1999; Adamiak et al., 2005, 2006). In a series of experiments (O'Callaghan and Boland, 1999), oocyte and embryo quality declined with increasing concentrate supplementation. In addition, the effect was particularly apparent when the concentrate was starch-based compared with a fermentable fiber-based supplement. The physiological mechanisms involved remain poorly understood but, as in the case for preovulatory performance, appear to be under the influence of glucose or glucose-derived metabolites or hormones (e.g., insulin or IGF-1). Glucose infusions before superovulation in ewes have resulted in reduced quality embryos (Yaakub et al., 1997), and glucose infusion is reported to reduce pregnancy rate (Rubio et al., 1997). Consistent with these infusion studies, glucogenic diets have been reported to reduce blastocyst rate in heifers and cows (Adamiak et al., 2005, 2006; Fouladi-Nashta et al., 2007). In comparison, fermentable fiber supplements have been reported to benefit embryo development (O'Callaghan and Boland, 1999).

In summary, these data indicate that the nutrient requirements for early resumption of ovarian cycles, follicle development, and embryo development are different at each of these different stages in the reproductive cycle, reflecting a potential advantage to individualized feeding to alter dietary ingredients through early lactation, thereby ensuring early resumption of estrus and excellent quality embryos. Such a diet would have high NSC until estrus is achieved, followed by a diet that did not promote insulin secretion until the end of the breeding season (Garnsworthy et al., 2009). However, further research is required on the effects of such a management protocol in pasture-based systems.

Dietary Protein. The effect of protein nutrition on reproductive physiology in dairy cattle has been controversial for more than $20 \mathrm{yr}$, with a general acceptance that dietary $\mathrm{CP}$ and, in particular, RDP negatively affects pregnancy rate (Butler, 1998). Because cows grazing fresh forage frequently ingest RDP surplus to microbial growth requirements, particularly during the breeding season (Roche et al., 2009a), this is an important nutritional area for consideration.

Preovulatory effects of dietary $\mathrm{CP}$ are inconsistent, with no effect and positive and negative effects on time to first estrus. For example, Garcia-Bojalil et al. (1994) offered diets differing greatly in their $\mathrm{CP}$ content (12 and $27 \% \mathrm{DM}$ ) and resulting BUN concentration (9.8 and $21.3 \mathrm{mg} / \mathrm{dL}$, respectively). They reported no differences in the number or percentages of preovulatory, anovulatory, and ovulatory follicles induced during superovulation. In comparison, Jordan and Swanson (1979) reported fewer days to first observed estrus (14 d postpartum) in cows receiving a high CP (19\% DM) ration and Ordonez et al. (2007) reported a shorter postpartum anestrus interval $(6 \mathrm{~d})$ in cows grazing nitrogen-fertilized pastures. In direct contradiction, Barton et al. (1996) reported a delay of $4 \mathrm{~d}$ in the time to first estrus in cows receiving a diet containing $20 \%$ DM CP compared with one containing 13\% DM, and Westwood et al. (2000) noted delayed resumption of estrous activity in cows consuming more RDP. The reason for the inconsistency in the effect of dietary $\mathrm{CP}$ on ovulatory function is not known, but the collated data indicate that dietary $\mathrm{CP}$ content in early lactation has little effect on follicle development and time to first postpartum estrus. Nutritional strategies to reduce BUN are, therefore, unlikely to result in a greater submission rate.

At first glance, the effect of dietary $\mathrm{CP}$ on pregnancy rate is much more consistent, with the majority of studies suggesting a negative effect of excess RDP on the probability of conception (Ferguson et al., 1988, 1993; Ferguson and Chalupa, 1989; Westwood et al., 1998, 2000; Rajala-Schultz et al., 2001; Arunvipas et al., 2003). Physiologically, high BUN and associated elevated concentrations of blood ammonia have been implicated in embryo degeneration and alterations to the uterine environment (Butler, 1998). Using BUN concentration as an indicator of surplus RDP, Ferguson et al. $(1988,1993)$ reported reduced likelihood of a successful pregnancy at BUN concentrations $>20 \mathrm{mg} / \mathrm{dL}$ $(3.3 \mathrm{mmol} / \mathrm{L})$. Consistent with this, Rajala-Schultz et al. (2001) reported that cows with MUN concentrations $<10.0$ and between 10.0 and $12.7 \mathrm{mg} / \mathrm{dL}$ were 2.4 and 1.4 times more likely to be confirmed pregnant than cows with MUN values $>15.4 \mathrm{mg} / \mathrm{dL}$, respectively. Similarly, MUN concentrations $>15.5 \mathrm{mg} / \mathrm{dL}$ were associated with a $37 \%$ reduction in the odds of conception in Canadian dairy cattle (Arunvipas et al., 2003), and dietary $\mathrm{CP}$ tended to be negatively associated with the likelihood of a cow to conceive. In comparison, Westwood et al. (2000) reported a lower conception rate to first service (45 vs. $72 \%$ ) in cows receiving a 
diet high in RDP, although BUN was not affected by treatment. They speculated that the effect was a result of the greater negative EBAL in cows receiving more RDP but did not rule out an effect of by-products of protein metabolism. In a recent meta-analysis including 21 studies, Lean et al. (2012) also concluded that the likelihood of pregnancy was lowered with increasing soluble protein in the diet.

The majority of studies reporting a negative effect of $\mathrm{CP}$ on fertility have been undertaken in cows being fed a TMR containing low to moderate dietary $\mathrm{CP}$ concentrations relative to the $\mathrm{CP}$ content of temperate pastures. Cows grazing temperate pastures often have blood and MUN well in excess of the "ideal" concentrations reported. For example, Roche et al. (2005) reported BUN concentrations of $42.0 \mathrm{mg} / \mathrm{dL}$ and MUN concentrations of $40.5 \mathrm{mg} / \mathrm{dL}$ in dairy cows grazing high CP pastures (29\% DM) in early lactation. Similarly, Kolver and Macmillan (1994) reported BUN concentrations increasing from $28.5 \mathrm{mg} / \mathrm{dL}$ at calving to $42.0 \mathrm{mg} / \mathrm{dL}$ at 8 wk in milk, and Ordonez et al. (2007) noted BUN of $>60 \mathrm{mg} / \mathrm{dL}$ in early lactation cows grazing nitrogen-fertilized pastures. If dietary CP, RDP, or BUN were negatively associated with reproductive outcomes, these data suggest that the problem should be greatest in grazing cows. Pregnancy rates, however, tend to be high in such systems (Horan et al., 2004; Burke et al., 2008) and do not appear to be influenced by dietary $\mathrm{CP}$ content or BUN concentration. Kenny et al. (2001, 2002) investigated the effect of dietary CP and fermentable energy supplementation on pregnancy outcomes in beef heifers. They concluded that although blood urea concentrations were $77 \%$ greater in their high CP treatments (29.9 vs. $16.9 \mathrm{mg} / \mathrm{dL}$ ), embryo survival was not affected and, in fact, embryo weight was greater in heifers receiving the high $\mathrm{CP}$ diet (Kenny et al., 2001). Ordonez et al. (2007) also reported no difference in embryo survival in dairy cows grazing 25 or $22 \%$ DM CP pastures, despite the very large differences in BUN ( 55 vs. $36 \mathrm{mg} / \mathrm{dL}$ ). Consistent with these data from grazing systems, Garcia-Bojalil et al. (1994) reported no difference in numbers or percentages of normal embryos, abnormal or retarded embryos, and unfertilized ova in nonlactating cows offered either 12 or $27 \%$ DM CP diets $(\mathrm{BUN}=9.8$ and $21.3 \mathrm{mg} / \mathrm{dL}$, respectively).

In summary, there are sound physiological reasons for a negative effect of metabolites originating from surplus RDP on embryo survival, and consistent evidence shows a negative association between BUN and the probability of conception in vitro and in TMR-fed cows. Data from grazing systems, however, indicate a lack of effect of dietary CP, BUN, or MUN on fertility outcomes and this is consistent with the high conception rates in fertile dairy cow strains in these systems (Horan et al., 2004; Ordonez et al., 2007; Macdonald et al., 2008; Cummins et al., 2012a), despite the high dietary CP and the associated high BUN (Kolver and Macmillan, 1994; Roche et al., 2005; Ordonez et al., 2007). The reason for this inconsistency is not known, but may reflect genetic selection for urea or ammonia tolerance in cows exposed to high CP pastures, an adaptation to high CP diets through time, or possibly a limitation of the observational approach to scientific learning (i.e., the relationship between BUN and reproduction merely masks another causal relationship). Nevertheless, current data do not indicate a reproduction benefit to reducing dietary $\mathrm{CP}$ in pasture-based systems and there is no evidence, in these systems, that manipulating the makeup of $\mathrm{CP}$ will benefit reproduction. To improve our understanding of reproductive failure, large-scale intervention-type studies are needed to glean a greater understanding of the role of $\mathrm{CP}$, soluble $\mathrm{CP}$, and RDP on reproduction in grazing systems and, importantly, the physiological mechanisms that protect the grazing dairy cow from excess RDP.

Dietary Fat. The rationale behind altering dietary fat to improve reproduction outcomes is 2-fold: to increase ME intake (Lucy et al., 1992) and take advantage of positive physiological effects of FA in reproductive tissues (Mattos et al., 2000; Wathes et al., 2007). However, the influence of dietary fat on reproductive performance is poorly understood because much of the published data come from studies having nutritional rather than reproductive objectives (Staples et al., 1998).

The potential benefit of fat supplementation on ovarian function was validated in early postpartum cows by Lucy et al. (1991), who reported enhanced growth and function of the dominant ovarian follicle in cows supplemented with $2.2 \% \mathrm{DM}$ of calcium salts of long-chain unsaturated FA (UFA; Megalac, Church and Dwight Co. Inc., Princeton, NJ). Further research indicated that the positive effect of fat supplementation in early lactation was not due to improved EBAL, per se, but rather through a more direct effect on follicular function (Lucy et al., 1993). A likely explanation for this mechanistic action of fat involves the ovarian requirement for cholesterol to synthesize steroids (Gwynne and Strauss, 1982; Staples et al., 1998). Dietary fat consistently increases plasma cholesterol concentration in cows (Grummer and Carroll, 1991). Westwood et al. (2002) reported that higher concentrations of plasma cholesterol were associated with a shorter interval from calving to conception and a greater probability of conception and successful pregnancy by d 150 of lactation, a finding consistent with those of Kappel et al. (1984) and Ruegg et al. (1992), who also reported associations 
between cholesterol concentrations and fertility measures. Similarly, Moss (2001) reported that low blood cholesterol concentrations at mating were strongly associated with conception failure.

The effect of fat on steroid production appears limited to long-chain UFA. Zachut et al. (2008) reported increased follicular androstenedione and estradiol concentrations and a greater expression of P450 aromatase mRNA in granulosa cells in cows supplemented with long-chain UFA but not those supplemented with SFA (C16:0 and C18:0). In agreement with the hypothesis that UFA directly affect ovarian function, the total number of follicles, the size of the preovulatory follicle, and NEFA and insulin contents in follicular fluid have all been increased in cows supplemented with longchain UFA (Mattos et al., 2000; Zachut et al., 2008). In addition to the positive effect of UFA on follicular competency and oocyte quality, Scott et al. (1995) reported that a greater proportion of cows fed long-chain UFA displayed stronger signs of estrus compared with unsupplemented cows. These data reflect a positive effect of dietary UFA on preovulatory and periestrous physiology and create an expectation for an improved submission rate with UFA supplementation. The research, however, originates in relatively low-fat diets and few data are available on likely implications for cows grazing fresh forages already high in PUFA (Kay et al., 2005; Wales et al., 2009). With fresh temperategrass pastures containing 4 to $6 \%$ FA (Roche et al., 2009b) of which $>70 \%$ are long-chain UFA (Kay et al., 2005; Kay et al., 2006), supplementation is less likely to improve ovarian function and preovulatory reproductive success. In support of this statement, Kay et al. (2006) supplemented cows grazing perennial ryegrassdominant pastures with 1 of 2 sources of rumen protected FA; the sources were isolipid $(\sim 520 \mathrm{~g} / \mathrm{d}$ added lipid) but differed in their SFA to UFA ratio (62:38\% and 29:71\% SFA to UFA, respectively). Results from that experiment indicate no effect of supplementary FA or the composition of the FA supplement on the duration of the postpartum anovulatory interval, although negative EBAL was less in supplemented cows (J. R. Roche, unpublished data). These results may reflect the already high PUFA content of temperate pastures (Kay et al., 2005; Wales et al., 2009), with additional UFA failing to add benefit, or it may reflect the lower milk production of grazing cows and the associated lower metabolic challenge.

Considerable evidence indicates that dietary longchain PUFA act as specific regulators of postovulatory reproductive processes, but the effects are inconsistent in vitro and in vivo and there is a paucity of information on the effect of supplementary fat in grazing systems. Dietary FA can affect postovulatory reproductive function in 2 ways: (1) by affecting oocyte and embryo quality, and (2) by altering the maternal physiological processes involved in luteal regression, preventing the prostaglandin-induced termination of progesterone synthesis

Endometrial FA reflect dietary FA (Bilby et al., 2006; Childs et al., 2008; Meier et al., 2009). For example, Meier et al. (2009) reported a 50\% greater n-3 to n-6 ratio in the endometrium of grazing cows than traditionally reported for cows fed TMR (from 10 to $>15.5$; Bilby et al., 2006; Childs et al., 2008), consistent with the expected differences in dietary PUFA composition (Kay et al., 2005). These data reflect a better FA composition in the diet of grazing dairy cows from a reproduction standpoint than cows fed an unameliorated TMR.

The effect of dietary FA composition has been variable, with some reports of enhanced effects to changes in FA content and ratios on early embryo development and with other reports concluding no effect and even negative effects (for a complete review, see Roche et al., 2011). The reasons for the inconsistent effects of dietary fat content and FA composition on oocyte and embryo quality are not known and make recommendations to improve fertility impossible.

The inconsistent effects of dietary and tissue FA content on reproduction variables are difficult to interpret, and few studies have reported the effect of fat supplements on either conception rate or early embryo mortality. Staples et al. (1998) examined 100 research papers in which the effect of fat on reproduction was reported. Of those reporting conception rates, 11 studies observed positive effects or a tendency for a positive effect, whereas 3 studies reported strong negative effects. Since that review, one of the few studies reporting pregnancy losses, Ambrose et al. (2006), reported that a flaxseed (primarily n-3 PUFA: C18:3) supplement reduced pregnancy losses and increased conception rate to timed AI when compared with a sunflower seed (primarily n-6 PUFA: C18:2) supplement. A similar tendency for embryo mortality was reported by Petit and Twagiramungu (2006) when flaxseed was compared with other fat sources. These data indicate benefits of n-3 PUFA on pregnancy rate. More recently, Juchem et al. (2010) reported that a calcium salt rich in linoleic and other trans-octadecenoic acids resulted in greater pregnancy rates at 27 and $41 \mathrm{~d}$ after insemination compared with cows fed palm oil, suggesting a benefit of n-6 PUFA over SFA.

Although fresh pastures tend to be high in n-3 PUFA, increasing concentrate supplementation will result in a lowering of dietary fat percentage and shift in the dietary FA profile from n-3 PUFA to n-6 PUFA. In addition, with increasing grain supplementation, predicted 
MP deficiencies can lead to the inclusion of oilseed by-products. This leads to changes in dietary FA composition. It is unclear exactly what effect this will have on reproduction, but it may, in certain circumstances (e.g., where pasture fat percentage declines in summer or where a high proportion of the diet is conserved forages that are low in fat) create an environment wherein addition of FA to the diet would be beneficial from a reproductive perspective. However, for individualized fat feeding strategies to be effective, there needs to be a greater understanding of the role of particular FA in pre- and postovulatory reproductive physiology when using fresh temperature pasture as the base feed.

In summary, the effects of dietary fat and the type of fat consumed on reproductive outcomes is difficult to interpret. Supplementing cows receiving a low fat $(<2 \% \mathrm{DM})$ diet with rumen-protected $\mathrm{FA}$ reduced the duration of postpartum anestrus. The effect of FA type (SFA, MUFA, or PUFA) or FA grouping (n-3 or n-6) on reproduction variables is inconclusive. Reasons for the inconsistency in research results are unclear and the area requires further investigation. From what is known, cows grazing fresh forages tend to have high concentrations of dietary fat $(>4 \% \mathrm{DM})$, of which more than $50 \%$ are n-3 PUFA and more than $25 \%$ are n-6 PUFA. The amount of fat and the balance of $n-3$ PUFA to n-6 PUFA would, therefore, appear sufficient for optimal ovarian function and to ensure maximum pregnancy rates. Supplementing grazing cows with FA is unlikely to be beneficial.

\section{Potential for Individualized Feeding to Improve Reproduction in Grazing Dairy Cows}

Diet composition has a putative role in reproductive success and failure. There is evidence for an anestrusreducing effect of altering the NSC to structural carbohydrate ratio in early lactation; however, supplementation with NSC in pasture-based systems does not appear to elicit this effect. In addition, a high NSC to structural carbohydrate ratio reportedly results in greater embryo mortality. Further research is required to better understand the effect of carbohydrate type on pre- and postovulatory reproductive function because, if influential, there is a potential role for individualized feeding of different feed ingredients to dairy cows at different DIM or relative to their reproduction stage.

The effect of $\mathrm{CP}$, soluble $\mathrm{CP}$, and $\mathrm{RDP}$ in reproductive function is not clear. Pasture-based evidence does not support a role for altering protein amount or composition from a reproductive standpoint, but there is a paucity of large-scale interventionist studies to confirm this. This is an area for future research effort in grazing systems. Like CP, the effects of dietary fat and FA composition are not clear, but with increasing supplement provision in grazing systems, there may be an advantage to the addition of specific FA to the ration. Further research is required to determine the role of FA on pre- and postovulatory reproductive function.

\section{A FARMING SYSTEMS APPROACH TO INDIVIDUALIZED FEEDING OF CONCENTRATE SUPPLEMENTS IN A PASTURE-BASED SYSTEM}

Relatively simple automated decision trees for allocation of concentrate supplements, usually based on milk production, BW, or both, are used by most farms that possess technology for individualized feeding. This review has identified complexities in both cow- and system-level parameters (e.g., pasture allowance and substitution rate, among others) that could affect an individual cow's response to a particular supplement. It is necessary to consider these parameters when determining how best to allocate supplements to individual cows. The potential use of parameters other than milk yield and BW is currently limited by the lack of routinely available data of suitable quality that could be used to support a decision-making process and by knowledge of what combination of parameters could be used to achieve the most efficient response to supplements.

Below is a summary of the parameters identified in this review that could be used as part of a whole-system decision-support model to individualize concentrate supplements for optimal productivity in pasture-based dairy system.

\section{Milk Yield, BW, and BCS}

Where current or 7-d rolling average milk production is measured, individual cow supplementary feeding levels can be increased until a reduction in the milk response to this feed occurs. A potential problem with using milk production alone is that it only takes into account the short-term milk response to the supplement. In a farming systems context, the optimum response to a supplement needs to take into account not only the immediate milk response to the supplement, but also overall expenditure associated with returning a cow to optimum body condition before the next lactation. Cows ideally should calve between BCS 3.0 and 3.25 (5-point scale; equivalent to 5.0 to 5.25 on an 8-point scale or 5.0 to 5.5 on a 10 -point scale) to allow for near-maximum milk production and to fully utilize the genetic merit of the cows, while ensuring that subsequent reproductive performance, health, and animal welfare are not compromised (Roche et al., 2009a). In this context, BW could be used in addition 
to milk production to enable adjustment of the amount or type of supplementary feed offered that achieves a target BW precalving. However, BW alone may not be as indicative as BCS of the optimum condition required precalving; BW explains less than $25 \%$ of the variation in BCS (Roche et al., 2009a). Technology to enable regular automated collection of BCS is being developed (e.g., Ferguson et al., 2006; Bewley et al., 2008) and could be used instead of BW to ensure cows are fed to achieve the target precalving body condition.

\section{Yield of Milk Components}

As highlighted in the review, it may be of benefit to focus on milk component responses rather than milk volume changes, because differing payment schedules exist in many markets. This is becoming a real possibility with new technology providing real-time assessments of the fat and protein content of individual cow's milk during milking. To date, no research has compared flat-rate and individualized feeding in pasture-based systems using the response of individual cow milk components to supplementary feeds as a basis for determining appropriate levels of supplementation.

\section{EBV for Milk or Milk Components Yield}

Using a measure of individual genetic merit could be useful in targeting expected response to supplements. For example, targeting supplement feeding levels based on EBV for milk fat and protein yields could allow for greater marginal milk production responses to supplementary feeds. In addition, the differential between potential genetic merit for milk yield and actual milk yield could be targeted using the hypothesis that cows with a greater differential between potential and actual milk yield may respond better to increases in concentrate supplement (Fulkerson et al., 2008).

\section{Pasture DMI, Grazing Behavior, and Substitution Rate}

Although a measure of pasture DMI and substitution rate is important in determining the optimum response to supplements in pasture-based systems, the ability to routinely measure pasture DMI and substitution rate at the individual animal level is not yet possible. Sensors that measure cow activity (including grazing time) could be used as a surrogate measure of pasture DMI response to differing levels of supplementary feed, but further research is required to determine the ability of sensors that measure activity and other behaviors to predict DMI.
Of particular interest is the identification of suitable biomarkers that are linked to voluntary pasture and total DMI and substitution rates. This review has identified the importance of neuroendocrine factors (e.g., ghrelin) in regulating the pasture DMI response to supplementary feeds and could, therefore, be used in the selection of cows that produce more milk from every kilogram of supplement consumed, thereby enhancing feed conversion efficiency in grazing systems. However, further research would need to be conducted to determine if selection of animals on the basis of reduced substitution and increased marginal response to the supplement is not going to be at the cost of some other associative trait (e.g., fertility).

\section{Nutrient Contents of the Pasture and Supplement}

Any increase in production through supplementation will be determined by the most limiting resource, with ME intake being the factor that usually limits production in cows grazing high-quality pastures (high ME and $\mathrm{CP}$ content) at low to medium levels of supplementation. Other factors such as $\mathrm{CP}$ or individual AA deficiencies may limit production when the level of supplementation exceeds 30 to $50 \%$ of DMI. This is particularly the case where low-CP GBC supplements are used, leading to a requirement to "balance" the concentrate supplement for the most limiting nutritional factor through individualized feeding of different feed ingredients. For each situation, diet composition and cow production parameters need to be modeled to determine the nutrient limitation cascade, taking into account both the deficiencies and oversupply of particular feed ingredients. For this to be possible, an assessment of the nutrient content of both the pasture and supplement is required. Regular assessment of the nutrient content of pasture could be achieved using near infrared technology (Foley et al., 2010). A limiting factor with regard to applying this to individual animals is the large variation in nutritive value within a pasture allocation and, therefore, what is being consumed by individual dairy cows in the same herd (Delagarde et al., 2000; Clark, 2013), partly because of the variation in time cows arrive back at pasture after milking. The time of milking or bail placement order could be used as a parameter to assist with accounting for the variability, but further research needs to be conducted to determine the correlation between these parameters and the nutritive value of pasture on offer and the marginal response to supplementary feeds. If a good correlation is established, it may be possible to match energy and protein supplementary requirements to the predicted pasture nutritive value that each cow 
in the herd accesses. Whether this would be beneficial should be investigated because, in most circumstances, it is not the nutritive value of the pasture, per se, that is the issue, but the pasture allowance and the quantity and nutritive value of the supplement offered.

\section{Health}

Any automated system used to assist with determining optimum supply of supplements to individual cows should also take into account the implications of the concentrate supplement upon the health status of each cow. For example, if using individual milk yield response to concentrate DMI level without monitoring for rumen health parameters, excessive concentrate DMI may occur, leading to an increase in acidosis and other related conditions such as laminitis.

Measurements of rumen $\mathrm{pH}$, rumen temperature, and the level of active rumination may indicate the onset of conditions such as acidosis, but further research needs to be conducted to find better correlations between measures of rumen function and susceptibility to conditions such as acidosis. Further development of technology is needed to measure parameters such as rumen $\mathrm{pH}$ and rumen temperature to enable long-term reliable automated collection of this type of data. There may be opportunities to provide rumen modifiers to cows that are identified as being at risk for acidosis because of the allocation of high levels of NSC-based concentrates, but the benefits of these for preventing acidosis at high levels of NSC supplementation is debatable.

\section{Reproductive Traits}

Several strategies have been highlighted in this review that could improve reproductive outcomes of cows through targeted feeding of different ingredients relative to the cow's reproductive stage (DIM). For example, altering the NSC to structural carbohydrate ratio in early lactation could lead to a shortened period of anestrus, although further research in pasture-based systems is required to confirm this effect, particularly as it relates to individual variability. Further research is also required on the effect of type of carbohydrate pre- and postovulation. From a reproductive perspective, current pasture-based research evidence does not support altering protein amount or composition, but there are too few large-scale interventionist studies to confirm this view. The role of additional dietary fat is also uncertain, but there may be an advantage in feeding specific FA at specific reproductive stages, although further research is required to determine the role of FA on pre- and postovulatory reproductive function.

\section{Other Parameters}

Other parameters that could be considered as part of an algorithm for the allocation of concentrate supplements to grazing dairy cows include environmental measurements, such as ambient temperature, humidity, and wind speed, as well as physical effects on cows associated with ambulation, both distance and elevation. These parameters may assist in adjusting the level of supplement allocated to animals grazing pasture to accommodate potential welfare concerns in addition to optimizing production and profitability on farm.

It will be challenging to integrate and interpret the significant amounts of information collected to enable meaningful and profitable feeding decisions for individual cows within a herd. This will require the development of intelligent decision-support systems capable of processing and interpreting all the incoming data to achieve meaningful decisions. Via this intelligent decision-support system, farmers could allocate different supplements to individual cows based on complex algorithms that include details about the feed (pasture type, grain type), animal (genetic merit, BW, BCS, specific biomarkers), and environmental parameters (heat or cold stress) rather than just 1 or 2 parameters, such as milk yield and BW, as is currently the case for farms with automated feeding technology.

\section{CONCLUSIONS AND RECOMMENDATIONS}

The existence of variability between animals is critical in achieving potential benefits from individualized management strategies, such as supplementary feeding. Variability between animals in their response to concentrate supplements provides an opportunity to optimize the use of feed supplements at an individual cow level. Although much of the past research conducted under conditions of ad libitum feeding failed to identify any advantage to individualized feeding strategies, there is a need to determine responses to individualized feeding strategies in rotational grazing situations, in which pasture allowance is restricted.

This review highlights the complexity in determining responses to supplementary feeds and has provided compelling evidence that both cow-level (e.g., genotype, parity, DIM, BW, BCS, DMI) and system-level (e.g., pasture allowance and other grazing management strategies and climate) parameters can influence the marginal milk production response to supplements. The challenge remains to identify the parameters or combination of parameters that may enable improvement in the marginal milk production response to supplements as a result of a reallocation of supplements according 
to individual cow requirements rather than at the same flat rate to all animals in the herd.

The significant gaps in our understanding of the consequences of individualized feeding in a restricted pasture-based grazing system highlight the current need to develop an integrated research program that analyzes the potential of parameters discussed in this review, under more controlled research conditions and under differing systems. Of particular priority in pasture-based systems is research to quantify the variation in DMI between animals and the nutritive content of pasture consumed. Although pasture DMI and nutritive content cannot currently be measured routinely, these 2 factors have the potential to significantly affect both milk and BCS response to concentrate supplements.

There is also a need for longer-term comparisons of flat-rate feeding with individualized feeding in restricted pasture-based dairy systems. The research should be designed to allow for not just the comparison of feeding systems, but also the acquisition of key data that could be used to develop new algorithms, which may, in turn, improve the way supplements are fed to cows. Gaining a better understanding of the potential benefits for individualized feeding will enable an assessment of the cost:benefit ratio for investing in the technology for individualized feeding.

\section{ACKNOWLEDGMENTS}

The authors acknowledge the financial support of Australian and New Zealand dairy farmers, through their respective levy organizations: Dairy Australia Limited (Southbank, Victoria, Australia; project number: C100000585) and DairyNZ (Newstead, Hamilton, New Zealand; project number: FD 1205). The generous contribution of the New Zealand Ministry of Primary Industries, through the Sustainable Farming Fund (Wellington, New Zealand; project number: 12-021), is also gratefully acknowledged.

\section{REFERENCES}

Adamiak, S. J., K. Mackie, R. G. Watt, R. Webb, and K. D. Sinclair. 2005. Impact of nutrition on oocyte quality: Cumulative effects of body composition and diet leading to hyperinsulinemia in cattle. Biol. Reprod. 73:918-926.

Adamiak, S. J., K. Powell, J. A. Rooke, R. Webb, and K. D. Sinclair 2006. Body composition, dietary carbohydrates and fatty acids determine post-fertilisation development of bovine oocytes in vitro. Reproduction 131:247-258.

Al-Saiady, M. Y., M. A. Al-Shaikh, S. I. Al-Mufarrej, T. A. Al-Showeimi, H. H. Mogawer, and A. Dirrar. 2004. Effect of chelated chromium supplementation on lactation performance and blood parameters of Holstein cows under heat stress. Anim. Feed Sci. Technol. 117:223-233.

Allen, M. S., and B. J. Bradford. 2009. Control of eating by hepatic oxidation of fatty acids. A note of caution. Appetite 53:272-273.
Allen, M. S., B. J. Bradford, and M. Oba. 2009. The hepatic oxidation theory of the control of feed intake and its application to ruminants. J. Anim. Sci. 87:3317-3334.

Ambrose, D. J., J. P. Kastelic, R. Corbett, P. A. Pitney, H. V. Petit, J. A. Small, and P. Zalkovic. 2006. Lower pregnancy losses in lactating dairy cows fed a diet enriched in alpha-linolenic acid. J. Dairy Sci. 89:3066-3074

André, G., P. B. M. Berentsen, B. Engel, C. de Koning, and A. Lansink. 2010a. Increasing the revenues from automatic milking by using individual variation in milking characteristics. J. Dairy Sci. 93:942-953.

André, G., P. B. M. Berentsen, G. Van Duinkerken, B. Engel, and A. Lansink. 2010b. Economic potential of individual variation in milk yield response to concentrate intake of dairy cows. J. Agric. Sci. 148:263-276.

Anukulkitch, C., A. Rao, F. R. Dunshea, and I. J. Clarke. 2009. A test of the lipostat theory in a seasonal (ovine) model under natural conditions reveals a close relationship between adiposity and melanin concentrating hormone expression. Domest. Anim. Endocrinol. 36:138-151.

Arora, S., and Anubhuti.. 2006. Role of neuropeptides in appetite regulation and obesity - A review. Neuropeptides 40:375-401.

Arunvipas, P., E. R. Leger, J. A. VanLeeuwen, I. R. Dohoo, and G. P. Keefe. 2003. The effect of nutrition and management factors and milk urea nitrogen levels on reproductive performance in Canadian dairy herds. Pages 258-261 in 10th Symp. Int. Soc. Vet. Epidemiol. Econ. International Symposia on Veterinary Epidemiology and Economics, Vina Del Mar, Chile.

Aston, K., J. D. Sutton, and W. J. Fisher. 1995. Milk production from grass-silage diets-Strategies for concentrate allocation. Anim. Sci. $61: 465-480$

Auldist, M. J., L. C. Marett, J. S. Greenwood, M. Hannah, J. L. Jacobs, and W. J. Wales. 2013a. Effects of different strategies for feeding supplements on milk production responses in cows grazing a restricted pasture allowance. J. Dairy Sci. 96:1218-1231.

Auldist, M. J., L. C. Marett, J. S. Greenwood, M. M. Wright, M. Hannah, J. L. Jacobs, and W. J. Wales. 2013b. Replacing wheat with canola meal in a partial mixed ration increases the milk production of cows grazing at a restricted pasture allowance in spring. Anim. Prod. Sci. 54:869-878. http://dx.doi.org/10.1071/AN13154.

Bargo, F., L. D. Muller, J. E. Delahoy, and T. W. Cassidy. 2002. Milk response to concentrate supplementation of high-producing dairy cows grazing at two pasture allowances. J. Dairy Sci. 85:17771792

Bargo, F., L. D. Muller, E. S. Kolver, and J. E. Delahoy. 2003. Production and digestion of supplemented dairy cows on pasture. J. Dairy Sci. 86:1-42.

Barton, B. A., H. A. Rosario, G. W. Anderson, B. P. Grindle, and D. J. Carroll. 1996. Effects of dietary crude protein, breed, parity, and health status on the fertility of dairy cows. J. Dairy Sci. 79:2225-2236.

Baudracco, J., N. Lopez-Villalobos, C. W. Holmes, and K. A. Macdonald. 2010a. Effects of stocking rate, supplementation, genotype and their interactions on grazing dairy systems: A review. N. Z. J. Agric. Res. 53:109-133.

Baudracco, J., N. Lopez-Villalobos, C. W. Holmes, and K. A. MacDonald. 2010b. Prediction of herbage dry matter intake for dairy cows grazing ryegrass-based pastures. Proc. N.Z. Soc. Anim. Prod. 70:80-85.

Bauman, D. E., and W. B. Currie. 1980. Partitioning of nutrients during pregnancy and lactation-A review of mechanisms involving homeostasis and homeorhesis. J. Dairy Sci. 63:1514-1529.

Baumgard, L. H., B. A. Corl, D. A. Dwyer, A. Saebo, and D. E. Bauman. 2000. Identification of the conjugated linoleic acid isomer that inhibits milk fat synthesis. Am. J. Physiol. Regul. Integr. Comp. Physiol. 278:R179-R184.

Bazeley, K., and P. Pinsent. 1984. Preliminary observations on a series of outbreaks of acute laminitis in dairy cattle. Vet. Rec. 115:619622 .

Beam, S. W., and W. R. Butler. 1997. Energy balance and ovarian follicle development prior to the first ovulation postpartum in 
dairy cows receiving three levels of dietary fat. Biol. Reprod. 56:133-142.

Beam, S. W., and W. R. Butler. 1999. Effects of energy balance on follicular development and first ovulation in postpartum dairy cows. J. Reprod. Fertil. Suppl. 54:411-424

Berman, A. 2005. Estimates of heat stress relief needs for Holstein dairy cows. J. Anim. Sci. 83:1377-1384.

Bernabucci, U., N. Lacetera, L. H. Baumgard, R. P. Rhoads, B. Ronchi, and A. Nardone. 2010. Metabolic and hormonal acclimation to heat stress in domesticated ruminants. Animal 4:1167-1183.

Berry, D. P., F. Buckley, P. Dillon, R. D. Evans, M. Rath, and R. F. Veerkamp. 2003. Genetic relationships among body condition score, body weight, milk yield, and fertility in dairy cows. J. Dairy Sci. 86:2193-2204.

Berry, D. P., J. R. Roche, and M. P. Coffey. 2008. Body condition score and fertility-More than just a feeling. Pages 107-118 in Fertility in Dairy Cows. M. D. Royal, N. C. Friggens, and R. F. Smith, ed. Br. Soc. Anim. Sci., Penicuik, UK.

Beukes, P. C., C. R. Burke, G. Levy, and R. M. Tiddy. 2010. Using a whole farm model to determine the impacts of mating management on the profitability of pasture-based dairy farms. Anim. Reprod. Sci. 121:46-54.

Bewley, J. M., A. M. Peacock, O. Lewis, R. E. Boyce, D. J. Roberts, M. P. Coffey, S. J. Kenyon, and M. M. Schutz. 2008. Potential for estimation of body condition scores in dairy cattle from digital images. J. Dairy Sci. 91:3439-3453.

Bilby, T. R., T. Jenkins, C. R. Staples, and W. W. Thatcher. 2006. Pregnancy, bovine somatotropin, and dietary n-3 fatty acids in lactating dairy cows: III. Fatty acid distribution. J. Dairy Sci. 89:3386-3399.

Bines, J. A. 1985. Feeding systems and food intake by housed dairy cows. Proc. Nutr. Soc. 44:355-362.

Bines, J. A., and I. C. Hart. 1982. Metabolic limits to milk production, especially roles of growth hormone and insulin. J. Dairy Sci. 65:1375-1389.

Bland, I. M., K. DiGiacomo, S. R. O. Williams, B. J. Leury, F. R. Dunshea, and P. J. Moate. 2013. The use of infra-red thermography to measure flank temperatures of dairy cows fed wheat- or maize-based diets. Page 182 in Proc. Br. Soc. Anim. Sci. British Society of Animal Science, Penicuik, UK.

Block, S. S., W. R. Butler, R. A. Ehrhardt, A. W. Bell, M. E. Van Amburgh, and Y. R. Boisclair. 2001. Decreased concentration of plasma leptin in periparturient dairy cows is caused by negative energy balance. J. Endocrinol. 171:339-348.

Bramley, E., I. J. Lean, W. J. Fulkerson, M. A. Stevenson, A. R Rabiee, and N. D. Costa. 2008. The definition of acidosis in dairy herds predominantly fed on pasture and concentrates. J. Dairy Sci. 91:308-321.

Breier, B. H., P. D. Gluckman, and J. J. Bass. 1988. The somatotropic axis in young steers-Influence of nutritional status and oestradiol-17-beta on hepatic high effinity and low affinity somatotropic binding sites. J. Endocrinol. 116:169-177.

Brockman, R. P., and B. Laarveld. 1986. Hormonal regulation of metabolism in ruminants - A review. Livest. Prod. Sci. 14:313-334.

Buckley, F., P. Dillon, S. Crosse, F. Flynn, and M. Rath. 2000a. The performance of Holstein Friesian dairy cows of high and medium genetic merit for milk production on grass-based feeding systems. Livest. Prod. Sci. 64:107-119.

Buckley, F., P. Dillon, M. Rath, and R. F. Veerkamp. 2000b. The relationship between genetic merit for yield and live weight, condition score, and energy balance of spring calving Holstein Friesian dairy cows on grass based systems of milk production. J. Dairy Sci. $83: 1878-1886$

Buckley, F., K. O'Sullivan, J. F. Mee, R. D. Evans, and P. Dillon. 2003. Relationships among milk yield, body condition, cow weight, and reproduction in spring-calved Holstein-Friesians. J. Dairy Sci. 86:2308-2319.

Burke, C. R., R. C. Fowler, and R. M. Tiddy. 2008. Building towards the InCalf programme for New Zealand Pages 1-8 in Dairy Cattle Veterinarians Conference. T. J. Parkinson, ed. Palmerston North, New Zealand.
Burke, C. R., S. McDougall, and K. L. MacMillan. 1995. Effects of breed and calving liveweight on postpartum ovarian activity in pasture-fed dairy heifers. Proc. N.Z. Soc. Anim. Prod. 55:76-78.

Burke, C. R., and J. R. Roche. 2007. Effects of pasture feeding during the periparturient period on postpartum anovulation in grazed dairy cows. J. Dairy Sci. 90:4304-4312.

Burke, C. R., J. K. Kay, C. V. C. Phyn, S. Meier, J. M. Lee, and J. R. Roche. 2010a. Short communication: Effects of dietary nonstructural carbohydrates pre- and postpartum on reproduction of grazing dairy cows. J. Dairy Sci. 93:4292-4296.

Burke, C. R. Y. J. Williams, L. Hofmann, J. K. Kay, C. V. C. Phyn, and S. Meier. 2010b. Effects of an acute feed restriction at the onset of the seasonal breeding period on reproductive performance and milk production in pasture-grazed dairy cows. J. Dairy Sci. 93:1116-1125.

Butler, S. T., S. H. Pelton, and W. R. Butler. 2004. Insulin increases 17 beta-estradiol production by the dominant follicle of the first postpartum follicle wave in dairy cows. Reproduction 127:537545

Butler, W. R. 1998. Review: Effect of protein nutrition on ovarian and uterine physiology in dairy cattle. J. Dairy Sci. 81:2533-2539.

Carruthers, V. R., P. G. Neil, and D. E. Dalley. 1997. Effect of altering the non-structural: Structural carbohydrate ratio in a pasture diet on milk production and ruminal metabolites in cows in early and late lactation. Anim. Sci. 64:393-402.

Chagas, L. M., P. J. S. Gore, S. Meier, K. A. Macdonald, and G. A. Verkerk. 2007. Effect of monopropylene glycol on luteinizing hormone, metabolites, and postpartum anovulatory intervals in primiparous dairy cows. J. Dairy Sci. 90:1168-1175.

Chagas, L. M., M. C. Lucy, P. J. Back, D. Blache, J. M. Lee, P. J. S. Gore, A. J. Sheahan, and J. R. Roche. 2009. Insulin resistance in divergent strains of Holstein-Friesian dairy cows offered fresh pasture and increasing amounts of concentrate in early lactation. J. Dairy Sci. 92:216-222.

Chagas, L. M., G. E. Tunon, V. K. Taufa, C. R. Burke, and G. C. Waghorn. 2010. Reproductive performance of pasture-fed dairy cows supplemented with monopropylene glycol. N. Z. Vet. J. 58:17-22.

Chapman, D. F., B. R. Cullen, I. R. Johnson, and D. Beca. 2009. Interannual variation in pasture growth rate in Australian and New Zealand dairy regions and its consequences for system management. Anim. Prod. Sci. 49:1071-1079.

Chapman, D. F., S. N. Kenny, D. Beca, and I. R. Johnson. 2008. Pasture and forage crop systems for non-irrigated dairy farms in southern Australia. 2. Inter-annual variation in forage supply, and business risk. Agric. Syst. 97:126-138.

Chauhan, S., P. Celi, B. J. Leury, and F. R. Dunshea. 2012. Supranutritional levels of antioxidants maintains feed intake and reduces heat stress in sheep. J. Anim. Sci. 90(Suppl. 3):672. (Abstr.)

Childs, S., A. A. Hennessy, J. M. Sreenan, D. C. Wathes, Z. Cheng, C. Stanton, M. G. Diskin, and D. A. Kenny. 2008. Effect of level of dietary n-3 polyunsaturated fatty acid supplementation on systemic and tissue fatty acid concentrations and on selected reproductive variables in cattle. Theriogenology 70:595-611.

Clark, C. 2013. What are we feeding our cows? Pages 44-49 in Current topics in dairy production. Vol. 18. K. Kerrisk, S. C. Garcia, S. Catt, and M. Heward, ed. Dairy Research Foundation, University of Sydney, Australia.

Cronje, P. 2005. Heat stress in livestock-The role of the gut in its aetiology and a potential role for betaine in its alleviation. Pages 107-122 in Recent Advances in Animal Nutrition in Australia. Vol. 15. University of New England, Armidale, NSW, Australia.

Cummins, S. B., P. Lonergan, A. C. O. Evans, D. P. Berry, R. D Evans, and S. T. Butler. 2012a. Genetic merit for fertility traits in Holstein cows: I. Production characteristics and reproductive efficiency in a pasture-based system. J. Dairy Sci. 95:1310-1322.

Cummins, S. B., P. Lonergan, A. C. O. Evans, and S. T. Butler. 2012b. Genetic merit for fertility traits in Holstein cows: II. Ovarian follicular and corpus luteum dynamics, reproductive hormones, and estrus behavior. J. Dairy Sci. 95:3698-3710.

Cummins, S. B., S. M. Waters, A. C. O. Evans, P. Lonergan, and S. T. Butler. 2012c. Genetic merit for fertility traits in Holstein cows: 
III. Hepatic expression of somatotropic axis genes during pregnancy and lactation. J. Dairy Sci. 95:3711-3721.

Dalley, D. E., J. R. Roche, P. J. Moate, and C. Grainger. 2001. More frequent allocation of herbage does not improve the milk production of dairy cows in early lactation. Aust. J. Exp. Agric. 41:593599.

Danscher, A. M., H. L. Enemark, P. H. Andersen, B. Aalbaek, and O. L. Nielsen. 2010. Polysynovitis after oligofructose overload in dairy cattle. J. Comp. Pathol. 142:129-138.

Danscher, A. M., J. M. D. Enemark, E. Telezhenko, N. Capion, C. T. Ekstrom, and M. B. Thoefner. 2009. Oligofructose overload induces lameness in cattle. J. Dairy Sci. 92:607-616.

de Veth, M. J., E. Castaneda-Gutierrez, D. A. Dwyer, A. M. Pfeiffer, D. E. Putnam, and D. E. Bauman. 2006. Response to conjugated linoleic acid in dairy cows differing in energy and protein status. J. Dairy Sci. 89:4620-4631.

de Veth, M. J., and E. S. Kolver. 2001a. Digestion of ryegrass pasture in response to change in $\mathrm{pH}$ in continuous culture. J. Dairy Sci. 84:1449-1457.

de Veth. M. J., and E. S. Kolver. 2001b. Diurnal variation in pH reduces digestion and synthesis of microbial protein when pasture is fermented in continuous culture. J. Dairy Sci. 84:2066-2072.

de Vries, M. J., and R. F. Veerkamp. 2000. Energy balance of dairy cattle in relation to milk production variables and fertility. J. Dairy Sci. 83:62-69.

del Rincon, J.-P., K. Iida, B. D. Gaylinn, C. E. McCurdy, J. W. Leitner, L. A. Barbour, J. J. Kopchick, J. E. Friedman, B. Draznin, and M. O. Thorner. 2007. Growth hormone regulation of p85 alpha expression and phosphoinositide 3-kinase activity in adipose tissue-Mechanism for growth hormone-mediated insulin resistance. Diabetes 56:1638-1646.

Delaby, L., P. Faverdin, G. Michel, C. Disenhaus, and J. L. Peyraud. 2009. Effect of different feeding strategies on lactation performance of Holstein and Normande dairy cows. Animal 3:891-905.

Delagarde, R., J. L. Peyraud, L. Delaby, and P. Faverdin. 2000. Vertical distribution of biomass, chemical composition and pepsincellulase digestibility in a perennial ryegrass sward: Interaction with month of year, regrowth age and time of day. Anim. Feed Sci. Technol. 84:49-68.

DiGiacomo, K. 2011. The physiological and metabolic responses to heat in ruminants. PhD Thesis. The University of Melbourne, Australia.

DiGiacomo, K., B. J. Leury, and F. R. Dunshea. 2014. Potential nutritional strategies for the amelioration or prevention of high rigor temperature in cattle - A review. Anim. Prod. Sci. 54:430-443.

Dillon, P. 2006. Achieving high dry-matter intake from pasture with grazing dairy cows. Pages 1-26 in Fresh Herbage for Dairy Cattle: The Key to a Sustainable Food Chain. A. Elgersma, J. Dijkstra, and S. Tamminga, ed. Springer Verlag, Heidelberg, Germany.

Dillon, P., D. P. Berry, R. D. Evans, F. Buckley, and B. Horan. 2006. Consequences of genetic selection for increased milk production in European seasonal pasture based systems of milk production. Livest. Sci. 99:141-158.

Dillon, P., T. Hennessy, L. Shalloo, F. Thorne, and B. Horan. 2008 Future outlook for the Irish dairy industry: A study of international competitiveness, influence of international trade reform and requirement for change. Int. J. Dairy Technol. 61:16-29.

Diskin, M. G. 2008a. Reproductive management of dairy cows: A review (part I). Ir. Vet. J. 61:326-332.

Diskin, M. G. 2008b. Reproductive management of dairy cows: A review (part II). Ir. Vet. J. 61:403-411.

Diskin, M. G., D. R. Mackey, J. F. Roche, and J. M. Sreenan. 2003. Effects of nutrition and metabolic status on circulating hormones and ovarian follicle development in cattle. Anim. Reprod. Sci. 78:345-370.

Dulphy, J. P. 1978. Quantites ingerees et phenomenes de substitution; Consequences pour le rationnement. Pages 87-98 in La Vache Laitiere. M. Journet and A. Holden, ed. Institut National de la Recherche, Versailles, France.

Dunshea, F. R., D. E. Bauman, E. A. Nugent, D. J. Kerton, R. H. King, and I. McCauley. 2005. Hyperinsulinaemia, supplemental protein and branched-chain amino acids when combined can increase milk protein yield in lactating sows. Br. J. Nutr. 93:325-332.

Dunshea, F. R., B. J. Leury, F. Fahri, K. DiGiacomo, A. Hung, S. Chauhan, I. J. Clarke, R. Collier, S. Little, L. Baumgard, and J. B. Gaughan. 2013. Amelioration of thermal stress impacts in dairy cows. Anim. Prod. Sci. 53:965-975.

Dunshea, F. R., V. M. Russo, I. Sawyer, and B. J. Leury. 2012. A starch-binding agent decreases the in vitro rate of fermentation of wheat. J. Anim. Sci. 90(Suppl. 3):158.

Dunshea, F. R., G. P. Walker, E. Ostrowska, and P. T. Doyle. 2008. Seasonal variation in the concentrations of conjugated linoleic and trans fatty acids in milk fat from commercial dairy farms is associated with pasture and grazing management and supplementary feeding practices. Aust. J. Exp. Agric. 48:1062-1075.

Enemark, J. M. D. 2008. The monitoring, prevention and treatment of sub-acute ruminal acidosis (SARA): A review. Vet. J. 176:32-43.

Ferguson, J. D., G. Azzaro, and G. Licitra. 2006. Body condition assessment using digital images. J. Dairy Sci. 89:3833-3841.

Ferguson, J. D., T. Blanchard, D. T. Galligan, D. C. Hoshall, and W. Chalupa. 1988. Infertility in dairy cattle fed a high percentage of protein degradable in the rumen. J. Am. Vet. Med. Assoc. 192:659-662.

Ferguson, J. D., and W. Chalupa. 1989. Impact of protein nutrition on reproduction in dairy cows. J. Dairy Sci. 72:746-766.

Ferguson, J. D., D. T. Galligan, T. Blanchard, and M. Reeves. 1993 Serum urea nitrogen and conception rate-The usefulness of test information. J. Dairy Sci. 76:3742-3746.

Foley, J., A. Barbi, E. Eden, M. Jerred, A. Giri, and J. C. DeMatteo. 2010. Precision animal nutrition: The role of portable NIR on the farm. Proc. First North American Conference on Precision Dairy Management, Toronto, Canada. Accessed Dec. 19, 2014. http:// www.precisiondairy2010.com/proceedings/s11foley.pdf.

Forbes, J. M. 1992. Metabolic aspects of satiety. Proc. Nutr. Soc. 51:13-19.

Fouladi-Nashta, A. A., C. G. Gutierrez, J. G. Gong, P. C. Garnsworthy, and R. Webb. 2007. Impact of dietary fatty acids on oocyte quality and development in lactating dairy cows. Biol. Reprod. 77:9-17.

Fox, D. G., M. C. Barry, R. E. Pitt, D. K. Roseler, and W. C. Stone. 1995. Application of the Cornell net carbohydrate and protein model for cattle consuming forages. J. Anim. Sci. 73:267-277.

Friggens, N. C., P. Berg, P. Theilgaard, I. R. Korsgaard, K. L. Ingvartsen, P. Lovendahl, and J. Jensen. 2007. Breed and parity effects on energy balance profiles through lactation: Evidence of genetically driven body energy change. J. Dairy Sci. 90:5291-5305.

Friggens, N. C., C. Disenhaus, and H. V. Petit. 2010. Nutritional sub-fertility in the dairy cow: Towards improved reproductive management through a better biological understanding. Animal 4:1197-1213.

Friggens, N. C., K. L. Ingvartsen, and G. C. Emmans. 2004. Prediction of body lipid change in pregnancy and lactation. J. Dairy Sci. 87:988-1000.

Fulkerson, W. J., T. M. Davison, S. C. Garcia, G. Hough, M. E. Goddard, R. Dobos, and M. Blockey. 2008. Holstein-Friesian dairy cows under a predominantly grazing system: Interaction between genotype and environment. J. Dairy Sci. 91:826-839.

Fulkerson, W. J., J. Wilkins, R. C. Dobos, G. M. Hough, M. E. Goddard, and T. Davison. 2001. Reproductive performance in Holstein-Friesian cows in relation to genetic merit and level of feeding when grazing pasture. Anim. Sci. 73:397-406.

Garcia, S. C., and C. W. Holmes. 2005. Seasonality of calving in pasture-based dairy systems: Its effects on herbage production, utilisation and dry matter intake. Aust. J. Exp. Agric. 45:1-9.

Garcia, S. C., C. W. Holmes, J. Hodgson, and A. MacDonald. 2000a. The combination of the n-alkanes and C-13 techniques to estimate individual dry matter intakes of herbage and maize silage by grazing dairy cows. J. Agric. Sci. 135:47-55.

Garcia, S. C., M. Pedernera, W. J. Fulkerson, A. Horadagoda, and K. Nandra. 2007. Feeding concentrates based on individual cow requirements improves the yield of milk solids in dairy cows grazing restricted pasture. Aust. J. Exp. Agric. 47:502-508. 
Garcia, S. C., F. J. Santini, and J. C. Elizalde. 2000b. Sites of digestion and bacterial protein synthesis in dairy heifers fed fresh oats with or without corn or barley grain. J. Dairy Sci. 83:746-755.

Garcia-Bojalil, C. M., C. R. Staples, W. W. Thatcher, and M. Drost. 1994. Protein-intake and development of ovarian follicles and embryos of superovulated nonlactating dairy-cows. J. Dairy Sci. $77: 2537-2548$

Garnsworthy, P. C., A. A. Fouladi-Nashta, G. E. Mann, K. D. Sinclair, and R. Webb. 2009. Effect of dietary-induced changes in plasma insulin concentrations during the early post partum period on pregnancy rate in dairy cows. Reproduction 137:759-768.

Garnsworthy, P. C., A. Lock, G. E. Mann, K. D. Sinclair, and R. Webb. 2008. Nutrition, metabolism, and fertility in dairy cows: 1 . Dietary energy source and ovarian function. J. Dairy Sci. 91:3814-3823.

Gaughan, J., N. Lacetera, E. Valtora, H. H. Khalifah, L. Hahn, and T. L. Mader. 2009. Response of domestic animals to climate challenges. Pages 131-170 in Biometeorology for Adaptation to Climate Variability and Change. K. L. Ebi, I. Burton, and G. R. McGregor, ed. Springer, Auckland, New Zealand.

Gaughan, J. B., T. L. Mader, S. M. Holt, and A. Lisle. 2008. A new heat load index for feedlot cattle. J. Anim. Sci. 86:226-234.

Gibbs, J., and J. Laporte. 2008. Rumen function and lameness in South Island cows. Pages 268-273 in Proc. South Island Dairy Event (SIDE), Invercargill, New Zealand. Accessed Dec. 19, 2014. http://side.org.nz/wp-content/uploads/2014/05/Lame-Cows.pdf.

Gill, M. S., and J. R. Kaushal. 2000. Feeding of grass silage to dairy cows with special reference to systems of concentrate feeding in United Kingdom-A review. Agric. Rev. 21:71-79.

Golder, H. M., P. Celi, A. R. Rabiee, C. Heuer, E. Bramley, D. W. Miller, R. King, and I. J. Lean. 2012. Effects of grain, fructose, and histidine on ruminal $\mathrm{pH}$ and fermentation products during an induced subacute acidosis protocol. J. Dairy Sci. 95:1971-1982.

Golder, H. M., P. Celi, A. R. Rabiee, and I. J. Lean. 2014. Effects of feed additives on rumen and blood profiles during a starch and fructose challenge. J. Dairy Sci. 97:985-1004.

Gong, J. G., W. J. Lee, P. C. Garnsworthy, and R. Webb. 2002. Effect of dietary-induced increases in circulating insulin concentrations during the early postpartum period on reproductive function in dairy cows. Reproduction 123:419-427.

Gordon, F. J. 1982. The effect of pattern of concentrate allocation on milk production for autumn-calving heifers. Anim. Prod. 34:5561.

Grainger, C., and G. L. Mathews. 1989. Positive relation between substitution rate and pasture allowance for cows receiving concentrates. Aust. J. Exp. Agric. 29:355-360.

Grala, T. M., M. C. Lucy, C. V. C. Phyn, A. J. Sheahan, J. M. Lee, and J. R. Roche. 2011. Somatotropic axis and concentrate supplementation in grazing dairy cows of genetically diverse origin. J Dairy Sci. 94:303-315.

Griinari, J. M., M. A. McGuire, D. A. Dwyer, D. E. Bauman, D. M. Barbano, and W. A. House. 1997. The role of insulin in the regulation of milk protein synthesis in dairy cows. J. Dairy Sci. 80:2361-2371.

Grummer, R. R., and D. J. Carroll. 1991. Effects of dietary fat on metabolic disorders and reproductive performance of dairy cattle. J. Anim. Sci. 69:3838-3852

Gwynne, J. T., and J. F. Strauss. 1982. The role of lipoproteins in steroidogenesis and cholesterol metabolism in steroidogenic glands. Endocr. Rev. 3:299-329.

Hafez, E. S. E. 1969. The Behavior of Domestic Animals. The Williams and Wilkins Company, Baltimore, MD

Hall, L. W., F. R. Dunshea, J. D. Allen, A. Wood, S. D. Anderson, S. Rungruang, J. L. Collier, N. M. Long, and R. J. Collier. 2012. Evaluation of dietary betaine (BET) in heat-stressed Holstein cows in lactation. J. Anim. Sci. 90(Suppl. 3):556. (Abstr.)

Hansen, P. J. 2004. Physiological and cellular adaptations of zebu cattle to thermal stress. Anim. Reprod. Sci. 82-83:349-360.

Higgs, R. J., A. J. Sheahan, K. Mandok, M. E. Van Amburgh, and J. R. Roche. 2013. The effect of starch-, fiber-, or sugar-based supplements on nitrogen utilization in grazing dairy cows. J. Dairy Sci. 96:3857-3866.
Holmes, C. W., and J. R. Roche. 2007. Pastures and supplements in dairy production systems. Pages 221-242 in Pastures and Supplements for Grazing Animals. P. V. Ratray, I. M. Brooks, and A M. Nicol, ed. New Zealand Society of Animal Production, New Zealand.

Holmes, W. 1989. Grass: Its Production and Utilization. 2nd ed. British Grasslands Society. Blackwell Scientific Publications, Oxford, UK

Horan, B., P. Dillon, D. P. Berry, P. O'Connor, and M. Rath. 2005. The effect of strain of Holstein-Friesian, feeding system and parity on lactation curves characteristics of spring-calving dairy cows. Livest. Prod. Sci. 95:231-241.

Horan, B., P. Faverdin, L. Delaby, M. Rath, and P. Dillon. 2006. The effect of strain of Holstein-Friesian dairy cow and pasture-based system on grass intake and milk production. Anim. Sci. 82:435444

Horan, B., J. F. Mee, M. Rath, P. O'Connor, and P. Dillon. 2004. The effect of strain of Holstein-Friesian cow and feeding system on reproductive performance in seasonal-calving milk production systems. Anim. Sci. 79:453-467.

Hung, T. Y. 2012. The effects of nano-chromium on growth performance and metabolism of pigs and sheep. PhD Thesis. The University of Melbourne, Australia.

Jenkins, T. C., and M. A. McGuire. 2006. Major advances in nutrition: Impact on milk composition. J. Dairy Sci. 89:1302-1310.

Jonsson, N. N., W. J. Fulkerson, P. M. Pepper, and M. R. McGowan. 1999. Effect of genetic merit and concentrate feeding on reproduction of grazing dairy cows in a subtropical environment. J. Dairy Sci. 82:2756-2765.

Jordan, E. R., and L. V. Swanson. 1979. Serum progesterone and luteinizing hormone in dairy cattle fed varying levels of crude protein. J. Anim. Sci. 48:1154-1158

Juchem, S. O., R. L. A. Cerri, M. Villasenor, K. N. Galvao, R. G. S. Bruno, H. M. Rutigliano, E. J. DePeters, F. T. Silvestre, W. W. Thatcher, and J. E. P. Santos. 2010. Supplementation with calcium salts of linoleic and trans-octadecenoic acids improves fertility of lactating dairy cows. Reprod. Domest. Anim. 45:55-62.

Kadzere, C. T., M. R. Murphy, N. Silanikove, and E. Maltz. 2002. Heat stress in lactating dairy cows: A review. Livest. Prod. Sci. 77:59-91.

Kappel, L. C., R. H. Ingraham, E. B. Morgan, L. Zeringue, D. Wilson, and D. K. Babcock. 1984. Relationship between fertility and blood glucose and cholesterol concentrations in Holstein cows. Am. J. Vet. Res. 45:2607-2612.

Kaur, R., C. Clarke, A. Horadagoda, H. Golder, S. Garcia, K. Kerrisk, and M. D. Islam. 2013. Increasing feed conversion efficiency in automatic milking systems: The impact of grain-based concentrate allocation and kikuyu (Pennisetum clandestinum) pasture state on milk production. Pages 1723-1724 in 22nd International Grasslands Congress: Revitalising Grasslands to Sustain our Communities. Vol. 22, Sydney, Australia. New South Wales Department of Primary Industry, Orange, NSW, Australia.

Kay, J. K., C. V. C. Phyn, A. G. Rius, S. R. Morgan, T. M. Brala, and J. R. Roche. 2013. Once-day milking during a feed deficit decreases milk production but improves energy status in early lactating grazing dairy cows. J. Dairy Sci. 96:6274-6284.

Kay, J. K., J. R. Roche, E. S. Kolver, N. A. Thomson, and L. H. Baumgard. 2005. A comparison between feeding systems (pasture and TMR) and the effect of vitamin E supplementation on plasma and milk fatty acid profiles in dairy cows. J. Dairy Res. 72:322-332.

Kay, J. K., J. R. Roche, C. E. Moore, and L. H. Baumgard. 2006. Effects of dietary conjugated linoleic acid on production and metabolic parameters in transition dairy cows grazing fresh pasture. J. Dairy Res. 73:367-377.

Kellaway, R., and T. Harrington. 2004. Feeding concentrates: Supplements for dairy cows. Landlink Press, Melbourne, Australia.

Kellaway, R., and S. Porta. 1993. Feeding concentrates: Supplements for dairy cows. Dairy Research and Development Corporation, Victoria, Australia. 
Kennedy, G. C. 1953. The role of depot fat in the hypothalamic control of food intake in the rat. Proc. R. Soc. Lond. B Biol. Sci. 140:578-596.

Kennedy, J., P. Dillon, L. Delaby, P. Faverdin, G. Stakelum, and M. Rath. 2003. Effect of genetic merit and concentrate supplementation on grass intake and milk production with Holstein Friesian dairy cows. J. Dairy Sci. 86:610-621.

Kenny, D. A., M. P. Boland, M. G. Diskin, and J. M. Sreenan. 2001. Effect of pasture crude protein and fermentable energy supplementation on blood metabolite and progesterone concentrations and on embryo survival in heifers. Anim. Sci. 73:501-511.

Kenny, D. A., M. P. Boland, M. G. Diskin, and J. M. Sreenan. 2002. Effect of rumen degradable protein with or without fermentable carbohydrate supplementation on blood metabolites and embryo survival in cattle. Anim. Sci. 74:529-537.

Kolver, E. S. 2003. Nutritional limitations to increased production on pasture-based systems. Proc. Nutr. Soc. 62:291-300.

Kolver, E. S., C. R. Burke, and J. R. Roche. 2005. Genotype and feed effects on annual milk production and reproduction of grazing dairy cows. J. Dairy Sci. 88(Suppl. 1): 93-94. (Abstr.)

Kolver, E. S., and M. J. de Veth. 2002. Prediction of ruminal pH from pasture-based diets. J. Dairy Sci. 85:1255-1266.

Kolver, E. S., and K. L. Macmillan. 1994. Variation in selected bloodplasma constituents during the postpartum and breeding periods in dairy cows. N. Z. Vet. J. 42:161-166.

Kolver, E. S., and L. D. Muller. 1998. Performance and nutrient intake of high producing Holstein cows consuming pasture or a total mixed ration. J. Dairy Sci. 81:1403-1411.

Kolver, E. S., J. R. Roche, and P. W. Aspin. 2006. Plasma insulin, growth hormone, and IGF-1 concentrations of Holstein-Friesian cows of divergent genotype offered varying levels of concentrate in early lactation. Proc. N.Z. Soc. Anim. Prod. 66:403-408.

Kolver, E. S., J. R. Roche, M. J. d. Veth, P. L. Thorne, and A. R. Napper. 2002. Total mixed rations versus pasture diets: evidence for a genotype $\times$ diet interaction in dairy cow performance. Proc. N.Z. Soc. Anim. Prod. 62:246-251.

Koser, S. L., M. Thomas, and s. Donkin. 2008. Cloning the promoter region for bovine phosphoenolpyruvate carboxykinase gene and identification of propionate responsive region. J. Dairy Sci. 91(Suppl. 1):424. (Abstr.)

Larcombe, M. T. 1989. The effects of manipulating reproduction on the productivity and profitability of dairy herds which graze pasture. $\mathrm{PhD}$ Thesis. University of Melbourne, Australia.

Lean, I. J., P. Celi, H. Raadsma, J. McNamara, and A. R. Rabiee. 2012. Effects of dietary crude protein on fertility: Meta-analysis and meta-regression. Anim. Feed Sci. Technol. 171:31-42.

Lean, I. J., C. T. Westwood, H. M. Golder, and J. J. Vermunt. 2013. Impact of nutrition on lameness and claw health in cattle. Livest. Sci. 156:71-87.

Leaver, J. D. 1985. Milk production from grazed temperate grassland. J. Dairy Res. 52:313-344.

Leaver, J. D. 1988. Level and pattern of concentrate allocation to dairy cows. Pages 315-326 in Nutrition and Lactation in the Dairy Cow. P. C. Garnsworthy, ed. Butterworths, London, UK.

Leddin, C. M., C. R. Stockdale, J. Hill, J. W. Heard, and P. T. Doyle. 2009. Increasing amounts of crushed wheat fed with pasture hay reduced dietary fiber digestibility in lactating dairy cows. J. Dairy Sci. 92:2747-2757.

Leddin, C. M., C. R. Stockdale, J. Hill, J. W. Heard, and P. T. Doyle. 2010. Increasing amounts of crushed wheat fed with Persian clover herbage reduced ruminal $\mathrm{pH}$ and dietary fibre digestibility in lactating dairy cows. Anim. Prod. Sci. 50:837-846.

Leroy, J., G. Opsomer, S. De Vliegher, T. Vanholder, L. Goossens, A. Geldhof, P. E. J. Bols, A. de Kruif, and A. Van Soom. 2005. Comparison of embryo quality in high-yielding dairy cows, in dairy heifers and in beef cows. Theriogenology 64:2022-2036.

Liebig, V. 1840. Die Organische Chemie in Ihrer Anwen-Agrikultur und Physiologie. Friedrich Viewe, Braunschweig, Germany.

Liesman, J. S., J. P. McNamara, A. V. Capuco, M. Binelli, W. K. Vanderkooi, R. S. Emery, H. A. Tucker, and W. M. Moseley. 1995. Comparison of growth hormone releasing factor and somatotro-
pin-Lipid and glucose metabolism in dairy cows. J. Dairy Sci 78:2159-2166.

Linnane, M., B. Horan, J. Connolly, P. O'Connor, F. Buckley, and P. Dillon. 2004. The effect of strain of Holstein-Friesian and feeding system on grazing behaviour, herbage intake and productivity in the first lactation. Anim. Sci. 78:169-178.

Livesey, C. T., T. Harrington, A. M. Johnston, S. A. May, and J. A Metcalf. 1998. The effect of diet and housing on the development of sole haemorrhages, white line haemorrhages and heel erosions in Holstein heifers. Anim. Sci. 67:9-16.

Loxton, I., T. P. Grant, D. J. Reid, and R. J. Lawrence. 2007. Effects of a supplement containing betaine on feedlot steers exposed to a heat load. Pages 201-210 in Recent Advances in Animal Nutrition in Australia. P. Cronje and N. Richards, ed. University of New England, Armidale, NSW, Australia.

Lucy, M. C. 2001. Reproductive loss in high-producing dairy cattle: Where will it end? J. Dairy Sci. 84:1277-1293.

Lucy, M. C., R. L. Delasota, C. R. Staples, and W. W. Thatcher. 1993 Ovarian follicular populations in lactating dairy-cows treated with recombinant bovine somatotropin (sometribove) or saline and fed diets differing in fat-content and energy. J. Dairy Sci. 76:10141027.

Lucy, M. C., H. Jiang, and Y. Kobayashi. 2001. Changes in the somatotrophic axis associated with the initiation of lactation. J. Dairy Sci. 84(E. Suppl):E113-E119.

Lucy, M. C., J. D. Savio, L. Badinga, R. L. Delasota, and W. W Thatcher. 1992. Factors that affect ovarian follicular dynamics in cattle. J. Anim. Sci. 70:3615-3626.

Lucy, M. C. C. R. Staples, F. M. Michel, W. W. Thatcher, and D. J. Bolt. 1991. Effect of feeding calcium soaps to early postpartum dairy cows on plasma prostaglandin F2 alpha, luteinizing hormone, and follicular growth. J. Dairy Sci. 74:483-489.

Lucy, M. C., G. A. Verkerk, B. E. Whyte, K. A. Macdonald, L. Burton, R. T. Cursons, J. R. Roche, and C. W. Holmes. 2009. Somatotropic axis components and nutrient partitioning in genetically diverse dairy cows managed under different feed allowances in a pasture system. J. Dairy Sci. 92:526-539.

Macdonald, K. A., G. A. Verkerk, B. S. Thorrold, J. E. Pryce, J. W. Penno, L. R. McNaughton, L. J. Burton, J. A. S. Lancaster, J. H. Williamson, and C. W. Holmes. 2008. A comparison of three strains of Holstein-Friesian grazed on pasture and managed under different feed allowances. J. Dairy Sci. 91:1693-1707.

Mackle, T. R., D. A. Dwyer, K. L. Ingvartsen, P. Y. Chouinard, J. M. Lynch, D. M. Barbano, and D. E. Bauman. 1999. Effects of insulin and amino acids on milk protein concentration and yield from dairy cows. J. Dairy Sci. 82:1512-1524.

Mackle, T. R., D. A. Dwyer, K. L. Ingvartsen, P. Y. Chouinard, D. A Ross, and D. E. Bauman. 2000. Effects of insulin and postruminal supply of protein on use of amino acids by the mammary gland for milk protein synthesis. J. Dairy Sci. 83:93-105.

Mandok, K. S., J. K. Kay, S. L. Greenwood, G. R. Edwards, and J. R. Roche. 2013. Requirements for zero energy balance of nonlactating, pregnant dairy cows fed fresh autumn pasture are greater than currently estimated. J. Dairy Sci. 96:4070-4076.

Manson, F. J., and J. D. Leaver. 1988a. The influence of concentrate amount on locomotion and clinical lameness in dairy cattle. Anim. Prod. 47:185-190.

Manson, F. J., and J. D. Leaver. 1988b. The influence of dietary protein intake and of hoof trimming on lameness in dairy cattle. Anim. Prod. 47:191-199.

Mattos, R., C. R. Staples, and W. W. Thatcher. 2000. Effects of dietary fatty acids on reproduction in ruminants. Rev. Reprod. 5:38-45.

McCarthy, S., D. P. Berry, P. Dillon, M. Rath, and B. Horan. 2007. Influence of Holstein-Friesian strain and feed system on body weight and body condition score lactation profiles. J. Dairy Sci. 90:1859-1869.

McDowell, R. E., N. W. Hooven, and J. K. Camoens. 1976. Effect of climate on performance of Holsteins in first lactation. J. Dairy Sci. 59:965-973. 
McGuire, M. A., J. L. Vicini, D. E. Bauman, and J. J. Veenhuizen. 1992. Insulin-like growth factors and binding-proteins in ruminants and their nutritional regulation. J. Anim. Sci. 70:2901-2910.

McNamara, J. P. 1988. Regulation of bovine adipose tissue metabolism during lactation. 4. Dose responsiveness to epinephrine as altered by stage of lactation. J. Dairy Sci. 71:643-649.

McNamara, J. P., and J. K. Hillers. 1986a. Regulation of bovine adipose tissue metabolism during lactation. 1. Lipid synthesis in response to increased milk production and decreased energy intake. J. Dairy Sci. 69:3032-3041.

McNamara, J. P., and J. K. Hillers. 1986b. Regulation of bovine adipose tissue metabolism during lactation. 2. Lipolysis response to milk production and energy intake. J. Dairy Sci. 69:3042-3050.

Mee, J., R. Evans, and P. Dillon. 2004. Is Irish dairy herd fertility declining? Page 3431 in 23rd World Buiatrics Congress, Quebec, Canada.

Meier, S., A. J. Peterson, M. D. Mitchell, M. Littlejohn, C. G. Walker, and J. R. Roche. 2009. Genetic strain and reproductive status affect endometrial fatty acid concentrations. J. Dairy Sci. 92:37233730 .

Moe, P. W., and H. F. Tyrrell. 1972. Metabolizable energy requirements of pregnant dairy-cows. J. Dairy Sci. 55:480-483.

Moisey, F. R., and J. D. Leaver. 1985. Systems of concentrate allocation for dairy cattle. 3 . A comparison of 2 flat-rate feeding systems at 2 amounts of concentrates. Anim. Prod. 40:209-217.

Moss, N. 2001. The epidemiology of subfertility in Australian dairy cows. PhD Thesis. University of Sydney, Sydney, Australia.

O'Callaghan, D., and M. P. Boland. 1999. Nutritional effects on ovulation, embryo development and the establishment of pregnancy in ruminants. Anim. Sci. 68:299-314.

O'Grady, L., M. L. Doherty, and F. J. Mulligan. 2008. Subacute ruminal acidosis (SARA) in grazing Irish dairy cows. Vet. J. 176:4449.

Ordonez, A., T. J. Parkinson, C. Matthew, C. W. Holmes, R. D. Miller, N. Lopez-Villalobos, J. Burke, and I. Brookes. 2007. Effects of application in spring of urea fertiliser on aspects of reproductive performance of pasture-fed dairy cows. N. Z. Vet. J. 55:69-76.

Orskov, E. R. 1986. Starch digestion and utilization in ruminants. J. Anim. Sci. 63:1624-1633.

Ossent, P., and C. Lischer. 1997. Post mortem examination of the hooves of cattle, horses, pigs and small ruminants under practice conditions. In Pract. 19:21.

Østergaard, V. 1979. Optimum feeding strategies during lactation. Pages 171-194 in Feeding Strategy for the High Yielding Cow. W. H. Broster and H. Swan, ed. Crosby, Lockwood Staples, London, UK.

Palmquist, D. L., and E. A. Moser. 1981. Dietary fat effects on blood insulin, glucose utilization, and milk protein content of lactating cows. J. Dairy Sci. 64:1664-1670.

Patton, J., D. A. Kenny, S. McNamara, J. F. Mee, F. P. O'Mara, M. G. Diskin, and J. J. Murphy. 2007. Relationships among milk production, energy balance, plasma analytes, and reproduction in Holstein-Friesian cows. J. Dairy Sci. 90:649-658.

Pedernera, M., S. C. Garcia, A. Horagadoga, I. Barchia, and W. J. Fulkerson. 2008. Energy balance and reproduction on dairy cows fed to achieve low or high milk production on a pasture-based system. J. Dairy Sci. 91:3896-3907.

Penno, J. W. 2002. The response by grazing dairy cows to supplementary feeds. PhD Thesis. Massey University, Palmerston North, New Zealand.

Penno, J. W., K. A. Macdonald, and C. W. Holmes. 2001. Toward a predictive model of supplementary feeding response from grazing dairy cows. Proc. N.Z. Soc. Anim. Prod. 61:229-233.

Petit, H. V., and H. Twagiramungu. 2006. Conception rate and reproductive function of dairy cows fed different fat sources. Theriogenology 66:1316-1324.

Peyraud, J. L., and L. Delaby. 2001. Ideal concentrate feeds for grazing dairy cows - Responses to supplementation in interaction with grazing management and grass quality. Page 203 in Recent Advances in Animal Nutrition. P. C. Garnsworthy and J. Wiseman, ed. Nottingham University Press, Nottingham, UK.
Peyraud, J. L., and R. Delagarde. 2013. Managing variations in dairy cow nutrient supply under grazing. Animal 7:57-67.

Poole, D. A. 1987. Flat v step feeding of medium or high-levels of concentrates for dairy cows. Anim. Prod. 45:335-344.

Pryce, J. E., M. P. Coffey, S. H. Brotherstone, and J. A. Woolliams. 2002. Genetic relationships between calving interval and body condition score conditional on milk yield. J. Dairy Sci. 85:1590-1595.

Pryce, J. E., and B. L. Harris. 2006. Genetics of body condition score in New Zealand dairy cows. J. Dairy Sci. 89:4424-4432.

Pryce, J. E., B. L. Nielsen, R. F. Veerkamp, and G. Simm. 1999. Genotype and feeding system effects and interactions for health and fertility traits in dairy cattle. Livest. Prod. Sci. 57:193-201.

Radcliff, R. P., B. L. McCormack, B. A. Crooker, and M. C. Lucy. 2003. Growth hormone (GH) binding and expression of GH receptor 1A mRNA in hepatic tissue of periparturient dairy cows. J. Dairy Sci. 86:3933-3940.

RAGFAR (Reference Advisory Group on Fermentative Acidosis of Ruminants). 2007. Ruminal acidosis - Understandings, prevention and treatment. A review for veterinarians and nutritional professionals. Australian Veterinary Association, Queensland, Australia.

Rajala-Schultz, P. J., W. J. A. Saville, G. S. Frazer, and T. E. Wittum. 2001. Association between milk urea nitrogen and fertility in Ohio dairy cows. J. Dairy Sci. 84:482-489.

Rakes, A. H., and D. G. Davenport. 1971. Response of dairy cows to two systems of distributing annual concentrates over lactation cycle. J. Dairy Sci. 54:1300.

Renaudeau, D., A. Collin, S. Yahav, V. de Basilio, J. L. Gourdine, and R. J. Collier. 2012. Adaptation to hot climate and strategies to alleviate heat stress in livestock production. Animal 6:707-728.

Reynolds, C. K., and N. B. Kristensen. 2008. Nitrogen recycling through the gut and the nitrogen economy of ruminants: An asynchronous symbiosis. J. Anim. Sci. 86(E-Suppl.):E293-E305.

Rhoads, M. L., R. P. Rhoads, M. J. VanBaale, R. J. Collier, S. R. Sanders, W. J. Weber, B. A. Crooker, and L. H. Baumgard. 2009 Effects of heat stress and plane of nutrition on lactating Holstein cows: I. Production, metabolism, and aspects of circulating somatotropin. J. Dairy Sci. 92:1986-1997.

Rhoads, R. P., J. W. Kim, B. J. Leury, L. H. Baumgard, N. Segoale, S. J. Frank, D. E. Bauman, and Y. R. Boisclair. 2004. Insulin increases the abundance of the growth hormone receptor in liver and adipose tissue of periparturient dairy cows. J. Nutr. 134:1020-1027.

Rhodes, F. M., S. McDougall, C. R. Burke, G. A. Verkerk, and K. L. Macmillan. 2003. Invited review: Treatment of cows with an extended postpartum anestrous interval. J. Dairy Sci. 86:1876-1894.

Rijpkema, Y. S., L. Vanreeuwijk, and P. W. Goedhart. 1990. Effects of pattern of concentrate feeding on milk production of dairy cows offered silage ad-libitum. Neth. J. Agric. Sci. 38:461-474.

Rius, A. G., J. A. D. R. N. Appuhamy, J. Cyriac, D. Kirovski, O. Becvar, J. Escobar, M. L. McGilliard, B. J. Bequette, R. M. Akers, and M. D. Hanigan. 2010. Regulation of protein synthesis in mammary glands of lactating dairy cows by starch and amino acids. J. Dairy Sci. 93:3114-3127.

Roberts, A. J., R. A. Nugent, J. Klindt, and T. G. Jenkins. 1997. Circulating insulin-like growth factor I, insulin-like growth factor binding proteins, growth hormone, and resumption of estrus in postpartum cows subjected to dietary energy restriction. J. Anim. Sci. $75: 1909-1917$.

Roche, J. R. 2007. Milk production responses to pre- and postcalving dry matter intake in grazing dairy cows. Livest. Sci. 110:12-24.

Roche, J. R., D. P. Berry, and E. S. Kolver. 2006a. Holstein-Friesian strain and feed effects on milk production, body weight, and body condition score profiles in grazing dairy cows. J. Dairy Sci. 89:3532-3543

Roche, J. R., D. P. Berry, J. M. Lee, K. A. Macdonald, and R. C. Boston. 2007a. Describing the body condition score change between successive calvings: A novel strategy generalizable to diverse cohorts. J. Dairy Sci. 90:4378-4396.

Roche, J. R., D. Blache, J. K. Kay, D. R. Miller, A. J. Sheahan, and D. W. Miller. 2008a. Neuroendocrine and physiological regulation of intake with particular reference to domesticated ruminant animals. Nutr. Res. Rev. 21:207-234. 
Roche, J. R., C. R. Burke, S. Meier, and C. G. Walker. 2011. Nutrition $\times$ reproduction interaction in pasture-based systems: Is nutrition a factor in reproductive failure? Anim. Prod. Sci. 51:1045-1066.

Roche, J. R., P. G. Dillon, C. R. Stockdale, L. H. Baumgard, and M. J. VanBaale. 2004. Relationships among international body condition scoring systems. J. Dairy Sci. 87:3076-3079.

Roche, J. R., N. C. Friggens, J. K. Kay, M. W. Fisher, K. J. Stafford and D. P. Berry. 2009a. Invited review: Body condition score and its association with dairy cow productivity, health, and welfare. J. Dairy Sci. 92:5769-5801.

Roche, J. R., J. K. Kay, C. V. C. Phyn, S. Meier, J. M. Lee, and C. R. Burke. 2010. Dietary structural to nonfiber carbohydrate concentration during the transition period in grazing dairy cows. J. Dairy Sci. 93:3671-3683.

Roche, J. R., J. K. Kay, A. G. Rius, T. M. Grala, A. J. Sheahan, H. M. White, and C. V. C. Phyn. 2013a. Short communication: Immediate and deferred milk production responses to concentrate supplements in cows grazing fresh pasture. J. Dairy Sci. 96:2544-2550.

Roche, J. R., K. A. Macdonald, C. R. Burke, J. M. Lee, and D. P. Berry. 2007b. Associations among body condition score, body weight, and reproductive performance in seasonal-calving dairy cattle. J. Dairy Sci. 90:376-391.

Roche, J. R., S. Petch, and J. K. Kay. 2005. Manipulating the dietary cation-anion difference via drenching to early-lactation dairy cows grazing pasture. J. Dairy Sci. 88:264-276.

Roche, J. R., A. J. Sheahan, L. M. Chagas, and D. P. Berry. 2006b. Short communication: Genetic selection for milk production increases plasma ghrelin in dairy cows. J. Dairy Sci. 89:3471-3475.

Roche, J. R., A. J. Sheahan, L. M. Chagas, and D. P. Berry. 2007c. Concentrate supplementation reduces postprandial plasma ghrelin in grazing dairy cows: A possible neuroendocrine basis for reduced pasture intake in supplemented cows. J. Dairy Sci. 90:1354-1363.

Roche, J. R., A. J. Sheahan, L. M. Chagas, D. Blache, D. P. Berry, and J. K. Kay. 2008b. Long-term infusions of ghrelin and obestatin in early lactation dairy cows. J. Dairy Sci. 91:4728-4740.

Roche, J. R., A. J. Sheahan, L. M. Chagas, and R. C. Boston. 2008c. Short communication: Change in plasma ghrelin in dairy cows following an intravenous glucose challenge. J. Dairy Sci. 91:10051010.

Roche, J. R., L. R. Turner, J. M. Lee, D. C. Edmeades, D. J. Donaghy, K. A. Macdonald, J. W. Penno, and D. P. Berry. 2009b. Weather, herbage quality and milk production in pastoral systems. 2 . Temporal patterns and intra-relationships in herbage quality and mineral concentration parameters. Anim. Prod. Sci. 49:200-210.

Roche, J. R., L. R. Turner, J. M. Lee, D. C. Edmeades, D. J. Donaghy, K. A. Macdonald, J. W. Penno, and D. P. Berry. 2009c. Weather, herbage quality and milk production in pastoral systems. 3. Interrelationships and associations between weather variables and herbage growth rate, quality and mineral concentration. Anim. Prod. Sci. 49:211-221.

Roche, J. R., and R. White. 2012. Production responses to supplements in pasture based dairying systems. Pages 20-23 in Vetscript (October). New Zealand Veterinary Association, Wellington, New Zealand.

Rooney, L. W., and R. L. Pflugfelder. 1986. Factors affecting starch digestibility with special emphasis on sorghum and corn. J. Anim. Sci. 63:1607-1623

Royal, M. D., A. O. Darwash, A. P. E. Flint, R. Webb, J. A. Woolliams, and G. E. Lamming. 2000. Declining fertility in dairy cattle: Changes in traditional and endocrine parameters of fertility. Anim. Sci. 70:487-501.

Rubio, J. M., D. M. Hallford, and D. E. Hawkins. 1997. Effect of glucose administration during the estrous cycle on serum hormone profiles, mRNA for steroidogenic enzymes, and breeding performance of ewes. J. Anim. Sci. 75:775-780.

Ruegg, P. L., W. J. Goodger, C. A. Holmberg, L. D. Weaver, and E. M. Huffman. 1992. Relation among body condition score, serum urea nitrogen and cholesterol concentrations, and reproductive performance in high-producing Holstein dairy cows in early lactation. Am. J. Vet. Res. 53:10-14.
Russell, J. 2007. Can the heat of ruminal fermentation be manipulated to decrease heat stress? Pages 109-115 in Proc. 22nd Annu. Southwest Nutrition and Management Conference. University of Arizona, Tucson.

Sanchez, W. K., M. A. McGuire, and D. K. Beede. 1994. Macromineral nutrition by heat-stress interactions in dairy cattle - Review and original research. J. Dairy Sci. 77:2051-2079.

Santos, J. E. P., W. W. Thatcher, R. C. Chebel, R. L. A. Cerri, and K. N. Galvao. 2004. The effect of embryonic death rates in cattle on the efficacy of estrus synchronization programs. Anim. Reprod. Sci. 82-83:513-535.

Sartori, R., R. Sartor-Bergfelt, S. A. Mertens, J. N. Guenther, J. J. Parrish, and M. C. Wiltbank. 2002. Fertilization and early embryonic development in heifers and lactating cows in summer and lactating and dry cows in winter. J. Dairy Sci. 85:2803-2812.

Schneider, P. L., D. K. Beede, and C. J. Wilcox. 1986. Responses of lactating cows to dietary-sodium source and quantity and potassium quantity during heat-stress. J. Dairy Sci. 69:99-110.

Scott, T. A., R. D. Shaver, L. Zepeda, B. Yandell, and T. R. Smith. 1995. Effects of rumen-inert fat on lactation, reproduction, and health of high producing Holstein herds. J. Dairy Sci. 78:24352451.

Sechen, S. J., F. R. Dunshea, and D. E. Bauman. 1990. Somatotropin in lactating cows: Effect on response to epinephrine and insulin. Am. J. Physiol. 258:E582-E588.

Seeley, R. J., and M. W. Schwartz. 1997. The regulation of energy balance: Peripheral hormonal signals and hypothalamic neuropeptides. Curr. Dir. Psychol. Sci. 6:39-44.

Sheahan, A. J., R. C. Boston, and J. R. Roche. 2013a. Diurnal patterns of grazing behavior and humoral factors in supplemented dairy cows. J. Dairy Sci. 96:3201-3210.

Sheahan, A. J., S. J. Gibbs, and J. R. Roche. 2013b. Timing of supplementation alters grazing behavior and milk production response in dairy cows. J. Dairy Sci. 96:477-483.

Sheahan, A. J., E. S. Kolver, and J. R. Roche. 2011. Genetic strain and diet effects on grazing behavior, pasture intake, and milk production. J. Dairy Sci. 94:3583-3591.

Silanikove, N. 2000. Effects of heat stress on the welfare of extensively managed domestic ruminants. Livest. Prod. Sci. 67:1-18.

Smith, T. R., and J. P. McNamara. 1990. Regulation of bovine adipose tissue metabolism during lactation. 6. Cellularity and hormone sensitive lipase activity as affected by genetic merit and energy intake. J. Dairy Sci. 73:772-783.

Spicer, L. J., E. Alpizar, and S. E. Echternkamp. 1993. Effects of insulin, insulin-like growth factor-I, and gonadotropins on bovine granulosa-cell proliferation, progesterone production, estradiol production, and (or) insulin-like growth factor-I production in vitro. J. Anim. Sci. 71:1232-1241.

Sporndly, E. 1991. Supplementation of dairy cows offered freshly cut herbage ad-libitum with starchy concentrates based on barley or fibrous concentrates based on unmolassed sugar-beet pulp and wheat bran. Swed. J. Agric. Res. 21:131-139.

Sreenan, J., and M. Diskin. 1986. The extent and timing of embryonic mortality in the cow. Pages 1-11 in Embryonic Mortality in Farm Animals. J. Sreenan and M. Diskin, ed. Martinus Nijhoff Publishers, Amsterdam, the Netherlands.

Staples, C. R., J. M. Burke, and W. W. Thatcher. 1998. Influence of supplemental fats on reproductive tissues and performance of lactating cows. J. Dairy Sci. 81:856-871.

Steinhour, W. D., and D. E. Bauman. 1988. Propionate metabolism: A new interpretation. Pages 238-256 in Aspects of Digestive Physiology in Ruminants. A. Dobson and M. J. Dobson, ed. Comstock Publications, Ithaca, NY

Stipanuk, M. H. 2000. Biochemical and Physiological Aspects of Human Nutrition. W. B. Saunders Co., Philadelphia, PA.

Stockdale, C. R. 1999. The nutritive characteristics of herbage consumed by grazing dairy cows affect milk yield responses obtained from concentrate supplementation. Aust. J. Exp. Agric. 39:379387. 
Stockdale, C. R. 2000a. Differences in body condition and body size affect the responses of grazing dairy cows to high-energy supplements in early lactation. Aust. J. Exp. Agric. 40:903-911.

Stockdale, C. R. 2000b. Levels of pasture substitution when concentrates are fed to grazing dairy cows in northern Victoria. Aust. J. Exp. Agric. 40:913-921.

Sumner, J. M., and J. P. McNamara. 2007. Expression of lipolytic genes in the adipose tissue of pregnant and lactating Holstein dairy cattle. J. Dairy Sci. 90:5237-5246.

Taylor, W., and J. D. Leaver. 1984. Systems of concentrate allocation for dairy cattle. 2. A comparison of 2 patterns of allocation for autumn-calving cows offered 2 qualities of grass silage ad libitum. Anim. Prod. 39:325-333.

Taylor, W., and J. D. Leaver. 1986. Systems of concentrate allocation for dairy cattle. 4. A comparison of 2 amounts and 2 patterns of allocation. Anim. Prod. 43:17-26.

Thatcher, W. W., and C. J. Wilcox. 1973. Postpartum estrus as an indicator of reproductive status in dairy cow. J. Dairy Sci. 56:608-610.

Thoefner, M. B., C. C. Pollitt, A. W. van Eps, G. J. Milinovich, D. J. Trott, O. Wattle, and P. H. Andersen. 2004. Acute bovine laminitis: A new induction model using alimentary oligofructose overload. J. Dairy Sci. 87:2932-2940.

Thoefner, M. B., O. Wattle, C. C. Pollitt, K. R. French, and S. S. Nielsen. 2005. Histopathology of oligofructose-induced acute laminitis in heifers. J. Dairy Sci. 88:2774-2782.

Thorne, P., J. Jago, E. Kolver, and J. Roche. 2003. Diet and genotype affect feeding behaviour in Holstein-Friesian dairy cows during late lactation. Proc. N.Z. Soc. Anim. Prod. 63:124-127.

Van Soest, P. J. 1994. Nutritional Ecology of the Ruminant. 2nd ed. Cornell University Press, Ithaca, NY.

Vernon, R. G. 1992. Control of lipogenesis and lipolysis. Pages 59-82 in The Control of Fat and Lean Deposition. P. J. Buttery, K. N. Boorman, and D. B. Lindsay, ed. Butterworth-Heinemann, London, UK.

Vernon, R. G., and E. Finley. 1985. Regulation of lipolysis during pregnancy and lactation in sheep - response to noradrenaline and adenosine. Biochem. J. 230:651-656.

Wales, W. J., and P. T. Doyle. 2003. Effect of grain and straw supplementation on marginal milk-production responses and rumen fermentation of cows grazing highly digestible subterranean clover pasture. Aust. J. Exp. Agric. 43:467-474.

Wales, W. J., P. T. Doyle, C. R. Stockdale, and D. Dellow. 1999. Effects of variations in herbage mass, allowance, and level of supplement on nutrient intake and milk production of dairy cows in spring and summer. Aust. J. Exp. Agric. 39:119-130.

Wales, W. J., E. S. Kolver, A. R. Egan, and J. R. Roche. 2009. Effects of strain of Holstein-Friesian and concentrate supplementation on the fatty acid composition of milk fat of dairy cows grazing pasture in early lactation. J. Dairy Sci. 92:247-255.

Wales, W. J., E. S. Kolver, P. L. Thorne, and A. R. Egan. 2004. Diurnal variation in ruminal $\mathrm{pH}$ on the digestibility of highly digestible perennial ryegrass during continuous culture fermentation. J. Dairy Sci. 87:1864-1871.
Walker, C. G., M. D. Littlejohn, M. D. Mitchell, J. R. Roche, and S. Meier. 2012. Endometrial gene expression during early pregnancy differs between fertile and subfertile dairy cow strains. Physiol. Genomics 44:47-58.

Wang, J. P., D. P. Bu, J. Q. Wang, X. K. Huo, T. J. Guo, H. Y. Wei, L. Y. Zhou, R. R. Rastani, L. H. Baumgard, and F. D. Li. 2010 Effect of saturated fatty acid supplementation on production and metabolism indices in heat-stressed mid-lactation dairy cows. J. Dairy Sci. 93:4121-4127.

Washburn, S. P., S. L. White, J. T. Green, and G. A. Benson. 2002. Reproduction, mastitis, and body condition of seasonally calved Holstein and Jersey cows in confinement or pasture systems. J. Dairy Sci. 85:105-111.

Wathes, D. C., D. R. E. Abayasekara, and R. J. Aitken. 2007. Polyunsaturated fatty acids in male and female reproduction. Biol. Reprod. 77:190-201.

Wertz-Lutz, A. E., T. J. Knight, R. H. Pritchard, J. A. Daniel, J. A. Clapper, A. J. Smart, A. Trenkle, and D. C. Beitz. 2006. Circulating ghrelin concentrations fluctuate relative to nutritional status and influence feeding behavior in cattle. J. Anim. Sci. 84:32853300 .

Westwood, C. T., I. J. Lean, and J. K. Garvin. 2002. Factors influencing fertility of Holstein dairy cows: A multivariate description. J. Dairy Sci. 85:3225-3237.

Westwood, C. T., I. J. Lean, J. K. Garvin, and P. C. Wynn. 2000. Effects of genetic merit and varying dietary protein degradability on lactating dairy cows. J. Dairy Sci. 83:2926-2940.

Westwood, C. T., I. J. Lean, and R. C. Kellaway. 1998. Indications and implications for testing of milk urea in dairy cattle: A quantitative review. Part 2. Effect of dietary protein on reproductive performance. N. Z. Vet. J. 46:123-130.

White, H. M., S. S. Donkin, M. C. Lucy, T. M. Grala, and J. R. Roche. 2012. Genetic differences between New Zealand and North American dairy cows alter milk production and gluconeogenic enzyme expression. J. Dairy Sci. 95:455-459.

Williams, Y. J., W. J. Wales, P. T. Doyle, A. R. Egan, and C. R. Stockdale. 2005. Effects of grain or hay supplementation on the chewing behaviour and stability of rumen fermentation of dairy cows grazing perennial ryegrass-based pasture in spring. Aust. J. Exp. Agric. 45:1519-1528.

Yaakub, H., D. O'Callaghan, J. V. O'Doherty, and P. Hyttel. 1997. Effect of dietary intake on follicle numbers and oocyte morphology in unsuperovulated and superovulated ewes. Theriogenology 47:182.

Yan, T., F. J. Gordon, R. E. Agnew, M. G. Porter, and D. C. Patterson. 1997. The metabolisable energy requirement for maintenance and the efficiency of utilisation of metabolisable energy for lactation by dairy cows offered grass silage-based diets. Livest. Prod. Sci. 51:141-150.

Zachut, M., A. Arieli, H. Lehrer, N. Argov, and U. Moallem. 2008. Dietary unsaturated fatty acids influence preovulatory follicle characteristics in dairy cows. Reproduction 135:683-692. 